Illinois State University

ISU ReD: Research and eData

Theses and Dissertations

$3-12-2020$

\title{
Orientation and mobility service decisions: What is guiding them if it is not assessment?
}

Lauralyn Kay Randles

Illinois State University, lauralynbogart@gmail.com

Follow this and additional works at: https://ir.library.illinoisstate.edu/etd

Part of the Special Education Administration Commons, and the Special Education and Teaching Commons

\section{Recommended Citation}

Randles, Lauralyn Kay, "Orientation and mobility service decisions: What is guiding them if it is not assessment?" (2020). Theses and Dissertations. 1256.

https://ir.library.illinoisstate.edu/etd/1256

This Dissertation is brought to you for free and open access by ISU ReD: Research and eData. It has been accepted for inclusion in Theses and Dissertations by an authorized administrator of ISU ReD: Research and eData. For more information, please contact ISUReD@ilstu.edu. 


\title{
ORIENTATION AND MOBILITY SERVICE DECISIONS:
}

\section{WHAT IS GUIDING THEM IF IT IS NOT ASSESSMENT?}

\author{
Lauralyn Kay Randles
}

\section{Pages}

Objective: In this study, I sought to determine what tools are used during assessment and service delivery decisions for school age children with low vision or blindness. Also, the study worked to explore O\&M specialist's perceptions of factors impacting assessment results and service delivery decisions. Methods: A survey was employed to gather this information from O\&M specialists spread throughout Midwest region of the United States. Seventy six O\&M specialists completed the survey sharing about their experiences with O\&M assessments and service delivery decisions. Analysis was completed using Microsoft Excel and a codebook I established. Results: The participant's caseloads and employment details varied greatly from one to another. The results showed a combination of 5 assessments, 2 service delivery decision tools, and professional judgement used by O\&M specialist in the region. Outside of assessment results, participants report that three primary themes impact service qualification and delivery decisions. Conclusion: O\&M service delivery decisions are commonly impacted by the student, the district, and the O\&M specialist. Additional factors may be unique to the O\&M specialist or their employment situation. More research is needed to replicate these results in different regions of the United States for generalization.

KEYWORDS: orientation and mobility; assessment; service delivery 
ORIENTATION AND MOBILITY SERVICE DECISIONS:

WHAT IS GUIDING THEM IF IT IS NOT ASSESSMENT?

\title{
LAURALYN KAY RANDLES
}

\author{
A Dissertation Submitted in Partial \\ Fulfillment of the Requirements \\ for the Degree of \\ DOCTOR OF EDUCATION \\ Department of Special Education \\ ILLINOIS STATE UNIVERSITY
}


Copyright 2020 Lauralyn Kay Randles 


\title{
ORIENTATION AND MOBILITY SERVICE DECISIONS:
}

WHAT IS GUIDING THEM IF IT IS NOT ASSESSMENT?

\author{
LAURALYN KAY RANDLES
}

COMMITTEE MEMBERS:

Carrie Anna Courtad, Chair

Stephanie Gardiner-Walsh

Mark Zablocki

Olaya Landa-Vialard 


\section{ACKNOWLEDGMENTS}

From the bottom of my heart I want to thank everyone who has been part of this process and my four years at Illinois State University. Many in my life, personally and professionally, have made sacrifices and have gone above and beyond to support me . "Alone we can do so little; together we can do so much"-Helen Keller

Kenny, all I can say is thank you but it will never be enough. You made this all possible through your support and love. You kept our house and kids going when I was away in mind or body. You made me stronger, braver, kept me calm(er), and built me up when I started to crumble. This accomplishment is ours. Kaylee and Connor, though you didn't choose this path thank you for coming along for the ride and keeping me laughing along the way.

Jan and Mike, I am grateful for your never ending support and for accepting nothing less than excellence from me. Ken and Vicki, thank you for believing in me even when I did not. The four of you functioned as a great team to make sure that my kids never missed out on love, attention, and activities while I went for my dream and completed this degree. I will forever be in debt to you all. To my father, by the time you read this I will hopefully officially be Dr. Lauralyn 'Tweedleheart' Randles. I did it. We did it!

Gramma Gwen, I want you to know how much I have valued you in my life and on my side through everything, including this. You have been a role model to me my entire life helping me to be a stronger woman and person. The work ethic you instilled in me is the reason any of this was even possible.

To the wonderful friends I have met along the way, you have helped to keep me sane and moving. Anne, we quickly became the dynamic duo of the cohort and I cannot imagine it any other way. You have been a sounding board, cheerleader, vent friend, joke buddy, and more. I 
hope to always have you by my side, or at least in Google Hangouts. Molly, thank you for being a friend and helping me take our research and knowledge on the road. Amber, my NLCSD friend and roomie, we did it! Our late night chats made those trips for me and I cannot wait to see where we meet up next. Rachel, we survived together and I'm so glad we got a chance to bond over the good, bad, and ugly of our four years together. And last but definitely not least, Karla. You helped me champion causes at both ISU and NLCSD. Thank you for melding both worlds together with me.

To my committee, I would like to thank you all for your insights, support, guidance, and patience with me throughout this process. Dr. Carrie Anna Courtad, I want to start by thanking you for making my transition to a new committee set up seamless. Thank you for providing me with feedback and endless amounts of encouragement as we prepared to cross the finish line. I would not have been able to do this without you leading me and this committee.

Dr. Stephanie Gardiner-Walsh, you have been my lifesaver so many times over the last four years and I cannot thank you enough. You have become a good friend and a great mentor to me. Thank you for always making time for me and walking me through the foggy parts.

Dr. Mark Zablocki, thank you for joining my team in a moment of transition. You helped me to bring order to the foundation of my dissertation and display my findings in meaningful way without overwhelming the reader.

Dr. Olaya Landa Vialard, I cannot find adequate words to thank you for all that you have done for me. From our first encounter I knew I wanted to work with you in some way. Well, after the shock wore off that is. You brought me into this degree path and took me under your wing. You helped me build my confidence as a teacher, practioner, researcher, presenter, and more. You helped bring me out of the shadows and not only find my voice but the value of my 
voice. I will never be able to thank you enough. I cannot wait to see what we work on next together.

I would also like to thank NLCSD and the Office of Special Education Programs (OSEP) for making my dream of obtaining a doctorate a reality. You provided me with support, experiences, and a community to belong to.

L.K.R 


\section{CONTENTS}

$\begin{array}{lll}\text { Page } & \\ \end{array}$

ACKNOWLEDGMENTS

CONTENTS iv

TABLES vii

CHAPTER I: OVERVIEW OF THE STUDY 1

$\begin{array}{ll}\text { O\&M Specialists } & 7\end{array}$

$\begin{array}{ll}\text { O\&M Assessment } & 10\end{array}$

$\begin{array}{ll}\text { Service Delivery Tools } & 15\end{array}$

$\begin{array}{ll}\text { Translation to Service } & 17\end{array}$

$\begin{array}{ll}\text { Purpose of the Study } & 20\end{array}$

$\begin{array}{ll}\text { Rationale } & 21\end{array}$

$\begin{array}{ll}\text { Definition of Terms } & 22\end{array}$

$\begin{array}{ll}\text { Significance of the Study } & 24\end{array}$

$\begin{array}{ll}\text { Summary } & 24\end{array}$

CHAPTER II: REVIEW OF THE LITERATURE 25

$\begin{array}{ll}\text { Search Procedure } & 26\end{array}$

$\begin{array}{ll}\text { Inclusion Criteria } & 28\end{array}$

$\begin{array}{ll}\text { Article Coding } & 28\end{array}$

$\begin{array}{ll}\text { Results } & 29\end{array}$

$\begin{array}{ll}\text { Assessment } & 33\end{array}$

$\begin{array}{ll}\text { Service Delivery } & 36\end{array}$

$\begin{array}{ll}\text { O\&M Skills } & 41\end{array}$ 
$\begin{array}{ll}\text { Discussion } & 42\end{array}$

$\begin{array}{ll}\text { Limitations } & 45\end{array}$

$\begin{array}{ll}\text { Research Questions } & 46\end{array}$

$\begin{array}{ll}\text { Summary } & 47\end{array}$

$\begin{array}{ll}\text { CHAPTER III: METHODS } & 48\end{array}$

Research Questions $\quad 49$

Research Design $\quad 49$

$\begin{array}{ll}\text { Participants } & 51\end{array}$

$\begin{array}{ll}\text { Procedures } & 53\end{array}$

$\begin{array}{ll}\text { Data Analysis } & 53\end{array}$

$\begin{array}{ll}\text { Summary } & 56\end{array}$

$\begin{array}{ll}\text { CHAPTER IV: RESULTS } & 57\end{array}$

$\begin{array}{ll}\text { Research Questions } & 57\end{array}$

$\begin{array}{ll}\text { Data Collection } & 57\end{array}$

$\begin{array}{ll}\text { Data Analysis } & 58\end{array}$

$\begin{array}{ll}\text { Coding } & 58\end{array}$

$\begin{array}{ll}\text { Results } & 60\end{array}$

$\begin{array}{ll}\text { Participants } & 60\end{array}$

$\begin{array}{ll}\text { O\&M tools } & 67\end{array}$

$\begin{array}{ll}\text { Open Response } & 71\end{array}$

$\begin{array}{ll}\text { Summary } & 92\end{array}$

CHAPTER V: DISCUSSION OF FINDINGS 93

$\begin{array}{ll}\text { Discussion } & 93\end{array}$ 
What Tools Are O\&M Specialists Who Are Serving K-12 Students, Using To Guide Assessment Results And Service Delivery Recommendations?

What Factors, Outside Of Assessment Results, Are Impacting How K-12 Students With A Visual Impairment Are Qualifying For O\&M Services? What Is Impacting K-12 O\&M Service Delivery Decisions?

Is There A Relationship Between A Participant's Demographic Make-Up And Their Assessment Results And Service Delivery Decisions? Specifically, Their Certification,

Level Of Experience, Location, And Distance From A Preparation Program

Limitations

Future Implications

Conclusion 


\section{TABLES}

Table

Page

1. Orientation and Mobility Skills 2

2. Orientation and Mobility Assessment and Service Delivery Tools 12

3. Individual Search Terms and Yield Results 27

4. Cumulative Search Eliminations for Final Yield 27

5. Descriptive Summary of Research and Practitioners' Reports 30

6. Participant Certification Type, Extended Certifications, Employment Status, and $\begin{array}{ll}\text { Years of Experience } & 61\end{array}$

7. Participant's Contract Hours and the Number of Hours Devoted to O\&M Services 62

8. Percentage of Contract Hours Allocated to O\&M Services 62

9. Reported Direct and Indirect Caseload Size 63

10. Cross Tabulation of Geographic Area of Employment, Certification, Years of Experience, and Distance by O\&M Employment Contracts and Caseloads $\quad 64$

11. Number of Participants by State and by Nearest University Preparation Program 65

12. Breakdown of Distance to University Preparation Program Geographically by Program $\quad 66$

13. Participant Identified O\&M Assessment Tools Used with K-12 Students 68

14. Cross Tabulation of Geographic Areas of Employment by O\&M Assessment and Service Delivery Decision Tools

15. Participant Identified Tools for O\&M Service Delivery Decisions of K-12 Students 70

16. Frequency of Participants’ Response to Historical Response Matrix 83 
17. Cross Tabulation of Geographic Areas of Employment by the Historical 5-Year Matrix of Professional Experiences

18. Cross Tabulation of Single and Dual Certifications by the Historical 5-Year Matrix of Professional Experiences

19. Cross Tabulation of Years of Experience by the Historical 5-Year Matrix of Professional Experiences

20. Cross Tabulation of Distance from a University Preparation Program by the Historical 5-Year Matrix of Professional Experiences 


\section{CHAPTER I: OVERVIEW OF THE STUDY}

In 2018, the National Federation for the Blind (NFB) estimated a total of 7.3 million individuals were blind or visually impaired (NFB, 2018). Whereas, the Centers for Disease Control and Prevention (CDC) found this number to be much higher, at 21 million in 2013, when including the number of individuals whom "have trouble seeing" or are blind (CDC, 2014). For perspective, there are approximately 327 million people in the United States (USCB, 2018); this would mean that $2.2 \%(\mathrm{NFB})$ or $6.4 \%$ (CDC) of the population have a visual impairment. Part of the reason for these two vastly different numerical illustrations rests with the problem in defining characteristics of visual impairments and how professionals assess or qualify individuals with visual impairments.

With either numerical representation of the population, the number is a small fraction of the general population, referred to as low incidence. Individuals with a visual impairment benefit from a series of specialized training and instruction to ensure that they are able to become an independent adult member of society. According to the foundational texts in the field of low vision and blindness (Blasch \& Wiener, 2010; Hill \& Ponder, 1976), one key component to achieving this goal is through receiving training in the area of orientation and mobility (O\&M). O\&M is an individual with visual impairment's ability to travel safely and independently through their surroundings with purpose (Blasch \& Wiener, 2010; Wall Emerson \& Corn, 2006). An O\&M specialist is specifically trained to provide instruction in these specialized skills to achieve the goal of safe navigation. A complete table of these skills needed for an individual with low vision or blindness to travel established by the research of Lord (1969) and Wall Emerson and Corn (2006) can be found in table 1. 
Table 1

Orientation and Mobility Skills

\begin{tabular}{|c|c|}
\hline Category & Id and label hody narts \\
\hline \multirow{32}{*}{ Blind } & Id and label body parts \\
\hline & Recognizing object permanence \\
\hline & Determining shape, slope, and texture \\
\hline & Focusing on one cue or landmark instead of another \\
\hline & Maintaining a straight line of travel when walking \\
\hline & Reaching for sounds \\
\hline & Taking parallel or perpendicular line of direction \\
\hline & Demonstrating proper cane skills \\
\hline & Familiarity with a variety of canes \\
\hline & Finding dropped objects \\
\hline & Maintaining contact with object while traveling (trailing) \\
\hline & Negotiating stairs, door openings, unexpected obstacles \\
\hline & Recovering from a veer in a driveway \\
\hline & Relating body planes to the environment \\
\hline & Relating small scale to the large scale \\
\hline & Relating time and movement through space \\
\hline & Understanding sequencing \\
\hline & Exploring open spaces \\
\hline & Maintaining alignment after walking around an object \\
\hline & Maintaining orientation while being guided \\
\hline & Orienting to a room \\
\hline & Reversing map route in reality \\
\hline & Reorienting after exiting a vehicle \\
\hline & Spatially relating self to others \\
\hline & Understanding parallel and perpendicular alignment \\
\hline & Sequencing landmarks \\
\hline & Using electronic devices \\
\hline & Human guide \\
\hline & Self-protective techniques \\
\hline & Understanding address systems \\
\hline & Identifying edge of street at curb cuts when walking \\
\hline & Identifying, localizing, interpreting, and tolerating sounds \\
\hline
\end{tabular}

Table 1, Continues 
Table 1, Continued

\begin{tabular}{|c|c|}
\hline Category & Skill \\
\hline \multirow[t]{29}{*}{ Blind } & Judging and estimating distances \\
\hline & Maintaining orientation and alignment with environmental sounds \\
\hline & Reacting to differences in temperature \\
\hline & Remembering directions by listening carefully \\
\hline & Shorelining and veering \\
\hline & Using tactile maps \\
\hline & Using auditory, underfoot, and olfactory information \\
\hline & Using proprioceptive and tactile feedback from a cane \\
\hline & Using sensory input to orient and reorient \\
\hline & Demonstrating good balance and gait \\
\hline & Detecting openings and walls or obstacles with echolocation \\
\hline & Knowing features of driveway versus streets \\
\hline & Knowing how buildings are organized and how public places are commonly laid out \\
\hline & Traveling to bus stops, train stations, etc. \\
\hline & Carrying appropriate ID and medical information \\
\hline & Choosing canes, tips \\
\hline & Deciding between a cane and a guide dog \\
\hline & Deciding which cane skill fits a situation \\
\hline & Recognizing audible pedestrian signals \\
\hline & Auditory maps \\
\hline & Knowing characteristics of common environmental objects \\
\hline & Demonstrating time management skills \\
\hline & Finding an O\&M instructor \\
\hline & Facing people while conversing with them \\
\hline & Hiring and firing drivers \\
\hline & Appropriate public behavior in all travel environments \\
\hline & Exploring with different body parts \\
\hline & Knowing pertinent aspects of ADA, IDEA, and white cane laws \\
\hline & Knowing when to yield/give way \\
\hline
\end{tabular}

Table 1, Continues 
Table 1, Continued

\begin{tabular}{|c|c|}
\hline Category & Skill \\
\hline \multirow[t]{5}{*}{ Blind } & Reducing "stereotypical behaviors" or mannerisms \\
\hline & Observing safety precautions \\
\hline & Soliciting or refusing assistance \\
\hline & Teaching others how to use sighted guide \\
\hline & Using appropriate facial and body gestures, other nonverbal communication. \\
\hline \multirow[t]{16}{*}{ Low Vision } & Relating special concepts (fat, thin, tall, short, etc.) \\
\hline & Adapting to changing illumination in the environment \\
\hline & Anticipating and predicting events from distance information \\
\hline & Deciding when to use vision and how to combine vision with other sensory input \\
\hline & Detecting objects at different distances and in different visual fields \\
\hline & Knowing vehicles \\
\hline & Interpreting objects at different distances for identification and orientation \\
\hline & Scanning, tracking, shifting gaze etc. \\
\hline & Using optical devices \\
\hline & Using visual skills efficiently \\
\hline & Knowing street signs \\
\hline & Adapting to different lighting conditions \\
\hline & Knowing when it is more efficient to use nonvisual information \\
\hline & Knowing when to trust visual information. \\
\hline & Using eye contact \\
\hline & Interpreting movements of other vehicles, pedestrians \\
\hline \multirow{7}{*}{$\begin{array}{l}\text { Low Vision or } \\
\text { Blind }\end{array}$} & Cardinal Directions \\
\hline & Left and Right for self and others \\
\hline & Object to object relationships \\
\hline & Parallel and Perpendicular \\
\hline & Position of the sun \\
\hline & Self to object relationships \\
\hline & Spatial terminology (under, over, bigger, etc.) \\
\hline
\end{tabular}

Table 1, Continues 
Table 1, Continued

Category

Low Vision or

Landmarks and cues

Skill

Blind

Time concepts

Directing drivers to destinations

Location knowledge in unfamiliar environments

Route planning and travel

Good posture

Noticing and negotiating drop-offs

Using systematic search techniques

Estimating relation of distance to time

Adapting to variations in road conditions

Block distances, corners, intersections, and streets

Knowing traffic flow, signals at intersections

Locating specific addresses or rooms

Negotiating elevators, escalators, revolving doors

Understanding signage

Using mainline transit and paratransit

Altering travel for inclement weather

Reorienting to previous position

Interpreting environmental sounds

Paying attention to one cue/landmark over another

Making 90/180/360 degree turns

Position to objects

Making backup plans

Arranging rides

Behaving appropriately on public transportation

Requesting directions during a route

Soliciting information from dispatchers, drivers, stores, etc.

Using appropriate telephone manners

Table 1, Continues 
Table 1, Continued

\begin{tabular}{ll}
\multicolumn{1}{c}{ Category } & \\
\hline Low Vision or & Knowing advantages and disadvantages of different modes of travel \\
& Orienting and reading maps \\
& Position to map position \\
& Choosing appropriate clothing and gear \\
& Choosing between routes \\
& Locational concepts \\
& Temporal concepts \\
& Tolerance of movement and positional change \\
& Tactile exploration and discrimination \\
\hline Note ADA= Americans with Disability Act; ID= Identifying Document; Id= Identify; IDEA= \\
Individuals with Disability Education Act; O\&M= Orientation and Mobility \\
Corn (2006) study.
\end{tabular}

O\&M specialist is a relatively young career field that arose in response to veterans returning home from World War II with vision loss. However, O\&M was not a mandated service to school age children until the 1997 reauthorization of IDEA (IDEA, 1997). Prior to the reauthorization in 1997, the individualized education program (IEP) team could list O\&M services on the IEP if deemed necessary by the team but only as a support, not as an educational or related service (Crouse \& Bina, 2006). Since 1997, O\&M services are offered to students who meet the criteria as defined by their individual states, but not all states have criteria in place. For example, the Illinois State Board of Education (ISBE) clarifies that a Certified O\&M Specialist (COMS) is a professional who completes the environmental and travel assessments (ISBE, 2016). ISBE also notes that the IEP team should determine when to conduct an initial O\&M assessment, but does not provide any guidelines, or diagnosis, that would indicate the need for this assessment. IDEA simply indicates assessments should be "appropriate" and should be completed by someone who is "qualified personnel" in section 300.34 (c)(7). Explanation of the 
terms appropriate and qualified are not clarified within IDEA and are left to interpretation of the state and/ or serving district. However, within the field of O\&M there has been effort to define both terms. A qualified individual is an individual whom has completed an accredited university preparation program (Blasch \& Wiener, 2010). A study completed by Wall Emerson and Anderson (2006) surveyed working O\&M specialists in part to define appropriate in terms of assessment. These authors determined that appropriate meant assessments should be completed when an individual with a visual impairment is unable to navigate their school or home independently and safely. They further defined that reevaluations should occur every three years and when the individuals vision or school environment have changed.

Within a preparation program, O\&M specialist are specifically educated for the use of assessment, service delivery models, and instructional strategies (Blasch, Wiener, \& Welsh, 2006). However, beyond the preparation program, additional information and tools are available through the internet and professional networks. Due to the limited number of those in the profession and limited number of preparation programs, the history and practices of O\&M are predominantly shared through blogs, white papers, conference presentations, and professional networks. This differs greatly from many other areas of special education since those areas have an array of evidence-based practices to diagnose, assess, and provide appropriate researched interventions. However, there is not one study related to instructional strategies for O\&M that independently meets the requirements of What Works Clearinghouse (IES, 2018).

\section{O\&M Specialists}

The term O\&M specialists is a broad term used to note specialized training in the use, assessment, and instruction of skills necessary for safe and independent travel for individuals with a visual impairment (Blasch \& Wiener, 2010). To be considered an O\&M specialist, the 
professional must complete a university training program in O\&M. For the 2018-2019 academic year there were only 19 programs across the United States that produce on average 250 graduates a year (Ferrell, 2007; Sauerburger, 2016). Graduates primarily receive a masters or masters level certification, with the exception of Stephen F. Austin University that offers the only undergraduate certificate in the nation (Sauerburger, 2016). While graduates can practice nationally following graduation, O\&M specialists can pursue one of two additional certifications in the O\&M field, the Certified O\&M Specialist (COMS) licensure or the National O\&M Certification (NOMC) (ACVREP, 2018; Bell \& Mino, 2011).

COMS licensure is offered through an organization by the name of Academy for Certification of Vision Rehabilitation and Education Professionals (ACVREP) (ACVREP, 2018). The COMS licensure is structured and regimented similar to the military, where the profession originated. The skills are taught in a set sequence that practitioners are largely encouraged not to deviate from. Instructor involvement and supervision are heavy in the beginning and weaned off as the student or client approach a functional level. Eligible professionals must submit documentation of their completion of an approved university program, an internship with a current COMS, and sit for a certifying exam. The internship and the exam are to ensure that the COMS candidate meets the standards of rigor and knowledge that COMS are known for internationally. The exam was created in 1996, with frequent updates by a subject matter expert group of COMS under ACVREP (ACVREP, 2018; Bledsoe, 2010). While the process is costly, it is often recommended or sometimes required for O\&M positions in certain regions, or by some districts and agencies.

NOMC licensure is sponsored by the National Blindness Professional's Certification Board (NBPCB) (Bell \& Mino, 2011; NBPCS, 2008). This licensure was initially created to 
offer a different model for O\&M services called structured discovery (Bell \& Mino, 2011). The model encourages individuals with vision loss to use experimental learning guided by Socratic style questioning to promote understanding of their surroundings and how to travel through it. Similar to the COMS qualifying process, candidates are required to complete a recognized university program, internship, and certifying exam. However, NOMC also requires a lengthy immersion training process, where candidates must travel and explore under blindfold for 480 or more hours. The cost of the NOMC licensure is slightly less than a COMS licensure, though it is still expensive.

Whether the professional is an O\&M specialist, COMS, or NOMC they are entering a field with an estimated 10,000 person shortage (Ferrell, 2007; K. Ferrell personal communication, November 18, 2016; Mason, 2000). Ferrell (2007) also said that the approximately 250 new O\&M specialist each year can barely fill the vacancies left by the retiring baby boomers and is not able to shrink the estimated shortage. This is compounded by the fact that O\&M licensure is vast, following clients from birth until death. Following graduation O\&M specialist must choose to work with early intervention (birth to three), K-12, or adults. Rural areas and states without a preparation program show the greatest unmet demand (Mason, 2000). Per Mason's (2000) estimations, there are 72 students for every one O\&M specialist. There are 1800 minutes in a standard school week of 30 contact hours. Given no geographic dispersion and all students seen back to back in the same school this would still only allow for 25 minutes per week for each student. This is an unmanageable caseload for any one professional. This leads instructional teams to consider alternatives to mediate the loss of services. 


\section{O\&M Assessment}

For school age children an O\&M assessment is instigated by a referral from a family

member, health care provider, teacher, or an IEP team member(s) (Zimmerman \& Roman, 2006). According to IDEA, the team then acquires parental consent for an assessment to occur (IDEA, 2004). Upon receipt of consent the IEP team has 60 days to conduct all assessments and meet to discuss the findings as a team. Part of an O\&M assessment, the specialist should interview the student, teachers, and parents about the child (Zimmerman \& Roman, 2006). The interview gathers basic information about the reason for the referral and the student. This may include the student's personality, learning style, goals, struggles, and activities inside and outside of the school day. This information guides the type of assessment, delivery style of assessments, and potential future goals during services if the student qualifies for O\&M services. A review of the student's record, both academic and medical, also guides the O\&M specialists' assessment decisions. The O\&M specialist also observes the individual traveling, referred to as the traveler, in familiar and unfamiliar areas of their environment, typically indoors and on school grounds. Assessment tools are also available (see table 2) for use in conjunction with observations. Each tool was developed with an understanding of child development for peers with and without vision from projects, like Lord (1969), and through the collective knowledge and experiences of the developing team. O\&M specialists may choose to use one or more of the available assessment tools or they can create their own based on their experience and knowledge of the skill set. There is currently no research about the popularity of any given assessment tool.

TAPS. The Teaching Age Appropriate Skills (TAPS) is a comprehensive evaluation tool and curriculum that is specific to individuals with a visual impairment and O\&M skills (Pogrund et al., 2012). The TAPS is designed for use with individuals with vision loss who are 3-21 years 
old and is able to be used with children with multiple impairments. It can be used as either an initial qualifying assessment or as an ongoing assessment to track the traveler's growth. The curriculum portion aids O\&M specialists in creating goals for instruction and potential activities and strategies to help make those gains.

NMSBVI O\&M Inventory. The New Mexico School for the Blind and Visually Impaired Orientation and Mobility Inventory (NMSBVI O\&M Inventory) is an assessment tool designed for academic and functional students over the age of six (NMSBVI, 2016). Travelers are scored not capable (0) to independent (5) on the scope of O\&M skills in their chronological order of development. The tool was developed to utilize as the initial assessment to qualify for services and as a measure to track the travelers skill growth for the IEP. The tools are downloadable as a Word document or Excel spreadsheet. When utilizing the Excel version, O\&M specialists can even print out a series of tables and graphs displaying the traveler's growth for IEP team members.

Texas 2 Steps. The newest assessment tool for children with a visual impairment is the Texas 2 Steps (Sewall, et al., 2016). The tool guides the O\&M specialist through the assessment of birth through the beginning of movement. This utilizes pictures and descriptions to ensure that the O\&M specialist knows exactly what they are looking for. After each skill, there is a section that lays out why the skill is important to O\&M and activities to improve that area of development moving forward. 
Table 1

Orientation and Mobility Assessment and Service Delivery Tools

\begin{tabular}{|c|c|c|c|c|}
\hline Tool & Type & Population & Price & Note \\
\hline $\begin{array}{l}\text { Teaching Age Appropriate Skills } \\
\text { (TAPS) } \\
\text { (Pogrund et al., 2012) }\end{array}$ & Assessment & $\begin{array}{l}\text { 3-21 years old, } \\
\text { can be used } \\
\text { with students } \\
\text { with MI }\end{array}$ & $\$ 90$ & $\begin{array}{l}\text { A combination assessment and curriculum. Evaluated as } \\
\text { met }(+) / \text { not met(-). Skills divided by concept }\end{array}$ \\
\hline
\end{tabular}

The New Mexico School for the Blind and Visually Impaired Orientation and Mobility Inventory (NMSBVI O\&M

Inventory)

(NMSBVI, 2016)

Texas 2 Steps

(Sewell, et al., 2016)

Preschool O\&M Screening

N $\quad$ (Dodson-Burk \& Roman, 2012)

The Oregon Project for Preschool Children Who are Blind or Visually

Impaired

(Anderson, Boigon, Davia, \& deWaard, 2007)

The Peabody Mobility Scale (Harley, Wood, \& Merbler, 1976)
Assessment

6-21 years old

Free created for students with

MI

Assessment

0-start of independent movement

Assessment $0-5$ years old, can be used with students with MI

Assessment 0-5 years old, can be used with students with MI

Assessment 4-11 years old,
students with
MI

$\$ 57-$

$\$ 160$
The assessment is held in an excel document and scored from not capable (0) to mastery (5). Skills listed chronologically by age of development

\$40-\$75 This assessment guides through the parent interview and movement skill beginning with muscle tone and control.

This is a global assessment covering cognitive, language, compensatory, vision, self-help, social, fine motor, and gross motor development. O\&M may use some or all of this assessment. Skills are evaluated as met(+)/not met(-).

$\$ 530$

An early O\&M assessment focusing on motor and concept development, as well as sensory and mobility skills. Scored as not performed, not applicable, independent, with assistance, and observed. 
Table 2, Continued

\begin{tabular}{|c|c|c|c|c|}
\hline Tool & Type & Population & Price & Note \\
\hline $\begin{array}{l}\text { Michigan Severity Scale } \\
\text { (O\&MSR/O\&MSR+) } \\
\text { (MDE-LIO, 2017) }\end{array}$ & $\begin{array}{l}\text { Service } \\
\text { Delivery }\end{array}$ & $\begin{array}{l}3-21 \text { years old, } \\
\text { O\&MSR+ can } \\
\text { be used with } \\
\text { students with } \\
\text { MI }\end{array}$ & Free & $\begin{array}{l}\text { Completed after an assessment to determine service need from } \\
0 \text { minutes up to } 120 \mathrm{mpw}\end{array}$ \\
\hline $\begin{array}{l}\text { Orientation and Mobility Visual } \\
\text { Impairment Scale of Service Intensity of } \\
\text { Texas (O\&M VISSIT) } \\
\text { (Pogrund et al., 2017) }\end{array}$ & $\begin{array}{l}\text { Service } \\
\text { Delivery }\end{array}$ & $\begin{array}{l}3-21 \text { years old, } \\
\text { can be used } \\
\text { with students } \\
\text { with MI }\end{array}$ & Free & $\begin{array}{l}\text { Completed after an assessment to determine service need from } \\
0 \text { minutes up to } 120 \mathrm{mpw}\end{array}$ \\
\hline Professional Judgement & $\begin{array}{l}\text { Assessment/ } \\
\text { Service } \\
\text { Delivery }\end{array}$ & All & Free & $\begin{array}{l}\text { Supplements available tools, in some states can be used as the } \\
\text { stand alone tool. }\end{array}$ \\
\hline
\end{tabular}

Note. MI=Multiple Impairment; MPW= Minutes Per Week. 
Preschool O\&M Screening. The Preschool Orientation and Mobility Screening tool is utilized to assess travel skills of young children, birth to five years old, who have a visual impairment (Dodson-Burk, \& Hill, 1989). The assessment guides O\&M specialists through a movement evaluation that encourages assessment for weaknesses, but also strengths. The O\&M specialist can then communicate better with parents and other specialists exactly how the child is functioning and currently able to travel. Through establishing where a child is in a positive or neutral tone, the entire team can work to build the child up to their potential.

The Oregon Project. Similarly, the Oregon Project for Preschool Children Who are Blind or Visually Impaired explores the abilities of young children, birth to six years of age, with a visual impairment (Anderson, Boigon, Davia, \& deWaard, 2007). The Oregon Project is a global evaluation tool assessing all areas of development, an O\&M specialist can utilize the gross motor development section, as well as any others they deem necessary for the individual child. When the assessment is completed by the O\&M specialist in tandem with the vision specialist it provides an all-inclusive view of the child. This is important for all children with a visual impairment, but more so for children with complex support needs accompanying their visual impairment. Utilizing this tool, the team is able to calculate a rough estimate of the child functional age and utilize the tool to show growth in developmental areas over time.

These tools are not always required by the state or district, and subsequently the O\&M specialist may not use them. However, these tools provide the specialist with an established body of O\&M skills needed by an individual with a visual impairment to travel safely and independently for their developmental level. It is important to choose the correct assessment tool or tools for the individual's age, abilities, goals, endurance, and environment. When an O\&M specialist believes that there is not an appropriate assessment for the individual, they may choose 
to use tools created by their district or themselves, observational reports, or their own professional judgement as a snapshot of the individuals abilities.

The Peabody Mobility Scale. Based directly on the findings of Lord (1969), the Peabody Mobility Scale sought to evaluate the travel weakness inherent in students with vision loss and additional complex support needs (Harley, Wood, Merbler, 1976). The scale specifically targeted the motor development, concept development, sensory skills, and mobility skills for students from preschool until early adolescence. This tool pairs observation of a student in their natural routine with requested tasks such as climbing stairs as needed to round out the assessment.

\section{Service Delivery Tools}

Following the assessment process, the O\&M specialist produces a report for the IEP team, detailing the student's strengths and weaknesses of travel (Zimmerman \& Roman, 2006). Based on these findings, the specialist must also make a recommendation to the team about the need and quantity of O\&M services. O\&M specialists base this recommendation on professional judgement and/ or the results of a service delivery tool (see table 2).

Michigan Severity Scale. The Michigan Severity Scale (O\&MSR) was created in 1996 with several updated versions produced in the three decades following (MDE-LIO, 2017). The O\&MSR has different sections that allow the O\&M specialist to evaluate service needs for students with vision loss, as well as students with vision loss and multiple impairments. A secondary version of the tool is also available for use with students with a concomitant disability, the Michigan Severity Rating Scale for Students with Additional Disabilities (O\&MSRS+) This tool utilizes ocular and assessment results to provide a systematic recommendation for service 
minutes prior to an IEP meeting. The range of service recommendations varies from not indicated to twice a week for 30-60 minutes.

O\&M VISSIT. After thirty years, another service delivery tool came to market, the Orientation and Mobility Visual Impairment Scale of Service Intensity of Texas (O\&M VISSIT) (Pogrund et al., 2017). The O\&M VISSIT is for use with school age travelers who have a visual impairment and may or may not have additional support needs in preparation for an IEP team meeting. O\&M specialists rate the traveler's current need for a series of skills from no need (0) to intense need (10). The scale has additional questions to ensure it is responsive to medical needs, student's individual instructional time needs, family needs, and travel time to/from instructional environments. When all portions of the rating scale are complete, a tallied score will produce a recommendation for 0-240 minutes of service per week. The scale does lend itself to caseload creation as well. The scale lays out an instructional week case load of 2400 minutes or 480 minutes a day. This scale provides administration a number of needed minutes, and a quick reference for potential staffing needs during caseload development.

Professional judgement. While there are a few assessments and tools to help establish the need and amount of service, some professionals choose to use or supplement findings with their own professional judgement. O\&M specialists are guided by their university training program, as well as their personal and professional experiences. For example, by working with several students previously on simple three block $L$ shaped routes an O\&M specialist knew that this would take about 20 minutes to complete the lesson plus the amount of time to transport the student to and from the location. This then guides the amount of time that they recommend at the IEP. 
Service recommendation or service delivery decision are conveyed to the team as either a need for direct services and/or indirect services. Direct services are measured in minutes per week (MPW), month (MPM), or quarter (MPQ). Similarly, indirect or consultative services are measured in MPM, MPQ, minutes per semester (MPS), or minutes per year (MPY). Along with the recommendation for services, the O\&M specialist provides the team with recommended goals and objectives specific to the student reflecting the individual's struggles noted during the assessment. At the scheduled meeting, the IEP team reviews the assessment and service recommendations from the O\&M specialist. With consensus of the need for services reached, the team then reviews the goals and objectives similar to other IEP domains. The goals aim to build a student with a visual impairment to the point where they can: independently find their way to locations within their school, utilize a long white cane to detect tripping hazards, and cross a street independently, like their peers without vision loss. For a more comprehensive list of O\&M skills compiled through research and surveys of experienced practioners see table 1.

\section{Translation to Service}

Of the estimated 7.3 million individuals with a visual impairment in the United States, there are approximately 28,000 individuals with a visual impairment served with vision supports or services on an IEP in the K-12 school system (NCES, 2017; NFB, 2018). The NFB (2018) estimates that this number should actually be around 62,528 based on indication of a visual impairment on the student's IEP. According the National Longitudinal Transition Study-2 (NLTS2) findings, roughly 54 percent of K-12 students with a visual impairment receive O\&M training (Cameto, \& Nagle, 2008). Some leaders in the field argue that all individuals with a visual impairment would benefit from O\&M services (Cutter, 2007; Dignan, n.d.; Wall Emerson \& Corn, 2006). However, many students have reduced services or go without services for 
numerous reasons. Decisions about educational and related services are meant to be made on the basis of student need as established by an assessment (Pierangelo \& Guiliani, 2017). Yet Wall Emerson and Anderson (2014) felt that due to a shortage of available O\&M instructors these decisions would be made using the assessment and extraneous factors such as a student's propensity for growth, the student with the greatest need, or a student's access to other programming. A pilot survey of O\&M specialists in Illinois found that factors impacting service qualification and quantity of service included a lack of professional time, uncooperative team members or administration, and demands of academic students (Randles, 2018). While this point is anecdotally raised by many authors in the field, the potential factors impacting assessment decisions made by the O\&M specialist have not been explored in a research setting to date outside of the previously mentioned Randles pilot study. When viewing the discrepancy between the need for services and the available personnel for services through the lens of economic theory the potential for factors impacting service delivery becomes visible.

Market of services. The theory of supply and demand outlines the interaction between the supply of a resource and the demand for that resource (Hayes, 2018; Mullins, 2012). Supporting this theory are four basic laws:

1. If the demand for a product grows but the supply remains constant, that interaction grows the price and quantity of the product.

2. If the demand for the product slows but the supply remains constant, that interaction lowers the price and quantity of the product.

3. If the supply grows and the demand of the product remains constant, that interaction lowers the price while raising the quantity of the product. 
4. If the supply slows and the demand remains constant, that interaction leads to a higher price and lower quantity.

When applied to the O\&M field, the four basic laws:

1. If the demand/need for O\&M services grows but the number of O\&M specialists remains constant, that interaction grows the value/need for O\&M services and the number of students in need.

2. If the demand/need for O\&M services slows but the need for O\&M specialists remains constant, that interaction lowers the value/need for O\&M services and the number of students in need of the service.

3. If the number of O\&M specialists grows and the demand/need for O\&M services remains constant, that interaction lowers the value/need for O\&M services while increasing the number of students in need of services.

4. If the number of O\&M specialists slows but the demand/need of the students for O\&M services remains constant, that interaction leads to an increase in the value/need of O\&M services as well as the number of students in need of the service.

The fourth law best describes the current standing of the field. The need for services does not diminish, but the amount of available services does. This creates a conundrum for O\&M specialists must make a decision as to who receives services and who does not. O\&M specialists must decide whether all students will get a reduced amount of services, or is priority given to the students with the greatest need or students with greatest potential for growth (Wall Emerson \& Corn, 2000). When teachers and specialists are forced to make decisions about the student's services based on factors outside of their assessment results it produces a negative or challenging incident for the O\&M specialist. 
Until the field of O\&M increases the supply of qualified specialists, the field is best described through the fourth law of the theory of supply and demand. When the field of O\&M begins to grow at a greater rate than attrition, we would shift to a model more closely resembling the third law where the amount of time and the value of time will increase. This is due to the constant and even potentially growing number of students in need of the service. On a national scale this would likely look like this, as the vacancies fill the awareness of O\&M specialists' existence and role in the school community will grow. This will cause an influx of evaluation requests and potential students in need of services. The discrepancy of needed and available services could remain for an indeterminant amount of time due to this influx. This discrepancy means that a number of students with a visual impairment in need of O\&M services will remain without any services or insufficient services. In deficit models like our current position under the fourth law of supply and demand, as well as the described growing position under the third law, students remain unserved or underserved. This potentially forces these students to wait until adulthood for services, where they join long waiting lists for inpatient training that can take 6-9 months to complete or short homebased instruction, measured in total hours. Both the inpatient and homebased programs for adults are costly and not equivalent to services provided under an IEP.

\section{Purpose of the Study}

This study aimed to explore O\&M specialists' assessment and service delivery decision tools they are using in the K-12 educational system. Furthermore, participants completed a survey exploring their experiences with assessments and service delivery decisions. Specifically targeting what impacts their recommendations and service delivery decisions outside of the student and assessment results. While only one study to date has attempted to explore this topic 
(Randles, 2018), the authors Wall Emerson and Anderson (2014) postulated that O\&M specialists use factors like potential for growth, greatest need, and more to isolate which individuals qualify for services and which do not. To date, this has been anecdotally noted within the discussion section of studies but only explored in the state of Illinois. The survey results will report the response of O\&M specialists throughout the Midwest region collectively.

\section{Rationale}

For the last decade I have worked with children and adults with low vision and blindness in several states of the Midwest. Most of this time was used providing O\&M services to children. At each placement I was issued a caseload inherited from a predecessor where students in some cases were receiving inadequate amounts of service based on the calculations of the O\&MSRS. Each caseload varied greatly, but a common theme was the large and sometimes overwhelming size. Some caseloads had a large amount of students in a small area, other had a smaller number of students that were working on more time intensive skills, while others yet covered a large geographic area. My most difficult caseload included approximately 25 students in need of direct instructional minutes across 7 counties requiring over 60 hours of work in a given week. During that academic year, my administration continued to assign me additional students for service qualification assessments. After I completed the assessment I was asked to make a recommendation for services or a service delivery decision. Given my already overfull schedule and lack of additional personnel available, I was forced to decide whether I would qualify a student for the instructional minutes they needed or go against best practices and qualify them for the time that I had available. As I entered my doctoral program I began to wonder if this was just a problem that I encountered or if this was a common issue. Early on, I found resources like Wall Emerson and Anderson (2014) that confirmed the issue was not unique to myself. 
However, through conversations with my growing network of O\&M specialists I found out that this is not the case for all. This left me with the burning question of why this is happening and how is it impacting our students. So through this study I want to explore the process from the beginning. What research is out there about assessment and service delivery decisions? Then I want to hear from my peers about what they are using to complete assessments and make determinations about services. Furthermore, when they find themselves in this situation how are they making decisions about assessments and services?

\section{Definition of Terms}

Assessment/ evaluation. The examination of an individual with a visual impairment's ability to travel safely and independently about their environment (Blasch \& Wiener, 2010). Additional attention paid to the age appropriateness of the travel and the individuals ability to travel with purpose of function. Highly qualified individuals must complete the assessment under the regulations of IDEA (2004). Therefore, O\&M specialist, a certified O\&M specialist (COMS), or a national O\&M certificate (NOMC) must be the IEP team member completing the O\&M assessments (ACVREP, 2018; Blasch \& Wiener, 2010; NBPCB, 2008).

Blindness. A level of reduced vision that cannot be corrected through medical intervention or device (Duffy, 2015). This can include partial blindness, noted by the ability to see things such detection of the presence and/or location of light, large movements, or other objects or individuals without necessary clarity. Individuals may also experience total blindness or the inability to perceive light. This is also referred to as No Light Perception (NLP).

Individual with a visual impairment. An individual with reduced visual acuity, visual field, or other visual conditions without possible correction through the use of lenses or medical intervention (CDC, 2017). 
Legal blindness. A visual acuity of 20/200 or less in the better eye with best correction; or a monoptic field of vision of less than 20 degrees in the better eye (SSA, 2018).

Orientation and mobility (O\&M). A specialized set of skills employed by an individual with visual impairment to travel safely and independently through their surroundings with purpose (Blasch \& Wiener, 2010; Wall Emerson R. \& Corn, A., 2006)

Orientation and Mobility (O\&M) skills. The specialized skills specific to O\&M (see table 1). Graduates of university preparation programs must demonstrate proficiency in the execution and instruction of these skills (ACVREP, 2018; Lord, 1969; Wall Emerson \& Corn, 2006).

Orientation and mobility specialist (O\&M specialist). A related service provider, who provides instruction to individuals with a visual impairment on the skills and strategies necessary to travel safely and independently with purpose through their environment (Blasch \& Wiener, 2010). This is not to be confused with a Certified O\&M Specialist (COMS). COMS are O\&M specialists who have received additional credentialing from ACVREP as discussed above.

Service delivery. The prescribed frequency and duration of O\&M instruction based on the findings of the O\&M assessment (Blasch \& Wiener, 2010; Munro et al., 2018; Wall Emerson $\&$ Corn, 2006). Specialists prescribe services as direct and/or indirect services, and are measure in minutes per day, week, month, or semester.

Traveler. An individual with a visual impairment that employs orientation and mobility skills to travel safely and independently about their environment. The traveler may also utilize a long white cane and other orientation and mobility tools. 


\section{Significance of the Study}

Given the shortage experienced by the field of O\&M (Mason, 2000; Ferrell, 2007), this study endeavors to establish the additional factors that $\mathrm{O} \& \mathrm{M}$ are employing to determine who will receive services and how much services they will receive. For professionals in the field, the study can act as a guide for recognizing the factors inherent in their position, while continuing to strive to provide services solely based on the student's need. While researchers, professionals, and university preparation programs can use the study to guide the development of alternative programming options to meet the true needs of students with a visual impairment currently. They can also use the study as a justification for additional recruitment programs for the field, including personnel preparation support grants.

\section{Summary}

This chapter briefly outlined the O\&M profession, including certification and guiding policies, as well as the process of assessing students with low vision and establishing their need for services. The remaining four chapters will outline the study and its findings. Chapter II is a systematic review of the literature on O\&M assessment and service delivery, including the tools utilized and body of knowledge and competencies. Chapter III outlines the study based on the gaps of research isolated in Chapter II. The chapter covers the methodological design and procedures. The results and discussion of findings are found in Chapters IV and V respectively. 


\section{CHAPTER II: REVIEW OF THE LITERATURE}

Becoming an adult is different for every individual. For many, this coming of age is marked by their departure for college or gaining employment. For individuals with a visual impairment this level of independence requires additional skills to ensure access and safety. According to a National Longitudinal Transition Study-2 (NLTS2) report, one of the leading factors impacting individuals with visual impairments preparedness for college and employability is their orientation and mobility (O\&M) skills (Cmar, McDonnall, \& Crudden, 2018). These crucial O\&M services are provided to individuals with a visual impairment not in response to their diagnosis, but as a result of a qualifying assessment.

A review of the literature was conducted for information in the O\&M field. The purpose was to explore the articles produced by members in the O\&M field that might serve as guidance in the area of O\&M assessment and service delivery. The examination of the literature aimed to answer:

1. What are the reported assessments and screenings used for O\&M evaluations?

2. What other professional tools are guiding O\&M specialists in decisions about service delivery?

3. What is published in regard to O\&M skills as it relates to instruction and assessment? When an IEP team hopes to establish the potential travel needs of a student with vision loss there is a process that is initiated by their request for the student's evaluation. A O\&M specialist must evaluate or assess the student's need in regard to safe and independent travel (Blasch, Wiener, and Welsh, 2010). After the assessment is completed, the O\&M specialist must prepare a recommendation for the team that outlines whether or not the student qualifies for O\&M services as well as the frequency and duration of those services. For the purposes of this 
review and subsequent study this is referred to as a service delivery decision. Finally, the O\&M skills are the focus of instructional or service time for the student to ensure their ability to travel safely. In light of this, the rest of the chapter will report the findings of this literature follow in this manner.

\section{Search Procedure}

I conducted a systematic review of the literature for the field of O\&M. More specifically, the search was for articles pertaining to the assessment of students with a visual impairment and their ability to travel independently, as well as the service delivery model, and scope of the instruction. All searches were conducted utilizing the Illinois State University Milner Library search platform, employing the Academic Search Complete, ERIC, and PsycINFO databases. A trial search was conducted exploring the literature present within the last decade, 2008-2018, using the terms "orientation and mobility" and assessment. This search produced a limited yield of just two articles; therefore, no time parameters were utilized for the formal search in the hope of finding additional literature for analysis. I conducted six searches of the database, each containing "orientation and mobility" as the primary search term. The secondary terms for the six searches included: assessment, evaluation, screening, service*, instruction, and model. A tertiary search term, foreign countries, was added as a disqualifier or not within the search. This was included to isolate research conducted in the United States. The yield of each search was collected and delineated by step (see table 3). Searches were then limited to only include articles that were peer reviewed and presented in English, my native language. After the removal of exact duplicates, non-relevant subject terms were removed and recorded in table 3 . This left a combined yield of 160 articles for review with 33 duplicates between searches. Articles were reviewed by title, abstract, then full text based on potential relevance to the guiding 
Table 2

Individual Search Terms and Yield Results

\begin{tabular}{|c|c|c|c|c|c|c|c|c|}
\hline \multicolumn{3}{|c|}{ Terms } & \multicolumn{6}{|c|}{ Yields } \\
\hline Primary & Secondary & Tertiary & Initial & Peer Reviewed & English & Duplicates & Subjects Removed & Final \\
\hline And & And & Not & & & & & & \\
\hline $\begin{array}{l}\text { "orientation and } \\
\text { mobility" }\end{array}$ & Assessment & $\begin{array}{l}\text { Foreign } \\
\text { Countries }\end{array}$ & 114 & 68 & 65 & 59 & $\begin{array}{l}\text { Vocal cord surgery, vocal cord } \\
\text { disease, economic decisions, } \\
\text { societies, human sex differences }\end{array}$ & 24 \\
\hline $\begin{array}{l}\text { "orientation and } \\
\text { mobility" }\end{array}$ & Evaluation & $\begin{array}{l}\text { Foreign } \\
\text { Countries }\end{array}$ & 146 & 88 & 86 & 79 & $\begin{array}{l}\text { Allied health personnel, animal } \\
\text { assisted therapy, internet, health } \\
\text { care utilization, braille } \\
\text { instruction, interpersonal } \\
\text { communication }\end{array}$ & 37 \\
\hline $\begin{array}{l}\text { "orientation and } \\
\text { mobility" }\end{array}$ & Screening & $\begin{array}{l}\text { Foreign } \\
\text { Countries }\end{array}$ & 14 & 5 & 5 & 5 & None & 5 \\
\hline $\begin{array}{l}\text { "orientation and } \\
\text { mobility" }\end{array}$ & Service* & $\begin{array}{l}\text { Foreign } \\
\text { Countries }\end{array}$ & 7 & 6 & 6 & 6 & None & 6 \\
\hline $\begin{array}{l}\text { "orientation and } \\
\text { mobility" }\end{array}$ & Instruction & $\begin{array}{l}\text { Foreign } \\
\text { Countries }\end{array}$ & 232 & 152 & 149 & 145 & $\begin{array}{l}\text { Internet, braille instruction, } \\
\text { animal assisted therapy, } \\
\text { epidemiology, health personnel } \\
\text { attitudes, human finals, math }\end{array}$ & 64 \\
\hline $\begin{array}{l}\text { "orientation and } \\
\text { mobility" }\end{array}$ & Model & $\begin{array}{l}\text { Foreign } \\
\text { Countries }\end{array}$ & 81 & 60 & 57 & 49 & $\begin{array}{l}\text { Older adults, treatment, case } \\
\text { studies, computer mediated } \\
\text { communication, Ronald Ferguson }\end{array}$ & 24 \\
\hline
\end{tabular}

Table 3

Cumulative Search Eliminations for Final Yield

\begin{tabular}{|c|c|c|c|c|c|c|}
\hline \multirow{2}{*}{$\begin{array}{l}\text { Search } \\
\text { Yields }\end{array}$} & \multirow{2}{*}{$\begin{array}{c}\text { Duplicates } \\
\text { Removed }\end{array}$} & \multicolumn{3}{|c|}{ Remaining After Review } & \multirow{2}{*}{$\begin{array}{c}\text { Incorporated } \\
\text { By Manual Search }\end{array}$} & \multirow{2}{*}{$\begin{array}{l}\text { Final Yielc } \\
\text { for Review }\end{array}$} \\
\hline & & By Title & By Abstract & By Article & & \\
\hline 160 & 127 & 55 & 28 & 12 & 5 & 17 \\
\hline
\end{tabular}


questions (see table 4). Articles pertaining to medical treatment or individual skill instruction

(e.g. street crossings or cane movements) were eliminated. After this elimination it resulted in 12 articles for inclusion in this review. A secondary hand search of the Journal of Visual

Impairments and Blindness was conducted, leading to an additional five articles for review. A final yield of 17 articles were selected to answer the guiding questions.

\section{Inclusion Criteria}

Studies included peer reviewed practitioner and research articles addressing O\&M services and assessments presented in English, the author's native language. A research article contains original data from a research study conducted by the author (University of Missouri, n.d.). Whereas a practitioner articles refer to articles expressing the authors professional opinion or experiences on a given topic aimed at individuals currently practicing in the field. For an article to be included the assessments identified in the article were to have been administered by an O\&M specialists providing services through early intervention, K-12 school, or adult agencies in the United States. Medical evaluations or medical assessments were disqualified for not meeting this criteria as they were not administered by the O\&M specialist directly. Participants or the population of focus for each article could include O\&M specialists or individuals with visual impairments from any age group, but they had to be eligible to receive an O\&M assessment and potential services. Due to the limited number of articles available to the myself in this area, no criteria for publishing year were utilized.

\section{Article Coding}

The author identified 17 articles that met the inclusion criteria, 7 research articles and 10 practitioner articles. Information was pulled from each article about the type of article, participant or population of focus, the focus or purpose of the article, and the implications to the 
field. The author and coder of this literature review is a doctoral candidate completing her dissertation in the area of visual impairments.

Descriptive information. Information about the participants or the group of focus was identified and compiled (see table 5). The participants age and concomitant disabilities were included for research and practitioner articles when reported.

Focus and implications. O\&M skills require systematic instruction of the individual's skill areas of need. The duration and scope of instructional services needed are established through assessment and service delivery decisions. Based on this, information about each article's focus and implications to the fields were collected and included for review (see table 5).

\section{Results}

A brief summary of each of the 17 articles that met inclusion criteria for this study can be found in table 5. All articles were published between 1969 and 2018, with only seven articles published in the last decade. Of the 17 articles, 7 articles are research studies and 10 articles are practitioner studies. Included within the seven research studies were 279 children ages birth to graduation or 21 years old, 36 adults receiving services from the Veteran Administration (VA), and 253 O\&M specialists (Geruschat \& De l'Aune, 1989; Harley \& Merbler, 1980; Hill, Dodson-Burk, \& Talor, 1992; Lord, 1969; Munro et al., 2018; Wall Emerson \& Anderson, 2014; Wall Emerson \& Corn, 2006). The remaining 10 articles included: three geared toward O\&M services and assessment for individuals with deafblindness (Bourquin, Mascia, Rusenski, 2002; Geruschat, 1980; Smith \& Herlich, 2014), one geared toward O\&M for adult (Hill \& Hill, 1991), five geared toward O\&M in the K-12 education system (Barrella et al., 2011; Bryan, 1989; Daugherty, 2014; Hill \& Hill, 1990; O’Mea, 2013), and one was geared toward birth to three O\&M (Dewald et al., 2015). 
Table 4

Descriptive Summary of Research and Practitioners' Reports

\begin{tabular}{cccc}
$\begin{array}{c}\text { Study and Type of } \\
\text { Document }\end{array}$ & $\begin{array}{c}\text { Participants or Group } \\
\text { of Focus }\end{array}$ & Focus & Implications \\
\hline $\begin{array}{c}\text { Assessment and Body of Knowledge } \\
\text { (Geruschat, 1980) }\end{array}$ & $\begin{array}{l}\text { K-12 students with } \\
\text { deafblindness }\end{array}$ & $\begin{array}{l}\text { The author outlined a facility generated O\&M } \\
\text { assessment utilized as part of the intake process } \\
\text { for students with deafblindness. }\end{array}$ & $\begin{array}{l}\text { The O\&M assessment should include information } \\
\text { about visual and medical evaluations, communication } \\
\text { methods, behavior, and other factors relevant to the } \\
\text { child. The can be obtained through a transdisciplinary } \\
\text { approach to assessment. }\end{array}$
\end{tabular}

(Geruschat \& De Veterans age 22-76

l'Aune, 1989) N=36

Research Report

(Harley \& Merbler, 1980)

Research Report

e

(Hill, Dodson-Burk, \& Taylor, 1992)

Research Report

(Hill \& Hill, 1991)

Practitioner Report

(Lord, 1969)

Research Report

(O’Mea, 2013)

practitioner Report
Children/Young

Adults Ages 4-28 with multiple disabilities $\mathrm{N}=85$

O\&M Specialists $\mathrm{N}=20$; Children Age 6 months to 5 years $\mathrm{N}=21$

\section{Older Adults}

Children Ages 3-12, $\mathrm{N}=173$

$\mathrm{K}-12$ children with multiple disabilities
Researchers developed a 6-block outdoor course for assessment of O\&M skills. Staff was trained and provided bimonthly meetings to ensure reliability and validity of observations.

The researchers developed additional sections and adapted existing sections of the PMS for use on children with additional disabilities.

The researchers conducted a field test of the Preschool O\&M Screening.

Authors provided tips on how to administer O\&M assessments for older clients.

Researchers created and utilized a scale to measure travel competencies of young children with a visual impairment.

Outlines use of ABA for students with a visual impairment who have challenging behaviors.
Observational assessments can be used with reliability and validity given initial training and continued checkins for consistency.

Each skill has been broken down into segments of sub skills to allow for a more accurate view of the child's ability to travel.

Form A for children who are younger than two chronologically, developmentally, or motorically. While Form B is for children over the age of two in development. Intended for recording observations, however, participants assessment used it as assessment and service delivery qualifying tool.

Remain cognizant of stress levels, medical needs, and fatigue. Also incorporate a lot of encouragement into the assessment.

Backwards chain from the desired travel skill to note the foundational skills, i.e. you must crawl before you walk.

Practice travel skills in useful ways during instruction, i.e. travel with cane to deliver mail.

Find the root cause of the behavior and what works for the child individual to discourage/encourage the behavior.

Table 5, Continues 


\begin{tabular}{|c|c|c|c|}
\hline $\begin{array}{l}\text { Study and Type of } \\
\text { Document }\end{array}$ & $\begin{array}{l}\text { Participants or Group } \\
\text { of Focus }\end{array}$ & Focus & Implications \\
\hline $\begin{array}{l}\text { (Smith \& Herlich, } \\
\text { 2014) } \\
\text { Practitioner Report }\end{array}$ & $\begin{array}{l}\text { K-12 children who are } \\
\text { deafblind }\end{array}$ & $\begin{array}{l}\text { California School for the Deaf and Blind detail } \\
\text { their shift to collaborative services and } \\
\text { assessment for children who are DB. }\end{array}$ & $\begin{array}{l}\text { Observations and student interviews need to be } \\
\text { including initial assessments of children with } \\
\text { deafblindness. } \\
\text { Preteach vocabulary and simple directions, while using } \\
\text { physical modeling, and inclusion of interpreters. } \\
\text { Continuous collaboration from TOD and O\&M }\end{array}$ \\
\hline $\begin{array}{l}\text { (Wall Emerson \& } \\
\text { Corn, 2006) } \\
\text { Research Report }\end{array}$ & $\begin{array}{l}\text { O\&M specialists in } \mathrm{K}- \\
12 \text { setting, } \mathrm{N}=20\end{array}$ & $\begin{array}{l}\text { A committee of O\&M specialists completed a } \\
\text { series of surveys to establish the O\&M body of } \\
\text { knowledge and skills and when formal } \\
\text { assessments should begin. }\end{array}$ & $\begin{array}{l}\text { Conduct and O\&M assessment for changes of vision or } \\
\text { placement, or for transition or IEP. } \\
\text { Consult table } 2 \text { for a full list of O\&M skills for } \\
\text { assessment and instruction. }\end{array}$ \\
\hline \multicolumn{4}{|l|}{ Service Delivery } \\
\hline $\begin{array}{l}\text { (Barrella et al., 2011) } \\
\text { Practitioner Report }\end{array}$ & $\begin{array}{l}\text { O\&M specialist in } \mathrm{K}- \\
12 \text { setting }\end{array}$ & $\begin{array}{l}\text { California School for the Blind notes some of } \\
\text { their cost saving measures that still allow them to } \\
\text { meet the need of their population. }\end{array}$ & $\begin{array}{l}\text { Programming options like pairing students, when } \\
\text { possible, and distance lessons could provide creative } \\
\text { scheduling options for O\&M specialists. }\end{array}$ \\
\hline $\begin{array}{l}\text { (Bourquin et al., } \\
\text { 2002) } \\
\text { Practioner Report }\end{array}$ & $\begin{array}{l}\text { Children and Adults } \\
\text { with deafblindness }\end{array}$ & $\begin{array}{l}\text { The authors outline the approach to services for } \\
\text { individuals with deafblindness provided by the } \\
\text { HKNCDB. }\end{array}$ & $\begin{array}{l}\text { HKNCDB uses a transdisciplinary approach geared } \\
\text { toward vocational and transition goals. Service are } \\
\text { provided through a large network of centers and } \\
\text { community outreach for individuals who do not meet } \\
\text { the criteria for residential programming. }\end{array}$ \\
\hline $\begin{array}{l}\text { (Bryan, 1989) } \\
\text { Practioner Report }\end{array}$ & K-12 students & $\begin{array}{l}\text { The author presented recommendations for } \\
\text { service needs of student for O\&M. Options were } \\
\text { also presented for meeting the needs when the } \\
\text { shortage leaves students without consistent or } \\
\text { adequate services. }\end{array}$ & $\begin{array}{l}\text { Student's needs and assessment results guide service. } \\
\text { Recommendations: Prek-3rd 30-50 MPD; } 4 \text { th }-6 \text { th } 40-80 \\
\text { MPD; } 7_{\text {th }}-9 \text { th } 50 \text { MPD or no less than 3x a week; each } \\
\text { student needs a minimum of } 250-300 \text { hours to } \\
\text { complete O\&M training w/o concomitant disabilities. }\end{array}$ \\
\hline $\begin{array}{l}\text { (Daugherty, 2014) } \\
\text { Practitioner Report }\end{array}$ & $\begin{array}{l}\text { O\&M specialists in } \mathrm{K}- \\
12 \text { setting }\end{array}$ & $\begin{array}{l}\text { The article outlines the history of different } \\
\text { service models in the state of Texas. }\end{array}$ & $\begin{array}{l}\text { Summer and short-term programs as outreach could be } \\
\text { used for compensatory or in-depth O\&M services. } \\
\text { Another program is for transition to college or vocation } \\
\text { after high school that can include intensive O\&M if } \\
\text { needed. }\end{array}$ \\
\hline $\begin{array}{l}\text { (Dewald et al., 2015) } \\
\text { Practitioner Report }\end{array}$ & $\begin{array}{l}\text { O\&M specialists in } \\
\text { Birth to Three services }\end{array}$ & $\begin{array}{l}\text { Outlines early intervention O\&M services } \\
\text { provided in New Mexico and Utah. }\end{array}$ & $\begin{array}{l}\text { Consult table } 2 \text { for a list of birth to } 3 \text { O\&M skills. } \\
\text { Collaborative team approach is beneficial to the child } \\
\text { and enables earlier access to O\&M skill development. }\end{array}$ \\
\hline
\end{tabular}

Table 5, Continues 
Table 5, Continued

\begin{tabular}{|c|c|c|c|}
\hline $\begin{array}{l}\text { Study and Type of } \\
\text { Document }\end{array}$ & $\begin{array}{l}\text { Participants or Group } \\
\text { of Focus }\end{array}$ & Focus & Implications \\
\hline $\begin{array}{l}\text { (Geruschat, 1980) } \\
\text { Practioner Report }\end{array}$ & $\begin{array}{l}\text { K-12 children with } \\
\text { deafblindness }\end{array}$ & $\begin{array}{l}\text { The author describes a service delivery method } \\
\text { that includes three portions to instruction for each } \\
\text { lesson. }\end{array}$ & $\begin{array}{l}\text { Lessons divided into sensory stimulation, concept } \\
\text { development, and route travel. } \\
\text { Document progress data daily and update IEP as often } \\
\text { as needed, not just yearly. }\end{array}$ \\
\hline $\begin{array}{l}\text { (Harley \& Merbler, } \\
\text { 1980) } \\
\text { Research Report }\end{array}$ & $\begin{array}{l}\text { Children/Young } \\
\text { Adults Ages 4-28 with } \\
\text { multiple disabilities } \\
\mathrm{N}=85\end{array}$ & $\begin{array}{l}\text { The researchers adapted and modified the PMS } \\
\text { for individuals with multiple impairments. As } \\
\text { part of the modifications a series of programmed } \\
\text { instruction was outlined. }\end{array}$ & $\begin{array}{l}\text { Programmed instruction on sub skills employing } \\
\text { structured independence, guided completion, and } \\
\text { diminishing prompts until mastery of the skill is } \\
\text { reached. }\end{array}$ \\
\hline $\begin{array}{l}\text { (Hill \& Hill, 1990) } \\
\text { Practioner Report }\end{array}$ & K-12 students & $\begin{array}{l}\text { The authors developed at three tiered O\&M } \\
\text { program including home/family, school, and a } \\
\text { resource center. }\end{array}$ & $\begin{array}{l}\text { Utilize a transdisciplinary with role release approach to } \\
\text { assessment and instruction to combat shortage. } \\
\text { Incorporate skill work and instruction into daily } \\
\text { activities and routines. }\end{array}$ \\
\hline $\begin{array}{l}\text { (Munro, et al., 2018) } \\
\text { Research Report }\end{array}$ & $\begin{array}{l}\text { O\&M specialists in } K- \\
12 \text { setting, } N=24\end{array}$ & $\begin{array}{l}\text { Provides results from a social validity survey } \\
\text { regarding the use of the O\&M VISSIT }\end{array}$ & $\begin{array}{l}\text { O\&M VISSIT can be a useful tool for establishing and } \\
\text { justifying service needs after an assessment. It can also } \\
\text { be used by administration for staffing and caseload } \\
\text { decisions. }\end{array}$ \\
\hline $\begin{array}{l}\text { (Wall Emerson \& } \\
\text { Anderson, 2014) } \\
\text { Research Report }\end{array}$ & $\begin{array}{l}\text { O\&M specialist and } \\
\text { TVI in K-12 setting, } \\
\mathrm{N}=189\end{array}$ & $\begin{array}{l}\text { Provides results from a usage and validity survey } \\
\text { of the O\&MSR or Michigan Severity Scale. }\end{array}$ & $\begin{array}{l}\text { O\&MSRS is a tool to justify O\&M service needs } \\
\text { following an assessment. While it is not intended for } \\
\text { use in caseload assignments it has been by specialist in } \\
\text { the field. }\end{array}$ \\
\hline
\end{tabular}

Note $\mathrm{ABA}=$ Applied Behavior Analysis; HKNCDB= Helen Keller National Center for Deafblind Youth and Adults. IEP= Individualized Education Plan; K-12= Kindergarten Through 12th Grade; MPD=Minutes Per Day; O\&M= Orientation and Mobility; O\&MSRS= Orientation and Mobility Severity Rating Scale;

PMS= Peabody Mobility Scale; TOD= Teacher of the Deaf' TVI= Teacher of the Visually Impaired; VISSIT=Visual Impairment Scale of Service Intensity of Texas; $\mathrm{W} / \mathrm{O}=$ Without. 


\section{Assessment}

Nine articles discussed O\&M assessments or mentioned assessment in addition to the primary topic of the article. These articles discussed the creation of individual assessment tools, the assessment process, or other factors that may influence assessment results (Geruschat, 1980; Geruschat \& De l'Aune, 1989; Harley \& Merbler, 1980; Hill et al., 1992; Hill \& Hill 1991; Lord, 1969; O’Mea, 2013; Smith \& Herlich, 2014; Wall Emerson \& Corn, 2006). Two studies worked specifically to establish the travel and compensatory skills that should be targeted for assessment and instruction (Lord,1969; Wall Emerson \& Corn, 2006). In the seminal study conducted by Lord (1969), he observed children with low vision and blindness, both during independent play and while working with experienced O\&M specialists and other professionals to establish a set of 124 individual skills. These skills encompassed the progression of skills needed by student with visual impairments for movement and travel, sensory cues for travel, interest in new experiences, traveling with and without a long white cane, and movement for daily living routines like toileting.

Wall Emerson and Corn (2006) studied O\&M assessment from the O\&M specialist point of view through a series of surveys, teasing out the skills needed and the parameters of the assessment process. The study from Wall Emerson and Corn also produced a list of needed O\&M skills similar to the Lord study. They completed their study by sending out a series of surveys and encouraged participants to add skills they felt were needed for instruction and assessment for O\&M or to remove unneeded skills from the already compiled list. After each round the master list of skills was modified based on the results of the previous survey. Wall Emerson and Corn added to the list resulting in 148 skills that are used today when assessing a student's ability or need for O\&M services. The completed list is in table 1. Furthermore, the 
survey participants largely agreed that assessment should be completed formally for service qualification shortly after diagnosis, change of visual functioning, when vision is worse than 20/200, or with a central or peripheral loss. Reassessments should also be completed every three years and in preparation for transition to adult services in response to the mandates of the IEP process under IDEA. Additionally, Wall Emerson and Corn note that a reassessment on O\&M skills may be prudent when the student changes schools, districts, or residence.

The work over the last 40 years of identifying and refining the needed skills for safe and independent travel have led to the creation of several assessment tools (see table 2). The review of literature located three articles specifically looking at the tools for O\&M assessment and how O\&M specialists use them (Geruschat \& De l'Aune, 1989; Harley \& Merbler, 1980; Hill et al., 1992). Ahead of the creation of specialized tools, O\&M specialists utilized their professional judgement based on their training and professional experiences. In 1989, two researchers from the VA sought to test the reliability and validity of professional judgement as a tool for assessment (Geruschat \& De l'Aune, 1989). By creating a route protocol, they were able consistently observe the participant with visual impairments in outdoor skills like street crossings, drop offs, and locating landmarks. The O\&M specialists for the facility then received initial training on protocol and needed skill observations. Bimonthly meetings with the authors and the specialists occurred for continued training and troubleshooting. The authors reported that this protocol produced a high level of reliability for observations, between individual clients and different O\&M specialists.

While not an O\&M assessment, O’Mea (2013) explored the use of applied behavioral analysis (ABA) by O\&M specialists. This assessment can be conducted by the O\&M specialist when they encounter challenging behaviors during lessons. This may happen at a greater 
frequency when working with students with additional support needs beyond a visual impairments. Through the use of ABA, an O\&M specialist can isolate the challenging behavior(s) and analyze the root cause of these behaviors in order to create a plan for the student to build or discourage the behavior as appropriate. This can be completed formally and informally, on a continuous and documented biases to guide instruction.

For students with complex support needs, in addition to their vision loss, it is recommended to utilize a collaborative approach for assessment and service delivery decisions (Bryan, 1989; Geruschat \& De 1'Aune, 1980; Smith \& Herlich, 2014). Smith and Herlich (2014) used this approach at the California Schools for the Deaf and the School for the Blind with their shared students. They noted that all providers involved should observe and interview the student in their current setting prior to beginning the assessment. The educational team, including an O\&M specialist, come together to discuss the approach and needed vocabulary for the upcoming assessment. All vocabulary needs were to be pretaught to ensure travelers' understanding during the assessment when spoken English is not their native language. When the needed vocabulary is at a functional level of understanding, the assessment can continue. The authors noted that it is important that following the assessments the collaboration continues through the service delivery decisions. Geruschat added that when evaluating individuals with additional support needs, like those with deafblindness, that the collaborative assessment should include nursing for a medical evaluation, a teacher of the visually impaired, a behavior specialist, a movement specialist or physical therapist, and someone who specializes in the child's mode of communication (Geruschat, 1990).

Hill and Hill (1991) provide guidance on the administering of O\&M assessments to older clients; however, the information is beneficial to individuals with complex support needs as well. 
The most significant points these authors stressed was that the O\&M specialist must select the most appropriate tool and utilize observations to understand the client as a whole. Part of these recommendations included having the specialist, prior to the evaluation, give the client an opportunity to explore the environment and practice moving about in the same low-distraction space where the evaluation will take place. The evaluation should be chunked into smaller time frames to account for fatigue and additional health concerns. Also, specialists should allow extra time for clients to respond to questions or prompts. Lastly try to avoid building stress in the client, the tone of the evaluation should remain positive with a lot of encouragement built into the experience.

\section{Service Delivery}

Nine articles examined models of delivery and the decision making process in relation to service delivery (Barrella et al., 2011; Bourquin et al., 2002; Bryan, 1989; Daugherty, 2014; Dewald et al., 2015; Geruschat, 1980; Harley \& Merbler, 1980; Hill \& Hill, 1990; Munro et al., 2018; Wall Emerson \& Anderson, 2014). Of these articles, three incorporated original research (Harley \& Merbler, 1980; Munro, et al., 2018; Wall Emerson \& Corn, 2014). In the articles addressing service delivery, the major themes included; the tools for service decisions, how many service minutes are needed, what is included in services, and what are some programming alternatives in response to shortage areas.

Service delivery decision tools. Similar to the tools available for O\&M assessments, there are tools designed specifically to guide the O\&M specialist's recommendation for service qualification and service delivery decisions. Two research articles tested the reliability and validity of three different tools available, the Michigan Severity Rating Scale $(O \& M S R S)$, the Michigan Severity Rating Scale for Students with Additional Disabilities (O\&MSRS+), and the 
Visual Impairment Scale of Service Intensity of Texas for $O \& M(O \& M$ VISSIT) (Munro et al., 2018; Wall Emerson \& Anderson, 2014). All three tools were designed to guide and justify the need and quantity of O\&M services for a child served in the K-12 education system. However, within the studies participants noted that the tool was also useful when assigning the professional caseload of students and justification for additional personnel. Wall Emerson \& Anderson (2014) the $O \& M S R S$ and the $O \& M S R S+$ for individuals with multiple impairments. Authors found O\&M specialists had knowledge of the tools and $75 \%$ of the respondents had utilized the tool after an evaluation, at three year reevaluations, and if changes occurred to the student's vision or program. When O\&M specialists were asked why the current IEP does not match the recommendation obtained from the tool, the responses included; the amount of students, mandated service times, and factors that were not addressed by the tool.

Building upon this tool, the $O \& M$ VISSIT was created by Munro (2018) and her colleagues to address additional factors that the O\&MSRS limited its review of or failed to account for, like upcoming transitions, family support, medical needs of the student, time intensity of concepts or instruction, and travel to instructional environment. The tool guides specialists through O\&M skill areas, where they are to quantify students' need from 0 (no need) to 10 (intense need) in that area. After an O\&M specialists used the O\&M VISSIT the perceptions were requested regarding the new tool. While the specialists largely indicated the tool matched their professional judgment, some participants indicated that the results did not match the current service recommendation due to the inability to commit time for service due to an already oversized caseloads.

Service delivery decisions. In 10 of the 17 articles concerns were raised around the O\&M specialist's inability to qualify or adequately service students based on caseload size, 
professional schedule, and geographic dispersion of students or clients (Barrella et al., 2011; Bourquin et al., 2002; Bryan, 1989; Daugherty, 2014; Dewald et al., 2015; Hill \& Hill, 1990; Munro et al., 2018; Smith \& Herlich, 2014; Wall Emerson \& Anderson, 2014; Wall Emerson \& Corn, 2006). An article written by Bryan (1989) challenges that an O\&M specialist's availability or caseload should not dictate services, the IEP should outline the student's needs based on the assessment findings. Success and programming should be dictated by the individual need not the timetable of the provider, school, or district. He extended this sentiment to say that the shortage of providers is not an excuse for students not receiving services nor the receiving of inappropriate amount of services. Furthermore, if the school is unable to meet the needs of the student within the school year alternatives must be considered. Bryan suggested compensatory service delivery systems like extended school year, short-term residential programs, or cooperatives forming between districts to provide intensive group community instruction. $\mathrm{He}$ noted that administrative support is key to the provision of services.

Bryan (1989) and Lord (1968) both agreed that students or clients should receive a minimum of three lessons per week. However, Bryan (1989) expressed a need for daily instruction following the successful implementation of the VA's model for O\&M instruction, featuring one-to-one lessons twice a day for 50 minutes. It was his belief to obtain optimal results from O\&M training that the service model should include daily instruction in O\&M (Malamazian, 1972). Students in preschool through third grade should receive 30 to 50 minutes of O\&M instruction daily (Bryan, 1989; Mills, 1980). Students in grades fourth through sixth should receive 40 to 80 minutes of O\&M services a week. As the students begin secondary school and transition age, grades $7_{\text {th }}$ through $12^{\text {th }}$, the focus should shift to longer lessons of an hour or more, three or more times a week. This instruction should be framed around the student's 
goals with a focus of community-based instruction. Bryan believed that individuals with a visual impairment need 250 to 300 hours to complete or master an O\&M training program based on his research and another seminal pieces (Bryan, 1989; Lydon \& McGraw, 1973). However, he conceded that this number may be significantly higher for individuals with additional medical or learning support needs based on his professional opinion.

Service delivery models. Harley \& Merbler (1980) as part of their revamping of the Peabody Mobility Scale, believed any missed skills on an assessment should directly guide the activities during direct instructional minutes. Their philosophy was that the scale would lead to programmed instruction through behavior modification with a built-in system of positive reinforcement. They believed that any given task should directly link to the individual's goal or gaps in skill development with the belief that mastery of the task would be achieved after six consecutive correct attempts. If the student is unable to complete the task, the O\&M specialist would then guide the student through the task utilizing prompts and physical assistance as needed. A system of diminishing prompts in frequency and severity will lead the student to independent completion of the task. Geruschat (1980) disagreed with the singular focus of skill development, especially for students with additional support or communication needs. He felt that lessons should focus on three main objectives: the concept or skill outlined within the IEP; traveling a developmentally appropriate route; and activities to stimulate their remaining senses. Each lesson should then be well documented to guide progress updates of the IEP every year, or more frequently as needed. Furthermore, Geruschat (1980) held the belief that the transdisciplinary approach that began during the assessment process should continue through the year of instruction. Hill and Hill (1990) believed that transdisciplinary approach could foster a system or role release between the O\&M specialist and other providers. For example, the speech 
language pathologist (SLP) would work with the child on ensuring cane movement while traveling to the speech room and the O\&M specialist would incorporate the words or sounds of the SLP goals into route travel. This could be done by integrating instruction into daily activities and curriculum for school age children. Hill and Hill (1990) even created a three-tiered O\&M program that focused the team's involvement on supporting children at home with their family, at school, and a resource center for the parents and staff.

When specialists are unable to provide the needed services to the students in their geographic area alternatives must be found to meet the need. To mitigate loss of services, O\&M specialists may work with vision specialists and other school providers to ensure others are reinforcing proper travel skills as the child develops. This allows young children to build a strong foundation of motor skills and experiences in preparation for more complex travel skills. Three articles identified alternative ideas for service delivery in response to the shortage of funding and/ or personnel for O\&M services (Barrella et al., 2011; Daugherty, 2014; Dewald et al., 2015). Dewald explored the use of collaborative practices between the early intervention vision specialist and the early intervention O\&M specialist. This approach was employed by New Mexico and Utah through their respective schools for the blind to better meet the needs of the birth to three population with a visual impairment. The authors noted a lag of motor skills that could only be attributed to the vision loss. Through collaborative relationships, like described above, the author found toddlers with vision loss making large motoric gains toward their peers without vision loss.

The K-12 educational system in Texas and California utilize different models to ensure school age children with visual impairments continued to receive services despite the declining funds and limited personnel (Barrella et al., 2011; Daugherty, 2014). In Texas, Daugherty (2014) 
reported that the educational system utilizes the state school for the blind as its center for resources and provides outreach services for students and O\&M specialists throughout the state. The Texas state school also offers summer and short-term programming for compensatory services and more intensive programming options, like college transition and vocational preparation. Whereas California's school for the blind uses their limited funds in a way to promote efficiency (Barrella et al., 2011). For example, student may receive O\&M in pairs or small groups and they are taught how to repair materials like their long white cane. While California does not share the programming options or outreach through their geographically vast state, they do provide outreach virtually, likely as means of efficiency as well. The Helen Keller National Center for Deafblind Youths and Adults (HKNCD) utilizes a virtual network approach as well for clients not suited for their residential program (Bourquin et al., 2002). The program operates a large network of centers across New York and use a transdisciplinary style of collaboration to ensure the client receives a well-rounded and all-encompassing program despite the vast network and geographically dispersed faculty. To remain a cohesive team and maintain efficient use of resources, everyone meets on a biweekly or monthly basis virtually or in person. This helps to ensure that each member is receiving the needed support and communication, as well as providing an opportunity to update the team on the students' goals and progress.

\section{O\&M Skills}

In addition to their primary purpose of discussing service delivery or assessment, three articles also examined the body of knowledge and skills (Dewald et al., 2015; Lord, 1969; Wall Emerson \& Corn, 2006). Two articles studied the needed skills for O\&M development (Lord, 1969; Wall Emerson \& Corn, 2006). Lord (1969) observed young children with and without a visual impairment during unstructured play and instructional time. He sought to separate out 
what is typical development and what is an effect of the loss of vision. Whereas Wall Emerson and Corn (2006) surveyed experienced O\&M specialists to find the important skills for individuals with a visual impairment when traveling safely and independently resulting in a list of 148 distinct skills (see table 1). This study was the only one of the three to look at the skills without attributing the skills to a single age group. The other two articles looked specifically at the early childhood population with vision loss (Dewald et al., 2015; Lord, 1969). They noted that O\&M specialists should look at age appropriate travel skill and find any prerequisite skills to build up the individual's skills to meet what is age appropriate. For example, if a child without vision is learning to crawl while their peers run, they must work on crawling, toddling, and walking before they can learn to run. Dewald et al., took this concept one step further, explaining that travel must be meaningful to the child to encourage growth and development, without incentive they will remain stagnantly behind their peers.

\section{Discussion}

The ability to get from point A to point B, safely and independently, is an often overlooked keystone of adulthood. Being able to travel independently is an ability crucial for employment, recreational pursuits, and almost every area of adulthood (Cmar et al., 2018). However, individuals with a visual impairment will struggle to travel without specialized training from an O\&M specialist (Blasch, \& Wiener, 2010). To identify the needs of safely traveling for the individual with the vision impairment, the O\&M specialists must complete an assessment to develop an appropriate program.

I reviewed 17 articles centered around O\&M assessment and service delivery decisions. Three key findings emerged from this literature review: the selection and tailoring of 
assessments, alternatives for service delivery deficits, and the progressive and intensive nature of O\&M skills. Based on these findings recommendations for research and practice are offered.

First, assessments are the key for identifying who needs services and what skills need to be developed. As best practice, assessment guides goals and instructional services, not diagnosis or other factors (Pierangelo \& Guiliani, 2017). It is crucial that the O\&M specialist select the correct assessment because the entire education plan and ability of person with a visual impairment to move safely and independently rely on it (Bryan, 1989; Geruschat; 1980;

Geruschat \& De l'Aune, 1989; Harley \& Merbler, 1980; Hill et al., 1992; Hill \& Hill, 1991; Wall Emerson \& Corn, 2006). The specialist must ensure the tool is age and developmentally appropriate, as well as account for their individual medical and support needs (Geruschat, 1980; Hill \& Hill, 1991; O'Mea, 2013; Smith \& Herlich, 2014). There is a variety of tools available for O\&M assessments to meet the specialist's and individual's needs (see table 2). However, within the articles covered above there are only three specific assessment methods: the Peabody Mobility Scale, the Preschool Mobility Scale, and professional judgment (Geruschat, 1989; Harley \& Merbler, 1980; Hill et al., 1992). These tools were built or modified to meet a specific population of individuals with a visual impairment. Regardless of the assessment chosen, the specialist must remain cognizant of the specialized needs of the individuals they are assessing to ensure the validity of the results. Hill and Hill (1990) recommended strategies like administering assessment in manageable chunks, while observing for frustration, fatigue, and stress. Also, remaining positive and encouraging to enable the student to demonstrate the skill to the best of their abilities. By beginning with a solid and comprehensive assessment, determining the individuals needs for safe travel become more apparent. 
Following the assessment, the O\&M specialist is charged with providing the IEP or care team with a recommendation for O\&M services, including instructional goals and/or plan. Within the K-12 system there are two available tools to guide this recommendation outlined above and in table 2 (Munro et al., 2018; Wall Emerson \& Anderson 2014). Both tools outline services in terms of minute per week. Bryan (1989) contends that services need to exceed 250 collective hours of instruction and take place on a daily basis for optimal skill acquisition. However, several of the articles within this review noted a shortage of professionals and funding, causing unmanageable caseloads, vast geographic coverage areas, or areas without service, as a factor impacting assessment and service decisions (Barrella et al., 2011; Bourquin et al., 2002; Bryan, 1989; Daugherty, 2014; Dewald et al., 2015; Hill \& Hill, 1990; Munro, et al., 2018; Smith \& Herlich, 2014; Wall Emerson \& Anderson, 2014; Wall Emerson \& Corn; 2006). The last estimation of the shortage of O\&M specialists was a need of 10,000 additional O\&M specialists in 2007 and is believed to have remained the same (Ferrell, 2007; K. Ferrell, personal correspondence, November 27, 2016). These barriers or limitations to services impact the individual with a visual impairment and the O\&M provider. An individual with a visual impairment who does not receive adequate and specialized O\&M training could remain dependent on others and/ or have reduced employability (Cmar et al., 2018; Blasch, \& Wiener, 2010). Furthermore, an O\&M specialist may be forced to challenge what they believe to be best practices by making service decisions based on the greatest need or propensity for growth (Wall Emerson \& Corn, 2006). The impact to both parties is lasting and harmful to the field of O\&M. To mitigate this, we must strive to find creative service delivery solutions to meet the current need, such as: a transdisciplinary approach employing role release or O\&M assistants (Daughtery, 2014; Wall Emerson \& Corn, 2006); short term and distance programming (Barrella 
et al., 2011; Bourquin et al., 2002; Daugherty, 2014); community based instruction and outreach (Bourquin et al., 2002); and group lessons (Barrella et al., 2011).

Finally, O\&M skills are progressive, requiring lots of time to build an individual with a visual impairment ability to travel at the same level as their peers without a visual impairment (Blasch \& Wiener, 2010). However, the skills of movement and travel are not mastered in one session or overnight, they are developmental and progressive (Harley \& Merbler, 1980; Hill et al., 1992; Lord, 1969). As a parent yearns for their child to walk, this cannot be accomplished by simply standing the child up and encouraging them to walk. Children must begin the movement journey from holding themselves on all fours. They then progress through crawling, standing, and walking with furniture before they can achieve those first independent steps (Norris et al., 1957). This can be said for all skills of movement; an individual must be developmentally ready to achieve the skill. The progressive nature of skills development is the same for O\&M specific skills. As O\&M specialist, we must find where the individual's peer equivalent skills are and then chain backwards through the developmental sequence to where the individual's present functional level is. This chain should be shared with other members of the individuals care or IEP team. Through collaboration, the individual will receive additional practice and reinforcement of the skills (Dewald et al., 2014; Smith \& Herlich, 2014). An additional benefit to the chaining of skills, is that it identifies celebratory milestones along the way. This can be important for the motivation and morale of families and the individual with a visual impairment where traditional milestones may come at a slower rate.

\section{Limitations}

The findings of this literature review underline gaps in the body of research concerning O\&M assessments and service delivery. The literature search yielded a small amount of literature 
on the subject, with a roughly even amount of research and practitioner based articles. However, as the field evolves, the area of O\&M assessment should be bolstered through research-based publications. Also, within the literature only two research-based articles on service delivery were found, both were single tool specific. Research moving forward should provide either non tool specific research or a comparison of the two current tools.

In closing, an individual with a visual impairment, by nature of their disability, have limited access to the world around them. By developing a specialized set of skills under the guidance of vision specialists, like an O\&M specialist, their world begins to open to them. Through safe and independent travel, they can become part of a community and reach for goals that were originally thought to be unattainable. This journey starts with a foundation of individualized assessment that guides service delivery decisions and instruction. Continued research on the tools and practices of assessment and service delivery decisions can guide the generations of O\&M specialists to come. Through established, research-based tools and practices more individuals with a visual impairment can receive the services and supports needed to put their best foot forward.

\section{Research Questions}

To guide this study, I have identified the following four research questions based on this review of relevant literature, as well as my knowledge and experiences in the field of O\&M:

1. What tools are O\&M specialists who are serving K-12 students, using to guide assessment results and service delivery recommendations?

2. What factors, outside of assessment results, are impacting how K-12 students with a visual impairment are qualifying for O\&M services?

3. What factors, outside of assessment results, are impacting K-12 O\&M service delivery? 
4. Is there a relationship between a participant's demographics and choice of assessments and service delivery decisions? Specifically, their certification, level of experience, location, and distance from a preparation program.

\section{Summary}

This chapter outlined a systematic literature review of peer reviewed publications relating to O\&M assessment, service delivery, and instructional models. The review yielded 17 articles pertaining to the topic with a mixture of research and practitioner reports. Articles uncovered three basic themes: the necessity for selecting the appropriate O\&M assessment for the individuals age, development, and support needs; the dichotomy between the individuals need for services and the available O\&M specialist to provide those services; and the progressive nature of O\&M skills acquired overtime. Through this review the I established a need for additional research on what factors outside of the assessment are guiding service decisions in light of the shortage of O\&M specials available for service provision. In light of this, the following chapter will outline the methodological features of a survey study of current O\&M specialists, exploring the perceptions of these impacting factors. 


\section{CHAPTER III: METHODS}

There is a lack of guidance for practicing O\&M specialist in the areas of assessment and service delivery decisions as evidenced through the review of literature. Many of the articles discussed in Chapter II note a shortage of O\&M specialists working in the field, however, one article anecdotally discussed how the shortage of O\&M specialists could impact assessment and service decisions (Wall Emerson \& Anderson, 2014). Due to this limited guidance, the sparsity of O\&M specialists in the field, and other factors, this study attempted to discover how service providers make decisions about assessments and service delivery for children with low vision and blindness. Based on the review of literature and the findings of the pilot study I conducted using a similar instrument (Randles, 2018), the survey included questions about the participants' education and employment, as well as questions about their experiences with assessments and service delivery decisions. The survey was a cross-sectional questionnaire, collecting quantitative and qualitative data to explore O\&M specialist perceptions of their professional experiences with students who have vision loss. Through this survey I strived to understand what assessment tools O\&M specialists are choosing to use in the K-12 educational setting, as well as what factors are impacting the specialist's decisions.

In education, assessment is meant to guide instruction and learning supports, in part to deter use of extraneous factors that are not directly linked to the student's education (Pierangelo \& Guiliani, 2017). Due to an estimated shortage of 10,000 O\&M specialist in the United States, O\&M assessments may not be completed, or an existing specialist must use additional variables to inform service and assessment decisions (Ferrell, 2007; Wall Emerson \& Anderson, 2014). There was a dearth of research in the area of O\&M assessment for individuals with a visual impairment. However, the research was primarily specific to one tool, or method of assessment, 
or an approach that has been successful for an agency. In light of this gap in research, it was important to first establish what tools participants were using to complete assessments and make service delivery decisions. Also, Wall Emerson and Anderson (2014) briefly discussed, the unfortunate need for O\&M specialists to consider other factors when determining an individual's need for service due to limited resources and personnel available. It was important to delve into this notion further to explore what these factors could be specifically.

\section{Research Questions}

To guide this exploratory study I chose the following four research questions.

1. What tools are O\&M specialists serving K-12 students using to guide assessment results and service delivery recommendations?

2. What factors, outside of assessment results, are impacting how K-12 students with a visual impairment are qualifying for O\&M services?

3. What factors, outside of assessment results, are impacting K-12 O\&M service delivery?

4. Is there a relationship between a participant's demographics and choice of assessments and service delivery decisions? Specifically, their certification, level of experience, location, and distance from a preparation program.

\section{Research Design}

The goal of this study was to explore the perceptions and experiences of O\&M specialist in regard to assessment and service delivery tools and process. In order to capture the widest sampling of O\&M specialists in the region it was determined a survey design was the most appropriate means for data collection. A cross-sectional survey design was employed focusing on the attitudes and practices of O\&M specialists. This allowed me to collect information about individual participants a singular data point without checking for changes of perception or 
experience over time (Fraenkel, Wallen, Hyun, 2015). This was an important design decision that allowed for the participants confidentiality discussed further below.

Survey tool. The survey consisted of 22 questions, taking the respondents approximately 20 minutes to complete and it was active for four weeks. The survey was reviewed by Ph.D. level professionals in the area of sensory disabilities to ensure that the tool was valid. Informed consent to participate in the survey study was collected as the first question of the survey itself, see appendix A. Participants expressed consent by continuing through the survey after this question. The initial section of the survey requested demographic information to isolate potential participants meeting inclusion criteria. Survey participants identifying that they work as a TVI only, work solely outside of the K-12 education system, work outside of the Midwest, or have been retired for five or more years were redirected to message thanking them for their interest and participation. This was done by employing a feature in Qualtrics to apply skip logic, where a participant selecting an exclusionary response such as working as a TVI was routed to a message thanking them for their time. There were five questions using skip logic to remove participants not meeting the inclusion criteria for the survey. Results of the demographic questions of the survey guided me in determining that 50 respondents did not meet the criteria for the study and were removed from the potential participant pool.

The survey was held and distributed using the online platform, Qualtrics. By utilizing Qualtrics, I was able to provide participants an opportunity to share their experiences and information while remaining anonymous. Care was taken in the preparation of the survey to not collect a participants IP address or geographic location during survey participation. Through the features of Qualtrics, I limited for non-response errors leading to potential survey items with a zero response rate by increasing the pool of potential participants. 
To answer the research questions, it was important to capture the experiences and perceptions of O\&M specialists individually. Due to the geographic dispersion of the potential participants across the Midwest I used an electronic survey approach (Couper, 2000). The survey was a cross-sectional questionnaire, collecting data on the participants demographics, as well as open-ended and Likert response items to explore tools and factors that are guiding their professional judgement about O\&M service needs for students with vision loss. The survey instrument was adapted based on feedback and data collected from a pilot study conducted in the state of Illinois (Randles, 2018). The use of this survey method allowed participants to express their experiences and perceptions from a distance and with anonymity. The number of O\&M specialists in the Midwest is unknown, however the I estimate the number to be in the less than 500 working with all age categories. In light of this, it was important to provide anonymity to limit the potential for professional harm due to responses.

\section{Participants}

I utilized purposive sampling to select potential participants, from the Midwest specifically, based on their ability to meet the inclusion criteria for this survey study (Fraenkel, Wallen, \& Hyun, 2015). The potential participant pool included O\&M specialists or dually certified O\&M specialists providing services in the K-12 public education system. Participants needed to either be currently employed part or full-time basis or retired within the last five years in the Midwest region of the United States. For the purpose of this study, I utilized the Census Bureau's definition of the Midwest to include: Illinois, Indiana, Iowa, Michigan, Minnesota, Missouri, Nebraska, North Dakota, Ohio, South Dakota, and Wisconsin (U.S. Census Bureau, n.d). Ferrell (2007) and Mason (2000) postulate that rural communities experience the shortage of vision service providers at a greater level. According to the U.S. Census Bureau, 19\% of 
Americans live in rural communities across the nation (USCB, 2017). While there are rural communities in every state, each state of the Midwest region had in excess of the national percentage living in rural communities with the exception of Illinois (11.3\%; Misra, 2016). Illinois, however, holds Chicago which is third in population size nationally (USCB, 2017). This leaves a large portion of the remainder of the population of Illinois living in rural areas. As a secondary factor in selecting the Midwest region, the region only includes three university preparation programs to cover the 11 states of the Midwest. This likely creates pockets of geography that struggle to acquire and maintain O\&M specialists to provide needed services.

As described earlier, with the extreme shortage of O\&M service providers, the potential participants sample is small and their geographic dispersion is wide. By opening the survey to O\&M specialists throughout the 11 states of the Midwest and employing a web-based survey design I gained a more comprehensive view of perspectives, by collecting data for the region as a whole. I employed multiple points of dissemination via email listservs and social media presences for the following: the O\&M division of the Association for Education and Rehabilitation of the Blind and Visually Impaired (AERBVI) and Academy for the Certification of Vision Rehabilitation and Educational Professionals (ACVREP). These organizations responded to an email letter of support during April of 2019 (Appendix B, C, \& D), where they committed to share the call for participants via their listserv and/or social media presence. The email utilized to connect with the identified listservs and social media above can be found as Appendix E. The multiple points of dissemination lessen the possibility for a coverage error to occur, where not all members of the potential participant pool may have received an invitation to participate leading to possible bias of results. By inclusion of multiple different professional organizations, it was highly likely that all potential participants will receive the invitation at least 
one time. The Qualtrics system has the ability for potential participants to remain anonymous and limiting them the number of times they can take the survey regardless of the number of invitations they receive. I anticipated approximately 50-70 responses from the region, with at least one participant from each state.

\section{Procedures}

Prior to the dissemination of the survey an expedited Institutional Review Board (IRB) application was submitted and approved through Illinois State University Office of Research and Sponsored Programs (RSP) in April of 2019. Upon approval, I sent the participant recruitment email to the organizations whom have committed to disseminate the survey: ACVREP and AERBVI (see Appendix D).

\section{Data Analysis}

Analysis of the data derived from this survey was completed in Microsoft Excel.

Population data for the purpose of understanding the participants was analyzed using descriptive statistics. Thirteen questions were included for demographic analyses, including but not limited to employment history, certification, and caseload information. A quantitative analysis used to address the overarching question of exploring the tools used by O\&M specialists for assessment and service delivery decisions. This analysis included a frequency count of questions 16 and 18 , with a cross tabulation for geographic areas of employment, certification, years of experience, and distance from a preparation program.

Research questions two and three, examining factors impacting assessment and service delivery decisions outside of the student respectively were coded thematically. The themes chosen for inclusion in this study are adapted from a pilot study utilizing the survey tool adapted for this study (Randles, 2018). The pilot study employed an exploratory approach with codes 
established during analysis and inter-rater reliability completed by an advisor with a Ph.D. in sensory disabilities. The themes include professional judgement, potential for growth, professional time available, individualized education plan (IEP) team, district/administrator concerns, and student's academic placement.

Definition of codes. To ensure a high level of interrater agreement, in excess of $85 \%$, on a chosen sample of qualitative survey responses the following coding definitions are used:

Professional judgement. Statements referring to the O\&M specialists' experiences or personal training history. This does not include references to the experience or training of other member for the IEP team or school faculty.

Potential for growth. Statements referring to the O\&M specialist perception of a student's ability to attend to lessons and make progress toward their individualized travel goals, value of time on task, the potential impact on future independent living.

Professional's available time. Reference to the O\&M specialist schedule, caseload, or coverage area. References to district or agency dictated time availability per individual would not be included in this code.

Individualized education plan (IEP) team. Recommendations made by the members of the IEP team, *other* than the O\&M specialist, for O\&M qualifications, services, or skills.

District or administrator concerns. Recommendations made by Local Educational Agency (LEA) about the amount of service minutes or service availability of O\&M specialist that is meant to supersede the O\&M specialists' findings and/ or recommendation.

Student's academic placement. Indication that the student could or could not receive additional or needed services due to an educational programming. I.e. Transition placement, content or content delivery demands, or alternative schools. 
Medical reports and recommendations. Documentation from a medical professional about the student. This can include diagnostic testing, treatment plans, and recommendations for services.

Student availability. The student's schedule and availability for instructional time. Mentions of conflicting time may include school specials like art, music, library. Some districts or agencies may allow for related services to be performed outside of traditional school day. As a result, O\&M specialists may also indicate a time conflict with extra-curricular activities.

Health. Any other medical condition or disability that the student may have. This includes the student's level of attentiveness and stamina for instructional time.

Geographical location. If the student lives or attends school in a remote or distant location, causing the O\&M specialist to travel a long distance to either provide instruction, and/ or transport the student to and from a needed instructional site. I.e. transportation to a community with a lighted intersection or public transportation.

Assessment results. The results of formal and informal assessments conducted with the student by teachers and related services providers through the school.

Student profile. Information about the student's life goals, areas of interest, and their instructional needs. This may also include statements about the parents or families goals for the student's future.

Threats to validity. Participants of the study were asked to complete a short electronic survey. The survey responses are linked to an IP address within the Qualtrics system; however, this was not displayed to myself through settings within the Qualtrics system. This ensured that participants are only able to submit one time. Through the abbreviated length of the survey and the single snapshot in time approach participants have limited exposure to unplanned events or 
additional experiences altering their responses. This allowed for control of the historical threat to validity while maintaining their anonymity.

Further protections were in place for the participants to reduce potential risk for professional harm. This perceived potential for harm potentially produced a Hawthorne Effect threat to validity, causing participants to alter their survey responses. The Hawthorne Effect is a phenomenon where study participants perform or answer differently (Fraenkel et al., 2015). It is believed that this is due to the understanding that they are being watched or evaluated, or that their answers may have an impact on their lives. Due to the low incidence nature of the field of low vision and blindness and the geographic dispersion of working provider, I took additional care to ensure anonymity. Participants were asked to not provide readily identifiable data with examples of what that might include. Also, they identified their location only by which state they live in and thier distance from the closest O\&M university preparation program.

\section{Summary}

This chapter outlined the relevant methodological features of this study as it seeks to answer the identified research questions. The research design description included the study procedures, data collection and analysis, as well as information about the participant pool. Responses from participants outlined their experiences and perspectives surrounding this educational process. The following chapter offers the results obtained through the methodological design described in this chapter. 


\section{CHAPTER IV: RESULTS}

The purpose of this study was to explore the tools utilized by practicing O\&M specialists for assessment and service delivery decisions in the K-12 educational system. Additionally, the study investigated what factors outside of the assessment that O\&M specialist perceive to have an impact on a student's qualification for O\&M services and the quantity thereof. This chapter details the results of a survey of O\&M specialists detailing their education, employment, and experiences as a related service in the K-12 educational system in the Midwest region of the United States.

\section{Research Questions}

To guide the exploration of professional assessment tools and perceptions of experiences surrounding the assessment process, the study sought to answer the following research questions.

1. What tools are O\&M specialists serving K-12 students using to guide assessment results and service delivery recommendations?

2. What factors, outside of assessment results, are impacting how K-12 students with a visual impairment are qualifying for O\&M services?

3. What factors, outside of assessment results, are impacting K-12 O\&M service delivery?

4. Is there a relationship between a participant's demographics and choice of assessments and service delivery decisions? Specifically, their certification, level of experience, location, and distance from a preparation program.

\section{Data Collection}

The survey was adapted to incorporate feedback from survey participants and dissemination of the data from a pilot study conducted in the state of Illinois (Randles, 2018). The 22 questions included demographic data and a mixture of Likert and open ended responses 
offering participants an opportunity to share their professional experiences in regard to assessment and service delivery decisions. Participants for the study were recruited through listserv emails and social media posts sponsored by ACVREP and AERBVI. Two other organizations agreed to participate in survey recruitment, however, during the dissemination timeframe they were unavailable. Participants completed the survey online through a link included within the email and social media post utilizing the Qualtrics platform on their computer or mobile device.

\section{Data Analysis}

Quantitative and qualitative data gathered from participants through the online survey were analyzed using a Microsoft Excel. I used a combination of basic descriptive statistics and cross tabulations of the initial section of the survey. When examining the potential relationship between matrix responses and the participant's geographic areas of employment, the analysis was limited to participants who indicated that $50 \%$ or more of the time they were employed in rural, urban, or suburban districts. With the established threshold of $50 \%$ it is possible for a participant to be included in two different categories, for example both urban and suburban. The second portion of the survey explored the professional experiences of O\&M specialists in regard to service qualification and delivery decisions. This was analyzed using a codebook I established to explore recurring themes and their frequency by state.

\section{Coding}

Codes for the qualitative analysis of questions pertaining to factors impacting service qualification and service prescriptions were based on the results of pilot survey (Randles, 2018). The thematic codes include:

- professional judgment, guided by the O\&M specialists' training and experience; 
- potential for growth, the student's ability to attend to lessons and grow from them;

- professional available time, O\&M specialists' availability for lessons;

- individualized educational plan (IEP) team, information from members of the student's IEP team;

- district/administrator concerns, recommendations or policies from the LEA;

- student's academic placement, the student's educational program and environment;

- medical reports and recommendations, diagnostic results and recommendations from a medical professional;

- student availability, the student's availability for lessons during the school day and outside of the school day;

- health, other medical conditions the student may have;

- geographic location, where the student lives and attends school;

- assessment results, formal and informal assessments done by school personnel;

- student profile, the student's goals, interests, and needs.

*Each of these codes are further explored and defined in Chapter III.

Coding reliability of qualitative questions was established through inter rater reliability.

A Ph.D. level committee member and I conducted a review of one of the open response questions coding for each of the responding participant $(N=69)$. Both reviewers utilized the thematic codebook I established and were able to reach a level of 100\% agreement across all of the responding participants. 


\section{Results}

\section{Participants}

The call for participants yielded a potential field of 128 individuals, 76 of whom were found eligible by meeting inclusion criteria. For participant information to qualify for inclusion they were to be currently employed or recently retired from a position as an O\&M specialists in the Midwest working with students in the K-12 education system. Twenty eight participants were eliminated from the study based answers to three of the five inclusion questions. These questions included their employment position ( $N=7$ TVI or Other), state of employment ( $N=11$ Other), and if they work with 3-21 year old children $(N=10 \mathrm{No})$. The additional two inclusion questions yielded no eliminations. Another 24 participants dropped out from the study before completing the inclusion section of the survey, the first eight questions. Also, it is important to know that due to the extreme low incidence of the field certain data points were removed or analyzed separately for this report to protect the identity of the participants.

All of the participants are currently employed $(N=73)$ or have been employed within the last five years $(N=3)$ as an O\&M specialist in the $\mathrm{K}-12$ education system (see table 6). Thirtyfive participants reported that they are employed as an O\&M specialist or COMS, while 37 indicated that they were a dual O\&M or COMS/TVI and four noted they were a dual O\&M or COMS/ and another vision specialty (see table 6$)$. Most of the participants $(N=74 ; 97 \%)$ noted that they held the higher certification of COMS from ACVREP currently, with one individual listing as a lapsed COMS license (see table 6). Only a small portion $(N=18)$ of participated listed that they earned a university O\&M degree. However, this number should be higher as the university O\&M degree is a base requirement of the COMS license (ACVREP, 2018). This is likely due to participants selecting their highest earned certification, rather than all applicable as 
the question requested. Half of the surveyed participants indicated that they had over ten years of experience providing O\&M services, with $22 \%$ having in excess of 20 years (see table 6).

Table 6

Participant certification type, extended certifications, employment status, and years of experience

\begin{tabular}{|c|c|c|}
\hline Classifier & Participants & Percentage \\
\hline \multicolumn{3}{|l|}{ Certification Type } \\
\hline O\&M & 35 & $46 \%$ \\
\hline Dual O\&M/TVI & 37 & $49 \%$ \\
\hline $\begin{array}{l}\text { Dual O\&M/ Other VI } \\
\text { Specialty }\end{array}$ & 4 & $5 \%$ \\
\hline Total included & 76 & \\
\hline \multicolumn{3}{|l|}{ Extended Certification } \\
\hline $\begin{array}{l}\text { University earned } \\
\text { O\&M degree }\end{array}$ & 18 & $24 \%$ \\
\hline COMS & 74 & $97 \%$ \\
\hline NOMC & 0 & $0 \%$ \\
\hline Other & 2 & $3 \%$ \\
\hline $\begin{array}{l}\text { Indicating 2+ } \\
\text { responses }\end{array}$ & 17 & $22 \%$ \\
\hline Write in responses & (2) Lapsed COMS; university with graduating year & \\
\hline Total Included & 76 & \\
\hline \multicolumn{3}{|l|}{ Employment Status } \\
\hline Currently Employed & 73 & $96 \%$ \\
\hline Retired $<5$ years & 3 & $4 \%$ \\
\hline Total Included & 76 & \\
\hline \multicolumn{3}{|l|}{ Years of Experience } \\
\hline $1-2$ years & 12 & $16 \%$ \\
\hline $3-5$ years & 11 & $14 \%$ \\
\hline $6-10$ years & 13 & $17 \%$ \\
\hline $11-15$ years & 11 & $14 \%$ \\
\hline $16-20$ years & 10 & $13 \%$ \\
\hline $20+$ years & 17 & $22 \%$ \\
\hline Total Included & 74 & \\
\hline
\end{tabular}

Note COMS=Certified Orientation and Mobility Specialist; NOMC=National Orientation and Mobility Certification; O\&M=Orientation and Mobility; TVI=Teacher of the Visually Impaired; VI=Visually Impaired.

Employment contracts of participants ranged from 4 to 55 hours, with the average employment contract for 36.5 or an average of 7.3 hours per day that school is in session (see table 7$)$. As almost half of participants $(N=37)$ indicated that they were dually certified, participants were also asked to identify how many hours of their contract were devoted to O\&M 
services. They indicated that between 1 and 55 hours of their contract was devoted toward O\&M services, with an average of 20.5 hours devoted to O\&M services.

Table 7

Participant's contract hours and the number of hours devoted to O\&M services

\begin{tabular}{lll}
\hline Grouping & Participants total hours & Participants hours devoted to O\&M \\
\hline $1-10$ hours & 3 & 28 \\
11-20 hours & 1 & 15 \\
21-30 hours & 7 & 14 \\
31-40 hours & 61 & 17 \\
41-50 hours & 3 & 1 \\
51-60 hours & 1 & 1 \\
Non numerical & - & $(2)$ Not contracted for a set number of hours; very little \\
\hline Total & 76 & 76 \\
\hline \multirow{2}{*}{ Mean } & 36.5 & 20.5 \\
Range & $4-55$ & $1-55$ \\
Median & 37.5 & 18.75 \\
Mode & 40 & 10 \\
\hline
\end{tabular}

As the range of hours devoted to O\&M services varied greatly the choice was made to examine what percentage of hours were dedicated to O\&M services. This is captured in table 8. A third of participants indicated that they spend $91-100 \%$ of their contract providing O\&M services. However, roughly a third of participants said that they provided O\&M services for less than $30 \%$ of their contract (see table 8 ).

Table 8

Percentage of contract allocated to O\&M services

\begin{tabular}{lll}
\hline Percentage Range & \multicolumn{1}{c}{ Participants } & Percentage \\
\hline $1-10$ & 5 & $7 \%$ \\
$11-20$ & 9 & $12 \%$ \\
$21-30$ & 9 & $12 \%$ \\
$31-40$ & 6 & $8 \%$ \\
$41-50$ & 9 & $12 \%$ \\
$51-60$ & 1 & $1 \%$ \\
$61-70$ & 0 & $0 \%$ \\
$71-80$ & 7 & $9 \%$ \\
$81-90$ & 2 & $3 \%$ \\
$91-100$ & 26 & $34 \%$ \\
Non numerical responses & $(2)$ Not contracted for a set number of hours; very little \\
\hline$N$ & 76 & \\
\hline
\end{tabular}


In addition to the large variance in the employment contract of the participants, there was also a large range of caseload sized for direct and indirect services (see table 9). While some participants reported that they do not provide direct O\&M instruction or services to students, other reported direct caseloads of up to 58 students at any given time. The range was larger for indirect or consultation caseloads with some reporting zero students and others up to 200 students. However, the average caseload for participants was 12.4 direct instruction students and 8.1 indirect students.

Table 9

Reported direct and indirect caseload size

\begin{tabular}{ll}
\hline Caseload & Participants \\
\hline Direct & \\
$N$ & 75 \\
Mean & 12.4 \\
Median & 10 \\
Range & $0-58$ \\
Mode & 6 \\
Consult & \\
$N$ & 64 \\
Mean & 8.1 \\
Median & 3 \\
Range & $0-200$ \\
Mode & 2 \\
\hline
\end{tabular}

While participants from urban and suburban geographic areas experienced lower numbers of students receiving indirect services on average, 6.1 and 4.2 respectively, participants from rural communities reported an average of 12.8 students (see table 10). This suggests a relationship between geographic areas of employment and the number of student receiving indirect services for O\&M. Additionally, participants with dual certification were found to have similar employment contracts in terms of hours but held roughly half the number of O\&M hours as their singly certified peers suggesting a relationship between certification and number of service hours. Other areas of their employment contract and caseload appear to have minimal if any relationship with their experience, place of employment, and certification. 
Table 10

Cross tabulation of geographic areas of employment, certification, years of experience, and distance by O\&M employment contracts and caseloads

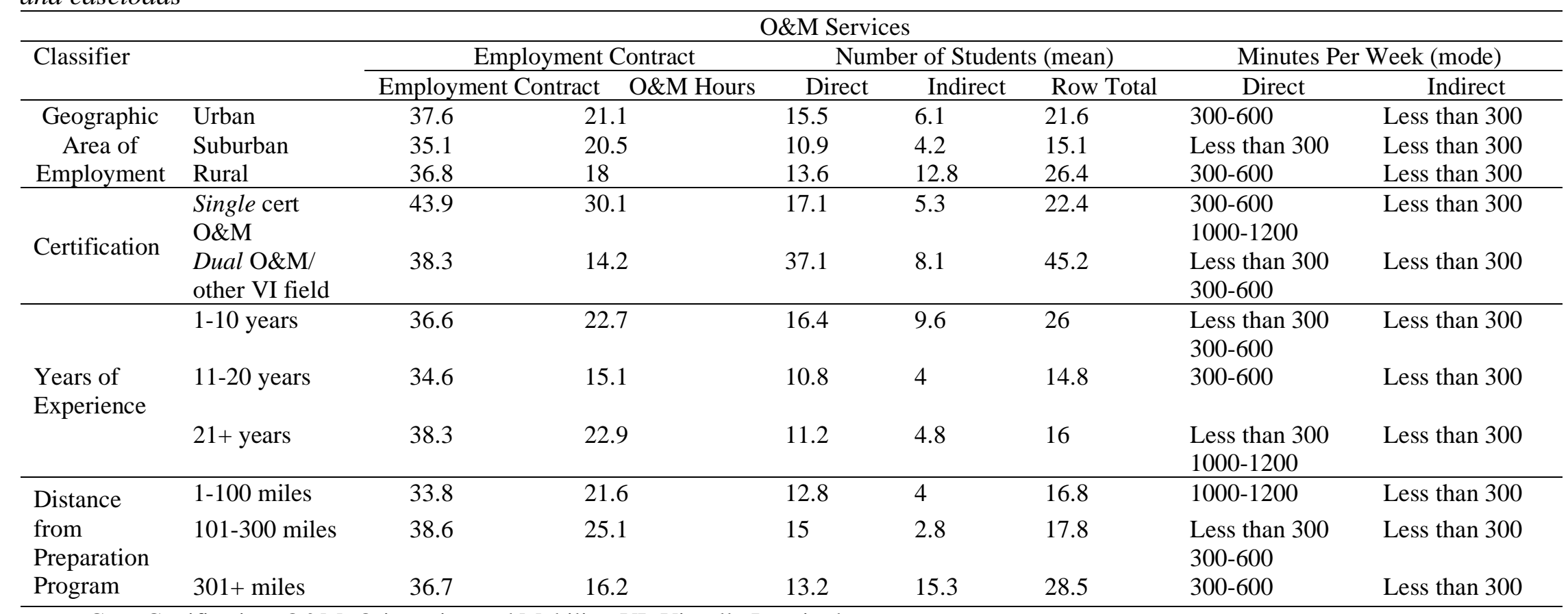

Note Cert=Certification; O\&M=Orientation and Mobility; VI=Visually Impaired. 
Location. Participants were employed throughout the Midwest region of the United States. For the purposes of this study, the Midwest includes Illinois, Indiana, Iowa, Michigan, Minnesota, Missouri, Nebraska, North Dakota, Ohio, South Dakota, and Wisconsin (U.S. Census Bureau, n.d.). The largest number of participants were employed in three states, Illinois and Ohio with 14 participants each and Michigan with 17 participants (see table 11). A majority of the participants are employed closest geographically to Northern Illinois University or Western Michigan University with 31.6 and $27.6 \%$ of the participants respectively (see table 11). With almost half (44.7\%) of participants working less than 100 miles away from the nearest preparation institution (see table 12).

Table 11 Number of participants by state and by nearest university preparation program

\begin{tabular}{lll}
\hline Location & Participants & Percentage \\
\hline By State & & \\
Illinois & 14 & $18 \%$ \\
Indiana & 8 & $11 \%$ \\
Iowa & 2 & $3 \%$ \\
Michigan & 17 & $22 \%$ \\
Minnesota & 3 & $4 \%$ \\
Missouri & 8 & $11 \%$ \\
Nebraska & 2 & $3 \%$ \\
North Dakota & 2 & $3 \%$ \\
Ohio & 14 & $18 \%$ \\
South Dakota & 2 & $2 \%$ \\
Wisconsin & 4 & $4 \%$ \\
Other & - & \\
By Nearest University Preparation Program & & \\
Florida State University (FSU) & 1 & $1 \%$ \\
Northern Illinois University (NIU) & 24 & $32 \%$ \\
Ohio State University (OSU) & 13 & $17 \%$ \\
Salus University (SaU; Pennsylvania) & 1 & $1 \%$ \\
Texas Tech University (TTU) & 1 & $1 \%$ \\
University of Arkansas, Little Rock (UALR) & 5 & $7 \%$ \\
University of Northern Colorado (UNC) & 7 & $9 \%$ \\
University of Pittsburgh (UoP) & 3 & $4 \%$ \\
Western Michigan University (WMU) & 21 & $28 \%$ \\
\hline
\end{tabular}


Table 12

Breakdown of distance to university preparation program geographically by program

\begin{tabular}{lllllllllll}
\hline Distance & Total & FSU & NIU & OSU & SaU & TTU & UALR & UNC & UoP & WMU \\
\hline Less than 50 miles & 11 & 0 & 5 & 4 & 0 & 0 & 0 & 0 & 0 & 2 \\
51-100 miles & 23 & 0 & 8 & 5 & 0 & 0 & 0 & 0 & 2 & 8 \\
$101-200$ miles & 14 & 0 & 4 & 2 & 0 & 0 & 0 & 0 & 1 & 7 \\
$201-300$ miles & 7 & 0 & 1 & 2 & 0 & 0 & 1 & 1 & 0 & 2 \\
$301-400$ miles & 5 & 0 & 2 & 0 & 0 & 0 & 2 & 1 & 0 & 0 \\
$400+$ miles & 16 & 1 & 4 & 0 & 1 & 1 & 2 & 5 & 0 & 2 \\
\hline$N$ & 76 & 1 & 24 & 13 & 1 & 1 & 5 & 7 & 3 & 21 \\
\hline
\end{tabular}

Note FSU=Florida State University; NIU=Northern Illinois University; OSU=Ohio State University; SaU=Salus

University; TTU=Texas Tech University; UALR=University of Arkansas, Little Rock; UNC=University of Northern

Colorado; UoP=University of Pittsburgh; WMU=Western Michigan University. 


\section{O\&M tools}

Practicing O\&M specialists working with school age children have access to a variety of tools to assess a student's need for O\&M services and another set to establish how much service the student will need. For the purpose of this study I will refer to tools used to evaluate a student's need for O\&M services as O\&M assessments or assessments. The tools used to establish how much time in O\&M services a student needs will be referred to as service delivery decision tools. Participants were asked to identify all of the tools that they use during an O\&M assessment and service delivery decision making from an established list with an opportunity to write in additional answers. Both questions allowed for the participants to select multiple tools. The established list of O\&M assessment provided to the participants included (a) Teaching Age Appropriate Skills (TAPS) ; (b) Oregon Project; (c) New Mexico School for the Blind and Visually Impaired O\&M Inventory (NMSBVI O\&M Inventory); (d) Preschool O\&M Screening; (e) Texas 2 Step; and teacher created assessments. While the provided list of service delivery decision tools included (a) Michigan Severity Scale (O\&MSRS); (b) The O\&M Visual Impairment Scale of Service Intensity of Texas (O\&M VISSIT); (c) professional judgment. When asked about assessment tools used for service qualification, 58.7\% participants selected two or more assessment tools (see table 13$)$. A majority of respondents $(N=63 ; 84 \%)$ included the TAPS assessment and curriculum. Over $80 \%$ of the participants for each geographic area of employment (Urban 81\%, Suburban $83 \%$, and Rural 84\%) indicated using the TAPS as an assessment for service qualification (see table 14). The remaining assessments tools used for qualification: the Oregon, the NMSBVI O\&M Inventory, and Preschool O\&M Screening; ranged from 24-38 participants or 32-50\% indicating their use (see table 13). However, only two participants indicated that they use the Texas 2 Step, which became commercially available in 
2018. Those participants noting that they use the Texas 2 Step assessment are employed at suburban districts or employment agencies for more than $50 \%$ of their contract (see table 14). Dually certified O\&M specialists with another vision specialty had a greater likelihood to use TAPS ( $N=24$ of $38 ; 71 \%)$ and a lower likelihood to use teacher created assessments ( $N=5$ of 15 ; $33 \%$ ) (see table 14). There seems to be no relationship between the O\&M specialist's years of experience or their distance from a university preparation program and the assessment tools that they select.

Similarly, a large number of respondents (64.8\%) selected two or more tools for use during service delivery decisions (see table 15). As a whole, the participants favored the use of professional judgement $(N=55 ; 77 \%)$ and the Michigan Severity Scale $(N=49 ; 69 \%$ see table 15). Twenty four participants noted that they use only one service delivery decision tool. Of those 24,13 (54\%; $18 \%$ of all participants) indicated that they use their professional judgement alone and 11 (46\%; 15\% of all participants) use the Michigan Severity Scale alone 11

Table 13

Participant identified $O \& M$ assessment tools used with $\mathrm{K}-12$ students

\begin{tabular}{llcc}
\hline Assessment Tool & \multicolumn{1}{c}{ Participants } & Percentage \\
\hline$N$ & 75 & $84 \%$ & \\
TAPS (Teaching Age Appropriate & 63 & $44 \%$ & \\
Skills) & & $37 \%$ & \\
Oregon Project & 33 & $32 \%$ \\
NMSBVI O\&M Inventory (New & 38 & $3 \%$ \\
Mexico School for the Blind and & & $44 \%$ \\
Visually Impaired O\&M Inventory) & 24 & $15 \%$ \\
Preschool O\&M Screening & 2 & $8 \%$ \\
Texas 2 Step & 33 & \\
Teacher Created & 11 & $32 \%$ \\
Other & 6 & $25 \%$ \\
Abstained & $(7)$ Michigan Severity Rating, None, State/District Created \\
Write in & Assessment, O\&M Curriculum Guide, Teacher tailored to client, \\
& Michigan O\&M Goal Bank & \\
2-3 selections & 24 & $1 \%$ & \\
4-5 selections & 19 & \\
$6+$ selections & 1 &
\end{tabular}


Table 14

Cross tabulation of geographic areas of employment by $O \& M$ assessment and service delivery decision tool

\begin{tabular}{|c|c|c|c|c|c|c|c|c|c|c|c|}
\hline & & & & & Assess & ent Tools & & & Service & elivery D & ision Tools \\
\hline Classifier & & $\mathrm{N}$ & TAPS & $\begin{array}{l}\text { Oregon } \\
\text { Project }\end{array}$ & $\begin{array}{c}\text { NMSBVI } \\
\text { O\&M }\end{array}$ & P. O\&M & $\begin{array}{c}\text { Texas } 2 \\
\text { Step }\end{array}$ & $\begin{array}{l}\text { Teacher } \\
\text { Created }\end{array}$ & $\begin{array}{c}\text { Michigan } \\
\text { Severity }\end{array}$ & $\begin{array}{c}\text { O\&M } \\
\text { VISSIT }\end{array}$ & $\begin{array}{c}\text { Professional } \\
\text { Judgement }\end{array}$ \\
\hline & Urban & 16 & 13 & 6 & 7 & 3 & 0 & 6 & 2 & 12 & 3 \\
\hline Geographic & Suburban & 37 & 31 & 21 & 20 & 16 & 2 & 18 & 28 & 10 & 29 \\
\hline Area of & Rural & 19 & 16 & 6 & 9 & 4 & 0 & 8 & 13 & 2 & 11 \\
\hline & Total & 72 & 60 & 33 & 36 & 23 & 2 & 32 & 43 & 24 & 43 \\
\hline & Single Cert & 27 & 10 & 16 & 10 & 1 & 15 & 10 & 20 & 7 & 26 \\
\hline Certification & Dual Cert & 38 & 24 & 22 & 15 & 1 & 22 & 5 & 28 & 8 & 29 \\
\hline & Total & 65 & 34 & 38 & 25 & 2 & 37 & 15 & 48 & 15 & 55 \\
\hline & $1-10$ years & 36 & 30 & 15 & 19 & 8 & 1 & 16 & 22 & 7 & 23 \\
\hline Years of & $11-20$ years & 22 & 20 & 10 & 11 & 9 & 1 & 9 & 17 & 2 & 3 \\
\hline & Total & 76 & 63 & 33 & 38 & 24 & 2 & 34 & 49 & 14 & 43 \\
\hline & $1-100$ miles & 34 & 27 & 19 & 17 & 9 & 1 & 13 & 21 & 6 & 20 \\
\hline $\begin{array}{l}\text { Distance } \\
\text { from }\end{array}$ & $\begin{array}{l}101-300 \\
\text { miles }\end{array}$ & 21 & 16 & 9 & 11 & 7 & 1 & 9 & 15 & 6 & 17 \\
\hline $\begin{array}{l}\text { Preparation } \\
\text { Prooram }\end{array}$ & $301+$ miles & 21 & 14 & 7 & 7 & 5 & 0 & 9 & 9 & 1 & 12 \\
\hline & Total & 76 & 57 & 35 & 35 & 21 & 2 & 31 & 45 & 13 & 49 \\
\hline
\end{tabular}

Note Cert=Certification; NMSBVI O\&M=New Mexico School for the Blind and Visually Impaired Orientation and Mobility Inventory; O\&M

VISSIT=Orientation and Mobility Visual Impairment Scale of Service Intensity of Texas; P. O\&M= Preschool Orientation and Mobility;

TAPS=Teaching Age Appropriate Skills. 
(46\%; $15 \%$ of all participants) use the Michigan Severity Scale alone (see table 15). Seventy-five percent of participants who noted their employment as primarily urban $(N=16)$ indicated a preference for the O\&M VISSIT ( $N=12$; see table 14$)$. While those from suburban $(N=37)$ and rural $(N=19)$ areas preferred to utilize their professional judgement $(N=29,78 \% ; N=11,58 \%)$ and the Michigan Severity Scale $(N=28,76 \% ; N=13,68 \%)$. However, regardless of certification, single $(N=27)$ and dually $(N=38)$, professionals indicated a preference to the Michigan Severity Scale $(N=20,74 \% ; N=28,74 \%)$ and professional judgement $(N=26,96 \% ; N=29,76 \%)$ over the O\&M VISSIT ( $N=7,26 \% ; N=8,21 \%$;see table 14$)$. All participants, regardless of experience

Table 15

Participant identified tools for O\&M service delivery decisions of $K-12$ students

\begin{tabular}{lll}
\hline Tool & Participants & Single Tool Selection \\
\hline$N$ & 71 & 24 \\
$\begin{array}{l}\text { The Michigan Severity } \\
\text { Scale (O\&MSRS) }\end{array}$ & $49(69 \%)$ & $11(46 \%)$ \\
$\begin{array}{l}\text { The O\&M VISSIT (O\&M } \\
\text { Visual Impairment Scale of }\end{array}$ & $16(23 \%)$ & $0(0 \%)$ \\
$\begin{array}{l}\text { Service Intensity of Texas) } \\
\text { My Professional Judgement }\end{array}$ & $55(78 \%)$ & $13(54 \%)$ \\
Other & $\begin{array}{l}\text { 8(11\%) } \\
\text { Write in }\end{array}$ & $\begin{array}{l}\text { (6)Team decision; Team, } \\
\text { Family/student input; Primary } \\
\text { disability as vision; Student needs and }\end{array}$ \\
& $\begin{array}{l}\text { goals; Amount of time in schedule; } \\
\text { Ocular Report }\end{array}$ & \\
& 46 (65\%) & \\
\hline
\end{tabular}

indicated a preference for the Michigan Severity Scale (73\%; 77\%; $56 \%$; see table 14). While participants with $1-10$ years of experience $(N=36)$ and $21+$ years of experience $(N=18)$ indicated preferences for the professional judgement ( $N=23,64 \% ; N=17,94 \%$; see table 14). Participants with $21+$ years of experience used professional judgment as a tool in service delivery decisions $(N=17,94 \%)$ at a much greater rate than their relative percentage of the participant pool $(N=18$; 24\%). Whereas the participants with 11-20 years of experience indicated a significantly lower rate of use of the O\&M VISSIT $(N=2 ; 9 \%)$ and their own professional judgment $(N=3 ; 14 \%)$ 
than their relative percentage of the pool $(N=22 ; 29 \%)$. In the subgroups for distance from a university preparation program $(N=34 ; N=21 ; N=21)$, each group showed a preference for the Michigan Severity Scale $(N=21,62 \% ; N=15,71 \% N=9 ; 43 \%)$ and professional judgement $(N=20,95 \% ; N=17,81 \% N=12 ; 57 \%)$ as tools in service delivery decisions (see table 14$)$. The O\&M VISSIT received smaller reported use across distance categories ranging from 5-28\%. However, the greatest percentage of those using the O\&M VISSIT were between 1-100 miles $(N=6,18 \%)$ and $101-300$ miles $(N=6,28 \%)$ away from a preparation program with six participants indicating its use for each group. Participants employed over 300 miles reported a significantly reduced rate $(N=1 ; 5 \%)$ relative to their percentage of the participant pool $(N=21$; $28 \%$ ). They compensated for this reduced use by reporting a higher rate of use of the Michigan Severity Scale $(N=9 ; 43 \%)$ and professional judgment $(N=12 ; 57)$.

\section{Open Response}

The final portion of the survey utilized a combination of open ended responses and a Likert scale matrix. The open ended questions encouraged the participant to share what they perceive to impact a student's recommendation or denial for O\&M services, as well the quantity of the services. While the matrix asked the participants to reflect on three particular questions regarding their professional experiences over the previous five years of employment. This portion of the survey encompasses the results for the second and third research question of this study. For a review of themes utilized for coding, please refer to the codebook included in chapter $\amalg$.

Service qualification. When asked to explain their justification process for recommendation or denial of O\&M services, participants' answers varied widely. Sixty-five individuals participated in survey questions 17, an open ended question capturing the process of 
justifying a student's need for O\&M services. While 69 participants responded to question 19 outlining factors impacting that process outside of the assessment.

Assessment results. Assessment results was the most frequently occurring theme across participants $(N=48[74 \%] ; N=22[32 \%])$ for both the process of assessment and service qualification. Participants recorded a need for a functional vision assessment (FVA), assistive technology assessment (AT); visual functioning compared to peers; observation; screening, indoor/outdoor assessment, and service decision tools. In addition, for service qualification a participant also indicated a need for a learning media assessment (LMA).

Student profile. General information about the student reported by the student themselves or a family member was the second largest theme ( $N=26[40 \%] ; N=26[38 \%])$ in regard to the assessment process and service qualification. In response to both questions, participant cited the families' goals, concerns, and insight about the student. This was mirrored by the concerns about independent travel and life goals from the student in both questions as well. Of the unique responses, a student's access to past O\&M services played a role for some participants in the assessment process. While service qualification was impacted more by a family's ability to follow through and motivation to incorporating travel skills into their routine, as well as general restrictions that the family may place on the student's travel. From the student, their ability to operate a motor vehicle and their exposure to the community and real life situations of travel.

Medical reports and recommendations. Outside of the assessment, the participants $(N=24 ; 37 \%)$ most often expressed that the reports and recommendations of the student's doctor played a part in the justification process. From these reports, participants were largely looking for details about the student's visual impairments including their acuity, level of field loss, the prognosis and stability of the condition, etc. Fifteen participants (22\%) also indicated that the 
medical reports and recommendations from the doctor was a factor impacting service qualification.

IEP team. Several participants $(N=9 ; 13 \%)$ noted that the IEP team was included in their justification during the assessment process. Largely the participants said they considered recommendations and needed supports from teachers, specialists, advocates, and parents as members of the IEP team. While one participant (1\%) expressed that it was an IEP team decisions for services starting and discontinuing.

Twice as many participants $(N=19 ; 28 \%)$ felt that the IEP team was a factor impacting service qualification. Team member and district personnel recommendations, observations, and services; staffs motivation to support the student's travel; the teams expectations/lack of expectations of the student's travel

Potential for growth. When discussing their approach to justifying services, eight participants $(12 \%)$ felt that the students' individual potential for growth toward independent travel guided their justification for O\&M services. Participants cited the students' motivation to learn independent travel $(N=4 ; 6 \%)$ and stamina $(N=2 ; 3 \%)$. As well as students' ability to attend to lesson $(N=1 ; 1 \%)$, follow directions $(N=1 ; 1 \%)$, or general statements about "functional limitations" $(N=2 ; 3 \%)$ or "level of cognition" $(N=2 ; 3 \%)$.

Ten participants (14\%) linked their perception of a student's potential for growth as a factor outside of the assessment impacting service qualification than as a part of the assessment process. These statements were not statements linked to assessment results directly so it is unknown if assessments impacted the participants' perceptions. Six (9\%) of these participants noted factors associated student challenges as impacting service qualification. Noting things like their emotional and behavioral challenges $(N=2 ; 3 \%)$, the student's level of physical and 
cognitive skills $(N=3 ; 4 \%)$ as well as their ability to retain concepts from the lesson $(N=1 ; 1 \%)$. Three participants (4\%) posed that the student's general potential impacted their recommendation for service. While another participant felt that external factors helped guide their recommendation when they were left with unanswered questions from the assessment. Also, discussed were the student's maturity level and their motivation to learn independent travel, each with one participant (1\%).

Health. Participants $(N=4[6 \%] ; N=12[17 \%])$ felt that students' health impacted the assessment process and their qualification for O\&M services. Both questions yielded responses about any additional disabilities the student may have, their general health, and the student's hearing.

District and administrative concerns. Concerns of the district and/or administration $(N=10 ; 14 \%)$ was one of the larger themes in regard to the justification of the assessment process. Participants $(N=5 ; 7 \%)$ shared that some of their districts have policies or established requirements for O\&M services. Some participants offered policies to exclude students with seizures, wheelchairs, and other complex support needs from receiving services through their district or facility. Another common thread within this theme was in reference to their caseload. Due to the limited personnel certified to provide O\&M instruction, some districts are establishing large caseloads without any help for overage. With some districts are instituting limitations on service minutes due to staffing or budget.

District and administrative concerns $(N=5 ; 7 \%)$. were also present in factors impacting service qualification. In addition to the district policies and guidelines referenced above, there was mention on the administrative drive for data when considering need for O\&M services. Two O\&M specialists $(3 \%)$ reported their districts have no understanding of O\&M services or a low 
level of importance placed on O\&M as a service. With one (1\%) noting that their district will disallow O\&M service recommendations.

Student's academic placement. Four participants (6\%) cited that the student's academic placement was a consideration during the assessment process. Specifically, they noted the student's school current and upcoming environments, including its needed modifications for safe and independent travel. Seven participants (10\%) posed that these same considerations were factors that could impact the student's qualification for O\&M services.

Professional judgement. Eight participants (12\%) drew a connection between their justification for services and their professional judgement, based on experience and education and how the approach an assessment. Statements centered on perception of needs or obstacles $(N=4 ; 6 \%)$ and personal beliefs of services $(N=4 ; 6 \%)$ Two participants $(3 \%)$ concentrated on a perceived need for O\&M services due to a concern for safety. While two other participants (3\%) posed that their perception of the amount of time needed to master the skill and their necessity for future independence was a consideration during assessment. The final two participants (3\%) incorporated "I" statements to allude to self-talk during the assessment process as a means of professional judgement. Outside of the assessment tool, three participants (4\%) noted their professional judgment as a factor impacting service qualification. Participants expressed a belief that all students with a visual impairment benefit from O\&M services or a perceived need for services in the school community.

Geographic location. Participants $(N=2[3 \%] ; N=3[4 \%])$ indicated that the geographic location of the student was a consideration during the assessment process and a factor that impacted service qualification. The participants agreed that the primary issue was the rural areas in which students live, as well as the distance the instructor and student would have to travel to 
find the needed instructional environments. Example of this would be the need for public transportation or light controlled intersections. Some rural communities do not have public transportation or light controlled intersections. Therefore the O\&M specialist and the student would need to travel to and from communities with these features for instruction adding to the total time needed with a student.

Professional's available time. In response to question 17 regarding the justification process during assessments, one participant (1\%) shared that they are a dually certified vision provider in schools for their state which is rare. Further sharing that they were not able to recommend what the assessments suggest. While other participants $(N=3 ; 4 \%)$ linked their professional available time as a factor that could impact their service qualification. A participant (1\%) cited a general lack of availability of time, with another (1\%) citing access to student during their open times. The final participant (1\%) included a profound statement. They say "when a student was border-line qualifying and I was working for an $\{$ LEA* $\}$ with an over-sized caseload, I would not recommend Direct Services, rather recommend monitoring through transitional periods". In the field of O\&M service transition periods refer to when a student is moving from one school building to another, moving from an elementary building to a middle school building, or graduating to adult services.

Student's availability. Two participants (3\%) listed that the students' availability due to academic schedule or other services built into the schedule were concerns during the assessment. While no participants indicated that the student's availability was a factor influencing whether or not they qualified for O\&M services.

Service delivery decisions. Following a thorough assessment of the student's ability to travel safely and independently within their own environment O\&M specialist are charged with 
creating a service delivery plan tailored to the student. Initially, this includes establishing the needs and goals for the student based on that assessment. However, a large part of that process is prescribing the duration and frequency of service. Outside of assessment results themselves, the survey sought to find the factors impacting service delivery decisions directly through one question with 69 participants.

Student profile. The largest theme of factors impacting service delivery decisions from participants responses $(N=23 ; 34 \%)$ was factors specific to the student as an individual and their family unit . Participants reported the need to consider Specific travel and instructional need $(N=12 ; 17 \%)$, as well as the student's and parent's goals for the future $(N=12 ; 17 \%)$. Two participants (3\%) note that a student's previous O\&M services should be considered when making decisions about their current service delivery needs, this includes the amount of time the service was available and the consistency in which it was delivered from year to year. A final participant $(1 \%)$ in said that they consider what opportunities the student has to practice travel skills outside of instruction in their home and community.

Professional judgement. One of the larger themes $(N=14 ; 21 \%)$ that emerged from participant responses regarding quantifying needed O\&M service minutes was the O\&M specialist's professional judgment. Five of the participants (7\%) included an "I" statement, like $I$ think or I believe eluding to their professional and educational experiences guiding their thoughts, where three (4\%) others simply said professional judgment or experience. One participant (1\%) combined their professional experiences with creativity to ensure that student received as close to their needed minutes as possible. This was done through using a variety of service models, varying the frequency (weekly, monthly, etc.) and duration of their visits. While another participant $(1 \%)$ used their professional experience with a sense of self-preservation to 
attempts to meet the needs of students. They offered "service minutes are determined by me. And really I just push just enough not to be called into a meeting”. From the context of the statement the meeting they are referring to is likely a disciplinary one.

Professional's available time. Another large theme $(N=16 ; 24 \%)$ centered around the O\&M specialists' professional schedule and the amount of time that they have available for new students. Participants shared statements about using creative scheduling to fit in another student or simply giving whatever time they had available in their already large caseloads. One of the most telling statements from participants came in the form of an equation of sorts. They said that, a "shortage of staff $=$ enormous caseloads $=1 / 2$ time [for students], if they are lucky". Another participant lamented that "unfortunately how much time I have to give them with the rest of my caseload [impacts service decisions]". While yet another shared that "my caseload was too big and spread out geographically given the amount of time allotted me. I couldn't handle more students and feared as much. I spoke to my supervisor who encouraged me to "see what happens" - which to me meant 'one more is doable'." Which speaks to district and administrative concerns as well.

Health. Fourteen participants $(21 \%)$ shared a general concern for a student's other medical conditions that may impact travel and learning as a potential factor impacting service delivery decisions .

Geographic location. In rural areas throughout the Midwest participants $(N=13 ; 19 \%)$ indicated that the geographic location of the student is an important factor that could impact service delivery decisions . Participants indicated that students may have home or school environments that are remote. They reported that this can lead to long travel times to and from lessons and environments for instruction. Only further complicated by difficult policies for 
transporting students. Some participants noted they must use the student's district's vehicle causing a small time delay, while others may have to use their employing districts vehicle causing an even longer delay.

Student's availability. A student's schedule and availability $(N=11 ; 16 \%)$ is a consideration when making service delivery decisions. Some participants indicated that they have to compete with other services or core academics when trying to decide the frequency and duration of services. Due to this and the distance to a needed instructional area could result in a need for service outside of the normal school day. For this reason, two participants $(3 \%)$ indicated that the students' availability for after school and weekend lessons was also an important consideration.

Student's academic placement. A student's academic placement $(N=9 ; 13 \%)$ was a recurring theme in both service qualification and service delivery decisions . Participants also indicated that the student's school environment, school schedule, and level of academics were factors considered in service delivery decisions.

District and administrative concerns. In addition to the supervisor above indicating one more student is 'doable' there were seven (10\%) other participants who mentioned the role of administration as a factor impacting service minute decisions. While largely the themes of policies for service provision, locations, and district vehicles remained a factor, a participant also indicated that districts establish caseloads and coverage areas. Other districts have approved amounts of services that they will contract for based on staffing and available funding. However, the O\&M specialists' district established caseload and coverage size left one participant to respond that, "I'm overwhelmed with no help in sight". 
Medical reports and recommendations. Some participants $(N=6 ; 9 \%)$ noted that medical reports and recommendations from the ocular physician were an impacting factor in service delivery decisions. The factors that they isolated were similar to those impacting service qualification discussed above. This included details about the student's visual impairment, like visual acuity, field loss, prognosis, and stability. A student's visual acuity and field loss, when stable, have a greater impact on their travel as they age and take on more difficult mobility tasks. For example, a peripheral or side field loss has a low level of impact on a kindergarten student who primarily travels following the person in front of them. However, a middle school student is expected to be able to cross a street. In this situation peripheral vision or compensatory vision skills are critical to executing a safe and independent cross. A student's prognosis and stability are also important. Prognosis is the path their vision loss will take and stability is how their vision can fluctuate over time. For example, a student with retinitis pigmentosa (RP) will gradually lose their peripheral field, closing in from the sides, potentially losing their vision entirely. O\&M specialists must work with a student with RP on their current O\&M needs as well as the needs they will have due to their increasing vision loss later.

IEP team. A minor theme $(N=6 ; 9 \%)$ in service delivery decisions was the members of the IEP team. The factors within the theme were similar to those impacting service qualification. The participants expressed that it was an IEP team decision and that was also impacted by the team establish supports. One participant (1\%) also indicated that the service minute decision was impacted by how supportive the other members of the team are in terms of the student receiving O\&M services.

Potential for growth. Some participants $(N=5 ; 7 \%)$ felt that during service prescription that the O\&M specialist should consider the student's ability to progress and grow. The 
participants indicated that they consider the student's general potential and willingness to participate. Others linked the student's potential for growth to the pace of learning and ability to attend to lessons.

Historical 5-year matrix. Professionals were asked to reflect on their last five years of employment centered around three questions. Participants $(N=68)$ responded to each question using a Likert score for frequency including always, some of the time, rarely, and never. These terms were undefined for participants and left to their interpretation. However, always and never were set to be near absolutes. Always indicating that it is a present factor in every or near every assessment or decision. Never indicating the opposite, where it is not a present factor in any assessment or decision. Some of the time and rarely were presented as less than absolute options. Rarely, notes that it does happen but seldomly. Some of the time was presented as the midline response between rarely and always, as a means of indicating that it was a factor impacting roughly half of the time. In addition to the basic analysis of the matrix responses, the responses were viewed as either best practices or against best practices. Best practices are the pedagogical practices viewed as optimal for student learning and engagement, typically based on research. In the field of O\&M this is based on research as well as guidance from individual and group leaders in the field. The first question of the matrix focuses on the impact of an existing caseload on service qualification. Based on the tenants IDEA, service qualification should be established through assessment and it should never be impacted by your caseload. In light of this responses of never are considered best practice and all others go against best practice. The same is true for the second question focusing on the impact of their caseload on service minute decisions. The final matrix question asks O\&M specialists if they ever qualify students for services they cannot provide without additional personnel. While always is the optimal response based on best 
practices, allowances for some of the time and rarely were made to capture anyone who recommended services beyond their own professional schedule.

An in depth analysis of the matrix included cross tabulation to search for potential relationships between participants responses and other details the reported about themselves and their employment. This included their geographic area of employment, years of experience, certification, and the distance they are from a preparation program. When analyzing a participants geographic area of employment they are group based on responses of 50\% or higher in a given category of rural, urban, or suburban. With this established threshold, a participant may either be excluded from analysis or included in two different categories as they have identified as $50 \%$ in each.

Service qualification. When participants were asked specifically about whether or not their caseload impacts students' service qualification, over half of the participants $(N=36 ; 53 \%)$ indicated that they have experienced this in the last five years of employment. This broke down to $3(4 \%)$ all of the time, 17 (25\%) some of the time, 16 (24\%) rarely and $32(47 \%)$ never (see table 16). So $52.9 \%$ of participants indicated that they go against best practice by allowing their caseload to impact a student's service qualification. When examining participants responses by geographic area of employment, $78.6 \%(N=11)$ of predominantly urban $(N=14)$ participants caseload to impact a student's service qualification. When examining participants responses differentiated by geographic area of employment, $78.6 \%(N=11)$ of predominantly urban $(N=14$; $21 \%$ of total responses) participants indicated that their caseload at least rarely impacts service qualification (see table 17). This is approximately 25 percentage points above the calculation for 
Table 16

Frequency of participants' response to historical response matrix

\begin{tabular}{lllll}
\hline Matrix Question & All of the time & Some of the time & Rarely & Never \\
\hline $\begin{array}{l}\text { Have you felt that your caseload has } \\
\text { impacted your recommendation to qualify }\end{array}$ & $3(4 \%)$ & $17(25 \%)$ & $16(24 \%)$ & $32(47 \%)$ \\
a student for O\&M services? & & & & \\
$\begin{array}{l}\text { Have you felt that your case load has } \\
\text { impacted your recommendation for O\&M } \\
\text { service minutes? }\end{array}$ & $7(10 \%)$ & $19(28 \%)$ & $16(24 \%)$ & $26(38 \%)$ \\
$\begin{array}{l}\text { Have you qualified a student for services } \\
\text { or identified needed service minutes that } \\
\text { may not be able to be fulfilled without } \\
\text { additional personnel? }\end{array}$ & $4(6 \%)$ & $20(29 \%)$ & $23(34 \%)$ & $21(31 \%)$ \\
\hline
\end{tabular}

caseload to impact a student's service qualification. When examining participants responses differentiated by geographic area of employment, $78.6 \%(N=11)$ of predominantly urban $(N=14$; $21 \%$ of total responses) participants indicated that their caseload at least rarely impacts service qualification (see table 17). This is approximately 25 percentage points above the calculation for all respondents (52\%; see table 16$)$, indicating a potentially strong impact of an O\&M specialists' geographic area of employment on service qualification based on their caseload. The largest percentage of this population group $(N=14)$ indicated that qualification was impacted some of the time $(N=5 ; 36 \%)$. Additionally, an emerging negative relationship, almost 10 percentage points of difference, for participants with a single certification in O\&M (Total N=30; $N=13,43 \%)$ and the participants with $11-20$ years of experience (Total $N=21 ; N=9,43 \%)$ from the total percentage against best practices (53\% and 53\%; see table $18 \& 19)$ While an emerging to strong relationship was suggested between the matrix responses and the distance to a preparation program with $8-22.9$ percentage point difference between the total population and each subgroup by distance (see table 20).

Service recommendation. The same participants were asked to reflect on if their caseload had impacted their recommendations for service minutes in the last five years. Nearly 62 percent 
Table 17

Cross tabulation of geographic areas of employment by the historical 5 year matrix of professional experiences

\begin{tabular}{|c|c|c|c|c|c|c|c|c|c|c|c|}
\hline \multirow{2}{*}{\multicolumn{2}{|c|}{ Classifier }} & \multicolumn{10}{|c|}{ Historical 5 Year Matrix of Professional Experiences } \\
\hline & & $\begin{array}{l}\text { All of } \\
\text { the time }\end{array}$ & Row \% & $\begin{array}{l}\text { Some of } \\
\text { the time }\end{array}$ & Row \% & Rarely & Row \% & Never & Row \% & $\begin{array}{l}\text { Row } \\
\text { Total }\end{array}$ & $\begin{array}{l}\% \text { Against } \\
\text { Best Practice }\end{array}$ \\
\hline \multirow{15}{*}{$\begin{array}{l}\text { Geographic } \\
\text { Area of } \\
\text { Employment }\end{array}$} & Have you felt th & your case & ad has in & pacted you & ecommen & ation to $c$ & lify a stu & ent for ( & M servic & & \\
\hline & Urban & 2 & $14.3 \%$ & 5 & $35.7 \%$ & 4 & $28.6 \%$ & 3 & $21.4 \%$ & 14 & $78.6 \%$ \\
\hline & Suburban & 2 & $6 \%$ & 6 & $18.2 \%$ & 9 & $27.3 \%$ & 16 & $48.5 \%$ & 33 & $51.5 \%$ \\
\hline & Rural & 0 & $0 \%$ & 4 & $23.5 \%$ & 4 & $23.5 \%$ & 9 & $52.9 \%$ & 17 & $47.1 \%$ \\
\hline & Column Totals & 4 & $6.3 \%$ & 15 & $23.4 \%$ & 17 & $26.6 \%$ & 28 & $43.8 \%$ & 64 & $56.2 \%$ \\
\hline & Have you felt th & your case & oad has it & ipacted you & ecommes & lation for & $\& \mathrm{M}$ serv & ce minut & & & \\
\hline & Urban & 2 & $14.3 \%$ & 4 & $28.6 \%$ & 4 & $28.6 \%$ & 4 & $28.6 \%$ & 14 & $71.4 \%$ \\
\hline & Suburban & 3 & $9.1 \%$ & 11 & $33.3 \%$ & 8 & $24.2 \%$ & 11 & $33.3 \%$ & 33 & $66.6 \%$ \\
\hline & Rural & 2 & $11.8 \%$ & 3 & $17.6 \%$ & 5 & $29.4 \%$ & 7 & $41.2 \%$ & 17 & $59.8 \%$ \\
\hline & Column Totals & 7 & $10.9 \%$ & 18 & $28.1 \%$ & 17 & $26.6 \%$ & 22 & $34.4 \%$ & 64 & $65.6 \%$ \\
\hline & $\begin{array}{l}\text { Have you qualif } \\
\text { additional perso }\end{array}$ & $\begin{array}{l}\text { d a studen } \\
\text { hel? }\end{array}$ & for servic & s or identif & needed & rvice $\mathrm{m}$ & tes that $m$ & y not b & le to be $f$ & lfilled & thout \\
\hline & Urban & 1 & $7.1 \%$ & 6 & $42.9 \%$ & 2 & $14.3 \%$ & 5 & $35.7 \%$ & 14 & $35.7 \%$ \\
\hline & Suburban & 3 & $9.1 \%$ & 7 & $21.2 \%$ & 13 & $39.4 \%$ & 10 & $30.3 \%$ & 33 & $30.3 \%$ \\
\hline & Rural & 0 & $0 \%$ & 7 & $41.2 \%$ & 4 & $23.5 \%$ & 6 & $35.3 \%$ & 17 & $35.3 \%$ \\
\hline & Column Totals & 4 & $6.3 \%$ & 20 & $31.3 \%$ & 19 & $29.7 \%$ & 21 & $32.8 \%$ & 64 & $32.8 \%$ \\
\hline
\end{tabular}


Table 18

Cross tabulation of single and dual certifications by the historical 5 year matrix of professional experiences

Classifier Historical 5 Year Matrix of Professional Experiences

\begin{tabular}{|c|c|c|c|c|c|c|c|c|c|c|c|}
\hline \multicolumn{2}{|l|}{ 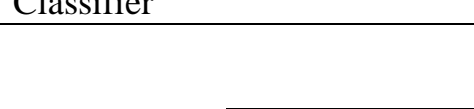 } & $\begin{array}{l}\text { All of } \\
\text { the time }\end{array}$ & Row \% & $\begin{array}{l}\text { Some of } \\
\text { the time }\end{array}$ & Row \% & Rarely & Row \% & Never & Row \% & $\begin{array}{l}\text { Row } \\
\text { Total }\end{array}$ & $\begin{array}{l}\% \text { Against } \\
\text { Best Practice }\end{array}$ \\
\hline & Have you felt th & your case & ad has in & pacted you & ecommen & ation to & lify a stu & ent for $\mathrm{C}$ & M servic & & \\
\hline & $\begin{array}{l}\text { Single O\&M } \\
\text { cert }\end{array}$ & 1 & $3.3 \%$ & 5 & $16.7 \%$ & 7 & $23.3 \%$ & 17 & $56.7 \%$ & 30 & $43.3 \%$ \\
\hline & $\begin{array}{l}\text { Dual O\&M/ } \\
\text { other VI field }\end{array}$ & 2 & $5.3 \%$ & 12 & $31.6 \%$ & 9 & $23.7 \%$ & 15 & $39.5 \%$ & 38 & $60.5 \%$ \\
\hline & Column Totals & 3 & $4.4 \%$ & 17 & $25 \%$ & 16 & $23.5 \%$ & 32 & $47.1 \%$ & 68 & $52.9 \%$ \\
\hline & Have you felt th & your case & oad has in & pacted you & ecomme & ation for & $\& M$ serv & e minut & & & \\
\hline & $\begin{array}{l}\text { Single O\&M } \\
\text { cert }\end{array}$ & 2 & $6.7 \%$ & 7 & $23.3 \%$ & 7 & $23.3 \%$ & 14 & $46.6 \%$ & 30 & $53.4 \%$ \\
\hline \multirow[t]{6}{*}{ Certification } & $\begin{array}{l}\text { Dual O\&M/ } \\
\text { other VI cert }\end{array}$ & 5 & $13.2 \%$ & 12 & $31.6 \%$ & 9 & $23.7 \%$ & 12 & $31.6 \%$ & 38 & $68.4 \%$ \\
\hline & Column Totals & 7 & $10.3 \%$ & 19 & $27.9 \%$ & 16 & $23.5 \%$ & 26 & $38.2 \%$ & 68 & $61.8 \%$ \\
\hline & $\begin{array}{l}\text { Have you quali } \\
\text { additional perso }\end{array}$ & $\begin{array}{l}\text { d a studen } \\
\text { hel? }\end{array}$ & or servic & or identi & needed & rvice $m$ & tes that $\mathrm{m}$ & not be & le to be $\mathrm{f}$ & lfilled & thout \\
\hline & $\begin{array}{l}\text { Single O\&M } \\
\text { cert }\end{array}$ & 1 & $3.3 \%$ & 10 & $33.3 \%$ & 11 & $36.7 \%$ & 8 & $26.7 \%$ & 30 & $26.7 \%$ \\
\hline & $\begin{array}{l}\text { Dual O\&M/ } \\
\text { other VI cert }\end{array}$ & 3 & $7.9 \%$ & 10 & $26.3 \%$ & 12 & $31.6 \%$ & 13 & $34.2 \%$ & 38 & $34.2 \%$ \\
\hline & Column Totals & 4 & $5.9 \%$ & 20 & $29.4 \%$ & 23 & $33.8 \%$ & 21 & $30.9 \%$ & 68 & $30.9 \%$ \\
\hline
\end{tabular}

Note Cert=Certification; O\&M=Orientation and Mobility; VI=Visually Impaired. 
Table 19

Cross tabulation of years of experience by the historical 5 year matrix of professional experiences

\begin{tabular}{|c|c|c|c|c|c|c|c|c|c|c|c|}
\hline \multirow{2}{*}{\multicolumn{2}{|c|}{ Classifier }} & \multicolumn{10}{|c|}{ Historical 5 Year Matrix of Professional Experiences } \\
\hline & & $\begin{array}{l}\text { All of } \\
\text { the time }\end{array}$ & Row \% & $\begin{array}{l}\text { Some of } \\
\text { the time }\end{array}$ & Row \% & Rarely & Row \% & Never & Row \% & $\begin{array}{l}\text { Row } \\
\text { Total }\end{array}$ & $\begin{array}{l}\% \text { Against } \\
\text { Best Practice }\end{array}$ \\
\hline \multirow{15}{*}{$\begin{array}{l}\text { Years of } \\
\text { Experience }\end{array}$} & Have you felt $\mathrm{t}$ & your case & ad has in & pacted you & ecommen & tion to $\mathrm{c}$ & lify a stu & ent for $C$ & M servic & & \\
\hline & $1-10$ years & 0 & $0 \%$ & 8 & $25.8 \%$ & 10 & $32.3 \%$ & 13 & $41.9 \%$ & 31 & $58.1 \%$ \\
\hline & $11-20$ years & 1 & $4.8 \%$ & 3 & $14.3 \%$ & 5 & $23.8 \%$ & 12 & $57.1 \%$ & 21 & $42.9 \%$ \\
\hline & $21+$ years & 2 & $12.5 \%$ & 6 & $37.5 \% \%$ & 1 & $6.3 \%$ & 7 & $43.8 \%$ & 16 & $56.2 \%$ \\
\hline & Column Totals & 3 & $4.4 \%$ & 17 & $25 \%$ & 16 & $23.5 \%$ & 32 & $47.1 \%$ & 68 & $52.9 \%$ \\
\hline & Have you felt $t$ & your case & oad has it & pacted yo & ecommen & ation for & $\& \mathrm{M}$ serv & e minut & & & \\
\hline & $1-10$ years & 2 & $6.5 \%$ & 8 & $25.8 \%$ & 9 & $29 \%$ & 12 & $38.7 \%$ & 31 & $61.3 \%$ \\
\hline & $11-20$ years & 1 & $4.8 \%$ & 6 & $28.6 \%$ & 4 & $19 \%$ & 10 & $47.6 \%$ & 21 & $52.4 \%$ \\
\hline & $21+$ years & 4 & $25 \%$ & 5 & $31.3 \%$ & 3 & $18.8 \%$ & 4 & $25 \%$ & 16 & $75 \%$ \\
\hline & Column Totals & 7 & $10.3 \%$ & 19 & $27.9 \%$ & 16 & $23.5 \%$ & 26 & $38.2 \%$ & 68 & $61.8 \%$ \\
\hline & $\begin{array}{l}\text { Have you quali } \\
\text { additional pers }\end{array}$ & $\begin{array}{l}\text { d a studen } \\
\text { hel? }\end{array}$ & for servic & s or iden & needed & vice $m$ & tes that $m$ & $y$ not b & le to be $f$ & lfillec & thout \\
\hline & $1-10$ years & 1 & $3.2 \%$ & 9 & $29 \%$ & 14 & $45.2 \%$ & 7 & $22.6 \%$ & 31 & $22.6 \%$ \\
\hline & $11-20$ years & 2 & $9.5 \%$ & 7 & $33.3 \%$ & 2 & $9.5 \%$ & 10 & $47.6 \%$ & 21 & $47.6 \%$ \\
\hline & $21+$ years & 1 & $6.3 \%$ & 4 & $25 \%$ & 7 & $43.8 \%$ & 4 & $25 \%$ & 16 & $25 \%$ \\
\hline & Column Totals & 4 & $5.9 \%$ & 20 & $2.9 \%$ & 23 & $33.8 \%$ & 21 & $30.9 \%$ & 68 & $30.9 \%$ \\
\hline
\end{tabular}


Table 20

Cross tabulation of distance from a university preparation program by the historical 5 year matrix of professional experiences

\begin{tabular}{|c|c|c|c|c|c|c|c|c|c|c|c|}
\hline \multirow{2}{*}{\multicolumn{2}{|c|}{ Classifier }} & \multicolumn{10}{|c|}{ Historical 5 Year Matrix of Professional Experiences } \\
\hline & & $\begin{array}{l}\text { All of } \\
\text { the time }\end{array}$ & Row \% & $\begin{array}{l}\text { Some of } \\
\text { the time }\end{array}$ & Row \% & Rarely & Row \% & Never & Row \% & $\begin{array}{l}\text { Row } \\
\text { Total }\end{array}$ & $\begin{array}{l}\% \text { Against } \\
\text { Best Practice }\end{array}$ \\
\hline \multirow{13}{*}{$\begin{array}{c}\text { Distance } \\
\text { from } \\
\text { Preparation } \\
\text { Program }\end{array}$} & Have you felt tl & your case & ad has in & pacted you & ecommen & ation to & lify a stu & ent for & M servic & & \\
\hline & 101-300 miles & 0 & $0 \%$ & 1 & $5 \%$ & 5 & $25 \%$ & 14 & $70 \%$ & 20 & $30 \%$ \\
\hline & $301+$ miles & 1 & $5 \%$ & 5 & $25 \%$ & 7 & $35 \%$ & 7 & $35 \%$ & 20 & $65 \%$ \\
\hline & \multicolumn{11}{|c|}{ Have you felt that your case load has impacted your recommendation for O\&M service minutes? } \\
\hline & $1-100$ miles & 4 & $14.3 \%$ & 10 & $35.7 \%$ & 6 & $21 \%$ & 8 & $28.6 \%$ & 28 & $71.4 \%$ \\
\hline & 101-300 miles & 1 & $5 \%$ & 2 & $10 \%$ & 4 & $20 \%$ & 13 & $65 \%$ & 20 & $35 \%$ \\
\hline & $301+$ miles & 2 & $10 \%$ & 7 & $35 \%$ & 6 & $30 \%$ & 5 & $25 \%$ & 20 & $75 \%$ \\
\hline & Column Totals & 7 & $10.3 \%$ & 19 & $27.9 \%$ & 16 & $23.5 \%$ & 26 & $38.2 \%$ & 68 & $61.8 \%$ \\
\hline & \multicolumn{11}{|c|}{$\begin{array}{l}\text { Have you qualified a student for services or identified needed service minutes that may not be able to be fulfilled without } \\
\text { additional personnel? }\end{array}$} \\
\hline & $1-100$ miles & 3 & $10.7 \%$ & 6 & $21.4 \%$ & 11 & $39.3 \%$ & 8 & $28.6 \%$ & 28 & $28.6 \%$ \\
\hline & $101-300$ miles & 0 & $0 \%$ & 8 & $40 \%$ & 7 & $35 \%$ & 5 & $25 \%$ & 20 & $25 \%$ \\
\hline & $301+$ miles & 1 & $5 \%$ & 6 & $30 \%$ & 5 & $25 \%$ & 8 & $40 \%$ & 20 & $40 \%$ \\
\hline & Column Totals & 4 & $5.9 \%$ & 20 & $29.4 \%$ & 23 & $33.8 \%$ & 21 & $30.9 \%$ & 68 & $30.9 \%$ \\
\hline
\end{tabular}


of participants reported they have gone against best practices by allowing their current caseload size to impact how many minutes of service they recommend for students. While the largest group $(N=26 ; 47 \%)$ reported that they never let their caseload impact service minutes, 42 participants (62\%) indicated that they have at least rarely (see table 16). When exploring the relationship between the participant's experiences with service recommendations and other questions of the survey two emerging relationships were discovered and two queries with no relationship. No relationship of note was found between single and dually certified providers or geographic area of employment (see table 18 \& 19). A positive emerging relationship was suggested with O\&M specialists with over 21 years of experience (Total $N=16 ; N=12 ; 75 \%)$ and a negative relationship with $11-20$ years of experience ( Total $N=21 ; N=11 ; 52 \%$ ) both emerging with $13 \%$ and almost $10 \%$ respectively from the collective percentage of $62 \%$ (see table 19). Finally, a large and mixed relationship was suggested between participants general responses $(62 \%)$ and those of the subgroups based on distance from a university preparation program. Those participants working less than $100($ Total $N=28 ; N=20 ; 72 \%)$ and more than 300 miles (Total $N=20 ; N=15 ; 75 \%$ ) from a preparation program reported a larger percentage of participants against best practices with a 10 and 14 percentage point difference respectively (see table 20). However, participants from 101-300 miles away from a program reported at a dramatically lower rate of 35\% ( $\operatorname{Total} N=20 ; N=7$ ), a nearly 27 percentage point difference.

Professional availability. Participants were asked one final question about their employment experience. They were to reflect if they qualified students for services that they would not be able to personally meet. While only four participants $(6 \%)$ indicated that they are doing this all of the time, the optimal response for best practices, 43 other participants (63\%) indicated that at least rarely they are qualifying students despite their inability to fulfill the 
service. By indicating never, $30.9 \%(N=21)$ of participants indicated that they may go against best practice by never recommending needed service minutes they cannot provide. This result is consistent across all geographic areas of employment within seven percentage points $(36 \% ; 30 \%$; $35 \%$; see table 17) and certifications ( $27 \% ; 34 \%$; see table 18$)$. However, $47.6 \%$ of participants with 11-20 years of experience indicated that they never recommend service that require additional personnel to fulfill. This is significantly higher than the collective response (31\%) and the other experience groups of 1-10 years (22.6\%) and 21+ years (25\%).

Final perceptions. Participants were given a final opportunity to share any additional factors or influences. Many of the themes recurred from the previously discussed questions so the same thematic codebook was utilized to evaluate the responses. Only newly occurring statements and extended strong statements will be discussed below. While not all participants responded to the final question, roughly $63 \%$ or 48 participant did. Eight participants used the opportunity to indicate that were no additional factors or influences. The remaining 40 participants were spread through the Midwest, with the exception of Iowa.

Potential for growth. While behavior was discussed previously as an impacting factor for service qualification, one participant indicated that potentially violent behaviors toward self and others should be considered.

Professional's available time. Participants have indicated that they carry large and sometimes dual caseloads. However, one participant (2\%) indicated that their role as a TVI is given priority over their role as a O\&M specialist. Another participant (2\%) noted a strong need for addition O\&M specialists to meet the growing needs of students. While another participant (2\%) said they were forced to give their limited time to the students that may benefit the most. This may be more frequent in large or high need caseloads. 
District and administrative concerns. Eleven participants (23\%) used the final question to offer thoughts about the district and administrative concerns impacted the students' qualification and services for O\&M. A participant succinctly put it that "administrative pressure" played a role in service qualification and provision. The other ten participants (21\%) recounted examples of policies and staffing or budgetary issues they had encountered. Two participants (4\%) indicated that districts were restricting or denying services due to a general lack of understanding of O\&M services or the legal requirement of evaluation and services under the tenets of IDEA. Several others $(N=4 ; 8 \%)$ noted restrictive district policies about after school and weekend lesson, pull out services, transporting students, use of school vehicles, and off campus or community based lessons that limit the ability of O\&M specialist to provide needed services.

Two participants (4\%) included statements encompassing different approaches that administration was using to deny or reduce services. The first centers around limited personnel and how an administrator may try to compensate for this by overruling the recommendation of the O\&M specialist.

"Unfortunately, if a supervisor of the O\&M program is aware that a student cannot be served with the recommendation of minutes from the COMS, they have the ability to change your minutes or service delivery. Even though it is a team decision, that should include parents, students (if age appropriate) and IEP team members. Due to the national shortage, students are not receiving adequate minutes either at all, or it is handed down from above the COMS to lower the direct/consult minutes to fit their staff's schedule."

Two other participants (4\%) also mentioned districts attempts to deal with personnel complications. Specifically, the participants noted that districts either placed preference 
on the TVI part of their caseload or replace a dually certified COMS/TVI with a singly certified TVI. Another participant simply said that the district needed to hire and maintain additional O\&M specialists to meet the need.

The second profound statement offered a different solution that a member of administration tried specifically in rural and "poor" district.

"Sometimes districts will think they cannot afford the services or want to give my minutes to a TVI and try to cut them back. I have had this brought up once but the administration at my employer educated them on why that is not legal. Lots of rural districts in $\{$ the western part of our state; redacted to ensure confidentiality*\} do not even know that mobility is an option."

Geographic location. Previously participants have indicated that the rural geographic environment that student live due to the remote nature of the environment and the distance to instructional spaces. Three new struggles in relation to rural communities were discussed. The first is the sparsity of O\&M providers available to cover that geographic area with the greater distance between school districts and communities. Due to this greater geographic area and the low incidence nature of O\&M services, O\&M specialists may be employed out of special education agencies or larger districts that contract out their services. By combining the large coverage area and the contract nature of the position it may be difficult to obtain transportation for students to instructional areas. If the provider uses a vehicle from their agency or district they may be required to drive to their agency to obtain the vehicle, to the student's district, then to the instructional area, return the student to their district, and then return the vehicle to the district. All before moving to the next student on the schedule. A final thought is most relevant to the 
chosen region of the US, the Midwest. One participant (2\%) indicated that their ability to safely drive to and with students during winter months is another consideration.

\section{Summary}

The purpose of this survey was to identify the tools used during assessment and service recommendation, as well as other factors impacting service decisions. The online survey polled O\&M specialists throughout the Midwest region of the United States. Participants were recruited through ACVREP and AERBVI listservs and social media platforms. The total number of participants included in the survey results is 76 with 68 (89\%) completing to question 21 and 48 (63\%)completing the open-ended final thoughts question. The survey was anonymous to protect the participants with some additional data or statistical calculations redacted for further protection due to the low incidence nature of the O\&M profession.

The chapter included a descriptive analysis of the demographics of the participants, including general and non-identifiable information about their employment, location, and caseload. A secondary descriptive analysis included a record of the tools used for O\&M assessments and service delivery decisions by all participants remining after inclusion criteria was met. The final open-ended portion of the survey was subject to a mixed-methods analysis using a combination of a thematic codebook I established, discussed in chapter three, and a binary coding for statistical analysis. The final chapter will include a discussion of the interpretation of the data obtained through the analysis of the survey results and its limitations, as well as the future directions for research. 


\section{CHAPTER V: DISCUSSION OF FINDINGS}

The purpose of this survey study was to find out the tools and other factors that are guiding O\&M specialists as they make recommendations for qualifications of O\&M services and the amount of services to students with blindness. This chapter includes a brief summary of the results and findings of the survey along with a connection the existing research base on O\&M assessment and service provision as they apply to the guiding research questions. The chapter concludes with the study's limitations and areas of potential future research.

\section{Discussion}

Based on the work of Mason (2000) and Ferrell (2007) the field of O\&M has accepted that we, like other areas of special education, are experiencing a critical shortage. When the impact of the shortage is examined through the lens of the economic theory of supply and demand it is framed as follows. A reduced number of O\&M specialists with consistent demand for the services of O\&M results in a higher need for services and thusly a reduced number of students receiving O\&M services. The supply of O\&M specialist is likely to decrease in the coming years rather than climb as the incoming millennial professionals are not entering into a profession largely built by the baby boomer generation (Blasch \& Wiener, 2010). With roughly 41,000,000 baby boomers reaching retirement age, by 2031 this trend will likely continue (Fry, 2018). In order to build their numbers O\&M specialists have turned to recruitment programs like Why Eye Teach, a practitioner group out of Illinois working to recruit potential new practitioners to the vision fields (Duncan, 2019). Although these efforts are crucial to the conservation of the O\&M field, O\&M specialist must continue to serve their students the best that they can. In order to do that, Wall Emerson and Anderson (2006) postulate that this pushes O\&M specialists to have to use other factors about the student, the district, or themselves when making decisions 
about qualifying students for services and how much they may receive. This study was completed to answer the remaining question about what these factors may be.

\section{What Tools Are O\&M Specialists Who Are Serving K-12 Students, Using To Guide Assessment Results And Service Delivery Recommendations?}

One aim of the study was to establish what tools O\&M specialists utilize during the assessment process and when making decisions about the student's need for services. As part of the survey participants were offered suggestions of possible publicly available assessments: the Teaching Age Appropriate Skills (TAPS), the Oregon Project, the New Mexico School for the Blind and Visually Impaired (NMSBVI) O\&M inventory, the Preschool O\&M screening, and the Texas 2 Step (see Chapter 1). When asked about tools specific to making service delivery decisions participants were offered a list of the two publicly available tools, the Michigan Severity Rating Scale (O\&MSRS), and the O\&M Visual Impairment Scale of Service Intensity of Texas (VISSIT). Participants could also indicate that they use their professional judgment or they were provided a write in option.

O\&M assessment tools. When provided with the list of O\&M assessment tools I provided, the participants indicated they use a combination of publicly available O\&M assessments, as well as assessment they have created themselves, or in conjunction with their employer. While the responses varied greatly, $59 \%$ of participants selected at least two O\&M assessment tools from the provided list with an additional $10 \%$ writing in response not included in the original list. By selecting more than one assessment the O\&M specialists are noting that they use the O\&M assessment tools in their practice, but it does not necessarily indicate that they use multiple assessment tools on the same individual. The survey did not allow O\&M specialists an opportunity to indicate whether they are used for different student populations on their 
caseload (e.g. based on age, coexisting disabilities, future goals, or present levels of travel) or used in conjunction as a means of triangulating assessment results.

When reviewing the tools specifically for use during the O\&M assessment there are six main tools on the market. When participants were asked about the tools used during O\&M assessments, $84 \%$ indicated that they use the TAPS assessment one of the most encompassing tools on our survey in terms of age and ability. The number of participants that said they used this tool was not surprising due to the age and the comprehensive nature of the product. There was no apparent relationship between the TAPS assessment and the O\&M specialists’ geographic area of employment, years of experience, or distance from a preparation program. However, O\&M specialists with dual certifications used the TAPS at a greater rate than their singly certified colleagues. This may be due to the supplemental pieces offered by the TAPS like the curriculum and goal creation tools that mirror some of the all-inclusive assessments' tools present in other vision specialties.

For instance, a specialist dually certified as O\&M and TVI, the TAPS offer curriculum activities that could be easily incorporated into a student's vision time or when transitioning to and from the vision time. The TAPS directly links the assessed skills with future lessons in the curriculum. An example of this would be a student in need of positional concepts on the assessment links to an activity for the inclusion of positional concepts in a kitchen lesson. A TVI may approach this lesson by placing the ingredients to the side of the student on a tray, having the student work from that point. Whereas a dual O\&M and TVI may have the student find the ingredients from their location in the cabinet using terms like parallel, perpendicular, and in front of to guide them. 
A singly certified O\&M specialist would likely incorporate the positional concepts into another target lesson such as route travel. The use of specific targeted lessons that include a multitude of O\&M specific skills such as route travel could explain the singly certified O\&M specialist preference for teacher created assessments. Singly certified O\&M specialists are only viewing the skills needed for O\&M development not those needed for development of other areas of the expanded core curriculum such as recreation, assistive technology, and functional life skills. This might be the cause of why more dually certified specialist use the TAPS.

Thirty-two percent of the participants indicated that they use another O\&M assessment tool in addition to the TAPS. Of the other O\&M assessment tools listed for participants, $43 \%$ used the Oregon Project, 50\% used the NMSBVI O\&M inventory, and 32\% used the Preschool O\&M screening. Each of these well-known tools are targeted to specific groups of students. The Oregon Project is a stand-alone global assessment for early development typically seen in infants and toddlers up to age six (Anderson, Doigon, Davia, \& deWaard, 2007). The assessment covers the child's cognitive, fine and gross motor, vision, and compensatory development. However, O\&M specialists may choose to only use one or two sections of the assessment to evaluate the child's travel skills. The Preschool O\&M screening covers a similar set of skill development for children up to age five but focuses on positive communication with the child's parents and support network (Dodson-Burk, \& Hill, 1989). While the NMSBVI O\&M inventory targets assesses of students at age six, but it may not accurately capture a student's abilities when a coexistent disability is present. The last assessment the Texas 2 Step, focuses on infancy through the developmental age of five. The number of participants $(N=2)$ using the Texas 2 Step assessment and curriculum pair is likely low due the "newness" of the tool. The Texas 2 Step was initially released in 2018 (Brown, et al., 2019). In appearance and function the Texas 2 Step 
is similar to the TAPS assessment. In order to be included in the survey participants indicated that they serve students ages 3-21. With the target group of the assessment set as children up to age 5, or early movers, this is another potential reason for the low report use. The use of this tool will most like increase in the future with O\&M specialists serving early intervention (birth to three programs) and early school age students. O\&M specialist serving students above age 5 may also find this tool useful in the future for students who initiated movement later. According to Lord (1969) and Blasch et al. (2010) many children with low vision and blindness begin to move at a later age then their peers without vision loss.

Whatever assessment tool the O\&M specialist uses, the hope is to capture as much information about the student and how they travel as possible. The assessment must show the O\&M specialist the student's strengths and struggles, what they can do independently and what skills still need support. With all of the information gathered through the assessment process the O\&M specialist must begin to create a plan for the student that includes the instructional goals and a recommendation for services. This recommendation is referred to as a service delivery decision.

Service delivery decision tools. For professional decisions on how many hours a student should receive services there are serval tools they can rely on. The participants in this survey indicated by a large majority (77\%) they used professional judgement as a tool to quantify a student's needs, with $18 \%$ of participants saying it was the only tool that they use (see table 15 ). There appears to be no relationship between the use of professional judgment and an O\&M specialists' certification or distance from a university preparation program. However, professional judgement was used at a higher rate by those from predominantly suburban areas and by experience teachers with 21 or more years of experience. For O\&M specialists with 21 or 
more years of experience, they began practicing either before or shortly after the creation of the O\&MSRS, the first publicly available service delivery tool. Also, this was the window of time referred to as the dot-com bubble when the internet became readily accessible to the masses (Hayes, 2019). As a result, the group of O\&M specialist with their experience may not have had access to this tool from its inception causing them to formulate their own means of determining service delivery decisions based on their professional judgement.

There are also two commercially available service delivery decision tools available to O\&M specialists. The Michigan Severity Scale (O\&MSRS) is the older of the two tools, debuting in mid 1990's with several updates during its tenure (MDE-LIO, 2017). For just over 20 years, this was the only tool specifically designed for quantifying a student's need for O\&M services and it was provided to the O\&M specialists online and free of charge. Due to the age and uniqueness of the assessment, it is not surprising that $69 \%$ of O\&M specialist surveyed use this tool, or that $15.5 \%$ of O\&M specialist indicated that they only use the O\&MSRS. The O\&MSRS, and its companion tool the O\&MSRS+ for students with concomitant disabilities, is a rubric based tool where the O\&M specialist answers questions based on the student's assessment results. Each square of the rubric is linked to a number of points. When the points are totaled at the end of the tool, the O\&M specialist is given a recommended range of services. The recommendations range from not indicated to twice a week for 30-60 minutes. This provides the O\&M specialists a data driven tool to share with administration and the IEP team as a justification for their service recommendation. Wall Emerson and Anderson (2014) even note that the tool can be used to assist in caseload decisions or as a means of justify additional faculty needs. While the O\&MSRS is not intended for use as an O\&M assessment tool, however two 
participants indicated that is how they used the tool when previously asked about O\&M assessment tools.

The newest tool for O\&M service delivery decisions is the O\&M Visual Impairment Scale of Service Intensity of Texas (O\&M VISSIT) came to market in 2017 (Pogrund et al., 2017). Likely due to its newness, this tool was understandably used less, with only $23 \%$ of participants reporting it use. However, it was used six times as often as the O\&MSRS by those employed in predominantly urban settings. The inverse was true for participants from predominantly rural and suburban locations. Prior to conducting the survey, there was an assumption that this tool would be used at a higher frequency by those in rural and mixed areas. This is due to the fact that the O\&M VISSIT compensates for the time needed for transporting students to and from areas of instruction, whereas the O\&MSRS does not. For those practicing in rural communities they may need to transport students 30 or more minutes to a community that has sidewalks, light controlled intersections, shopping centers, and public transit. O\&M specialists have to factor these extended times into their schedule, as well as the commuting time to and from students. According to the open responses of the survey $10 \mathrm{O} \& \mathrm{M}$ specialists wrote about this difficulty. While this was initially anticipated to be unique to rural or mixed caseloads the breakdown indicated that of the 10 participants four were from predominantly suburban areas with the remainder split between urban and rural. This indicates that the travel time is a concern across geographic regions and should be accounted for when assigning caseloads or completing workload analysis as discussed below. Additionally, three participants reported the difficulty of having to obtain and return district or cooperative owned vehicle adding additional transit time needs. Including these additional times in the O\& M specialist's schedule takes away time from 
working with students which is another negative impact factor to consider for the O\&M specialist.

Pogrund, Darst, and Munro (2019) recently presented on an extension of the O\&M VISSIT that is in development. The extension aims to help O\&M specialists petition administration for different caseload divisions or additional faculty to meet the needs of their students. As presented, this is a work study analysis that would examine the O\&M specialists' caseload service minutes, consultation minutes, workload beyond student services (IEPs, planning, observations, trainings, documentation, support, and so on), travel time between students or to obtain district vehicles, and lunch in a typical work week. Based on the data provided by the O\&M specialist a formula would provide the number of hours of work completed per week by the O\&M specialist. Pogrund and her team noted this can then be compared against the O\&M specialist's contract as a means of justifying either additional compensation or additional personnel. The extension also provides guidance of how to formally write up and present these findings to the appropriate member of administration. A small trial was successfully conducted in an urban school district in Texas that resulted in a posting for an additional O\&M specialist for the school district the following year.

Professional judgement is a subjective tool that can change and develop over time based on experiences, personal and professional, as well as continued education. In the open response questions of the survey 22 participants indicated their use of professional judgment during assessment and service delivery decisions. Many participants shared their experiences of being overwhelmed by their caseload size or schedule, having unsupportive districts or supervisors, and limited resources which could influence an O\&M specialist's professional judgment in service delivery. In addition, an O\&M specialist may feel pressured by a supervisor or district to 
carry additional students beyond their schedule. This can look like, discipline for failing to meet the needs of all students on an overfull schedule, threats to find more capable staff who can carry the full schedule, or attempts to guilt the O\&M specialist into adding just one more student. The use of professional judgment should be limited in regard to completion and interpretation of assessment results and in the ethical standards of practice (ETFO, 2016). Based on the ACVREP code of ethics for O\&M specialists,

The O\&M specialist will make the recommendation for the continuing or discontinuing of services with the learner and/or their legal representative and will base that recommendation upon an evaluation of the learner's needs, abilities, and skills. Their commendation will be made in the learner's best interest, independent of personal or agency convenience. (ACVREP, 2018).

As an exercise of their professional judgement, teachers may also choose to create their own assessments or create assessments with others in their agency or district. Forty-five percent of participants indicated that they use a teacher or district created tool. Only three participants (4\%) choose to use teacher or district created tools as stand-alone assessments. Use of teacher or district created assessments can be done when the available assessments cannot accurately capture a particular student's needs, because acquiring many of the assessments can be costly, or because they are time consuming to complete. When O\&M specialists create their own assessments, they are guided by their professional judgement, education and experiences, and potentially by the assessments that are currently on the market. Similarly, O\&M specialist can use a rubric they create or informal professional judgment for making decisions about how much service a student should receive. A study conducted by Geruschat and De l'Aune (1989) created an assessment and training program for the Veterans' Administration (VA) that was based on 
their professional judgement and their working knowledge of other assessment tools. By completing training with all of the O\&M specialists employed by their blind rehabilitation center (BRC) and creating a system of check ins and follow ups to the training they were able to implement their created assessment and curriculum with a high level of reliability. However, this would be a difficult system to apply to an itinerant model of instruction for school age children.

Professionals should be cognizant of their biases and in order limit those biases from creeping thorough in professional judgement situations work to create a check list or other structured assessment that can be used for their students. This will help limit the use of extraneous variables during service qualification and service delivery decisions. Due to the shortage of O\&M specialists experienced by many districts across the United States, Wall Emerson and Andersons (2014) imply that O\&M specialist may be forced to use their professional judgement to make decisions based not on the students' needs but based on extraneous factors. Participants of this study noted incidents where the needs or constraints of their professional schedule or the district policies and limitations impacted a student's qualification or service delivery model forcing them to override their professional judgment. What Factors, Outside Of Assessment Results, Are Impacting How K-12 Students With A Visual Impairment Are Qualifying For O\&M Services? What Is Impacting K-12 O\&M

\section{Service Delivery Decisions?}

As part of the study, I explored what factors or variables may impact a student's qualification for O\&M services and the O\&M specialist's service delivery decisions. It was initially hypothesized that the open ended questions pertaining to each would yield different themes. However, the primary theme recurred across both questions. In light of this, both research questions will be discussed together for chapter five. 
Student. When establishing the amount of O\&M services needed by the student, O\&M specialists reported that in addition to the assessment, they used information provided by medical professionals with a total of 47 mentions across the assessment $(N=24$ [37\%]; $N=17$ [25\%]) and service delivery decision $(N=6[9 \%])$ questions. This information included, but was not limited to, the student's diagnosis, visual acuity and prescription, the degree of field loss, ocular functioning, stability of the loss, and prognosis. Some participants noted they look for medical reports in regard to any concomitant disabilities discussed previously. While some of the assessments listed prompt you to collect this information, others do not. This information about the student can be collected through interviews with the student and their family, as well as review of documentation (medical, educational, etc.). All of this information would be gathered in the weeks leading up to the initial IEP meeting as part of the assessment process. In light of this, participants may attribute the collection information about the student's profile to the assessment process. Outside of a student's ability to travel, information about their future goals and vision should shape their present goals and service. For example, a student may have relatively good vision currently and be able to travel independently without a cane or guidance. However, their poor vision prognosis lets the O\&M specialist know that the student will lose most or all of their vision with a potentially rapid onset (e.g. retinitis pigmentosa), requiring the use of the cane. This is information that the O\&M specialist would find out over and above the assessment through reviewing medical documentation and/ or by interviewing the student's family. By considering only the assessment, the O\&M specialist would likely deny the student for services based on current needs. Yet this extra information about the student would result in the O\&M specialist qualifying the student to preemptively begin cane and independent travel skills instruction. 
Participants from all demographic groups reported general information about the student and how it impacted services qualification ( $N=52$; across 2 questions) and service delivery decisions $(N=23)$. While some participants $(N=23)$ acknowledged a focus on the student's future goals for travel (level of independence they want to maintain and the environments they want to explore) other participants $(N=28)$ noted a focus on the student and their family as impacting decision making. Participants included if they observed the parent put limitations on services or independence $(N=4)$, if the student has opportunities to practice what they learn outside of their O\&M service time $(N=6)$, or if they have had O\&M services before $(N=2)$. Other notable items mentioned by participants included, student motivation or interest in O\&M services $(N=4)$, or if the student has a history of refusing to attend or participate in O\&M services $(N=1)$. Some researchers stressed the need to consider the whole child, including their parental support, when making decisions about service (Geruschat, 1980; Hill \& Hill 1991). It is important to consider what drives a student, what causes stress, and their level of fatigue (Hill \& Hill, 1991). Whereas Geruschat (1980) noted the importance of studying the student's communication, behavior, and motivation. These considerations paired with those expressed by the participants help to ensure that the time spent with the student is meaningful. However, they also provide the O\&M specialist with insight into which students may benefit the most from services if service time in limited (Wall Emerson \& Anderson, 2014) in addition an attempt by service providers to consider the "whole" child.

Five participants indicated that the student's behavior was factored into their considerations for assessment or service delivery decisions. While not directly linked to the student's instructional needs, a student's motivation and emotional/behavioral needs could impact the instructional time and motivation level of the student. For example, a student who is 
prone to challenging behavior may require additional supports or behavioral interventions in place before instruction can be safe and meaningful. Challenging behaviors should not be a deciding variable on whether or not a student with vision loss qualifies for O\&M services or the amount of services provided to them. O'Mea (2013) presented a practitioner's approach to the use of applied behavioral analysis (ABA) during O\&M lesson when these challenging behaviors present themselves. This guides O\&M specialist to find the root cause of the behavior and build in a program to decrease or increase the behavior. However, this can be another time consuming component of O\&M services, as it is process of experimentation to find a program that can be implemented with fidelity. Conversely a student who is highly motivated to be independent could be expected to use their long white cane with greater fidelity across all environments increasing their amount of practice time and generalizability. This could be tied closely to the student and their family's goals for the future. If a student has the goal to attend college in a large city, they will need more experiences with public transportation, large light controlled intersections, and congested pedestrian traffic areas. A student whose goal is to remain in their small rural community will need less in depth travel instruction. However, if the student has goals of independence and the family has goals remaining in their small community the instruction will have to include a family component to encourage their releasing of the reigns of control over the student. These scenarios have a significant impact on the amount of time and commitment that will be required to ensure that the student meets their future goals. Furthermore, these scenarios indicate what type of instruction or instructional activities will be the most beneficial to the student. Lord (1969) indicated that travel must be useful, purposeful, and authentic to the student to ensure mastery and generalization of the skill. While Lord studied the travel needs of small children this is also applicable to older children preparing for transition 
to adulthood. If their goals are to walk to work in their community, ride trains to the city for work, or travel about a college campus this should factor into service qualification and decisions.

District or agency administration. Districts or employing agencies have a large number of policies, formal/written and informal/unwritten, that guide their employees' professional habits. The policies are typically written for employees working within the school building or district. However, these policies may hamper itinerant professionals from completing their jobs effectively and efficiently. A total of 22 participants (29\%) indicated that district policies or concerns impacted their O\&M assessments $(N=14 ; 18 \%)$ and service delivery decisions $(N=8$; $11 \%)$. Ninety-five percent of participants who indicated district or administrative policies were employed in excess of 30 hours a week in predominantly suburban (36\%) and rural (32\%) areas. Two participants noted that their district/cooperative has a policy against serving students with complex support needs, such as students with seizure disorders or those who a wheelchair or walker for ambulation. Another four participants reported that their districts did not allow lessons to occur off campus or outside of the immediate community. If the student's instructional needs indicated off campus travel, the O\&M specialists must then advocate for their student to the administration as the district policy is in violation of FAPE. This is due to the fact that under Section 300.24(b)(6)(i) of IDEA orientation and mobility services are to prepare individuals with a visual impairment to travel safely and independently in their school, home, and community. By denying access to one or more of these environments limits their access to skill instruction like public transportation and street crossings. This can allow a family to evoke their right to due process for violation of FAPE. A third of all participants who responded to the open ended questions, recounted policies that generally limited whom could be seen, when, where, and how often. Some linked this to generally restrictive policy or policy enforcement, others felt this was 
a budgetary concern associated with the elevated cost of providing O\&M services. These barriers may prove to be too significant for the O\&M specialist to provide efficient and or adequate O\&M services to the student.

IEP team. O\&M specialists must consider the IEP team that they will work with. Many participants reported that they take into account consultation and recommendations for the IEP team. However, others described times when they had to consider the level of support, or rather lack of support, they would receive from other team members. This included both the flexibility of scheduling and oversight of the student's travel support needs and practice. In the area of O\&M services for students with Deafblindness the use of transdisciplinary teams for assessment and service delivery has proven successful (Geruschat, 1980; Hill \& Hill, 1990; Smith \& Herlich, 2014). While this collaborative model is central for IEP teams working with individuals who have Deafblindness due to the unique needs of dual sensory loss, student with a singular sensory loss also possess their own unique needs. It is important for districts to create an environment and culture that is conducive for collaboration and transdisciplinary approaches to education. Hill and Hill (1990) felt that transdisciplinary approach with role release could help to mitigate some of the impact of the shortage of O\&M specialists on students. Five participants in the survey indicated the level of support from other teachers or specialists working with the student as a factor that could impact service delivery decisions.

Scheduling. While most of the themes occurred across the research questions addressing assessment for services and service delivery decisions in an even fashion, the professional and student's schedule primarily occurred when participants were asked about factors impacting service delivery decisions. Initially I hypothesized that conflicts in scheduling would have the largest impact on a student's qualification for O\&M services and the O\&M specialists' service 
delivery decisions. However, after analyzing the data this was not as prominent of a theme as others such as district policies, information about the student, and professional judgement. Creating a schedule is an arduous task where itinerant teachers must find a date and time for each individual student. Scheduling may not have been noted as a factor due to their perception that it is just part of the job. However, the size of a caseload in terms of quantity of students and geographic area, a general lack of time, and competition for a student's time all potentially impact the O\&M specialists ability to create a schedule meeting the needs of each of their students.

As an academic year begins each O\&M specialist, like many other itinerant services, must take their assigned caseload and create a schedule for whom is to be seen and when. This can be a difficult task as the O\&M specialist must take into account the schedule of the student and their other services. The majority of O\&M specialists serve multiple schools, districts, and sometimes counties. Some participants even reported that they were one O\&M specialist of only a few in their state. They were only able to give what was available in their professional schedule because as one participant offered "some service is better than no service".

Ferrell (2007), Wall Emerson and Anderson (2014) spoke of these experiences as a result of the shortage. The professional available time for O\&M specialists is a significant factor that can limit the duration and frequency of O\&M services a student may receive. When asked about their experiences of the last five years, $53 \%$ of the participants said that their available time rarely impacted service qualification. Therefore a majority of O\&M specialists are continuing to qualify students for O\&M services without considering the amount of time, or lack of time, they have available in the professional schedule. Most participants did not perceive their schedule as impacting their service delivery decisions as I hypothesized it would. However, it is my belief 
that the professional schedule does still have a large impact on service decisions in a way that was beyond the scope of this initial study.

However it is interesting to note that perhaps a reason why 33 participants (43\%) indicated they often work in excess of a full time school contract, 37.5 hours, with one participant indicating that they work 60 hours a week is because they are trying to follow best practice and provide service to every student who legitimately needs it. However, only three participants shared about their professional available time in the open response questions when asked about factors that may impact service qualification. One participant shared her districts recurring view that she could "squeeze" in one more student, but this was limited by her districts policies mentioned above. For example an O\&M specialist may only have a 30 minute block for services on Tuesday mornings, but the district has a policy against pulling students from reading instruction. These two factors paired together now mean the student may not receive the services they have qualified for or a sufficient amount of services. A student's and professional's schedule was primarily noted as a factor impacting service delivery decisions with 18 (26\%) participants referencing the two schedules. Each of these participants were employed for in excess of 30 hours or close to a full time school contract, 37.5 hours with $55 \%$ providing O\&M services for less than half of their contract. As discussed above some participants noted an administrative preference to vision services over O\&M services.

Further complicating scheduling is the need for O\&M specialists to compete for the student's available time for instruction with other specialized educational services or related services under the IEP. Batshaw (2002) noted that nearly a third of students with low vision and two thirds of students with no remaining usable vision have some type of concomitant disability. This can include but is not limited to hearing impairment, learning disabilities, and physical 
disabilities. While it is dependent on the student's particular needs, student's with concomitant disabilities may have a large number of specialist vying for their time with the student during the parameters of the school day. Within the survey there were seven statements about additional services that the student may receive for their concomitant disability. While not all IEP teams struggle or vie for the time of a student with complex support needs, it is possible that the participants may not consciously consider this an obstacle to service but simply a part of the student to be considered.

Possible solution. If the student has a full schedule one O\&M specialist noted that they use creative scheduling as a means of ensuring they receive as much services as possible. This may include lessons monthly, weekend, after or before school, or for reduced time each week. Barrella et al. (2011) suggested the use of creative scheduling as well in an effort to manage larger caseloads. While this method has its limitations, some O\&M specialists may have success serving larger caseloads by employing the use of group lessons, after or before school, and longer weekend lessons for specialty trips like large city transit. However, this may be limited by policies expressed formally or informally by the district. Districts may also have policies against what instructional time the student is allowed to miss. Two participants shared districts who had policies against pulling students from academic courses such as reading or math. Another 10 participants noted that the student's academic schedule or load was a factor that impacted service delivery decisions. It is unclear whether this was a self-imposed policy against pulling from academic coursework or if this was a generally accepted district policy that was not articulated during the survey. If creative scheduling does not work with the student's schedule the O\&M specialist may opt to reduce service minutes or transitions to indirect or consultation services 
leaving the O\&M specialists' time available for other students with open schedules (Wall Emerson \& Anderson 2014).

\section{Is There A Relationship Between A Participant's Demographic Make-Up And Their Assessment Results And Service Delivery Decisions? Specifically, Their Certification, Level Of Experience, Location, And Distance From A Preparation Program}

The characteristics of the participants varied greatly. Seventy-six O\&M specialists serving the K-12 education system throughout the Midwest participated and possessed certification of an O\&M specialists or dually certified O\&M specialists with another vision specialty $(N=37 ; 49 \%)$. The participants were all either currently employed or retired less than five years from positions that were part to full time, for 4 to 55 hours per week. Based on the Mason (2000) and Ferrell (2007) articles forecasting an overwhelming and 'critical' shortage of O\&M specialist nationally, one would assume participants to be primarily employed full time or even overtime when permissible. However, almost a third of the participants reported working less than 37 hours a week. Furthermore, half of the participants said that they work less than $50 \%$ of their contract providing O\&M services. Based on the open response portion of the survey this could be attributed to factors like (a) large caseloads geographically; (b) district policies placing limitations on services; and (c) dual certification caseloads with administrative preference given to TVI services. Eleven participants (15\%) indicated that the travel time from one student to another impacted service decisions and qualification, while another nine (12\%) noted that they must also consider the travel time to get a student to an appropriate instructional area. For example, if students are 30-60 minutes apart geographically, this significantly impacts the number of students that can receive O\&M services in one day. The same can be said of students in rural communities that may need to travel 30 minutes or more to an instructional area. While 
some participants $(N=3 ; 4 \%)$ reported their districts had limitations or bans on travel off campus, likely for this reason and the insurance liability, 15 participants (20\%) indicated a district policy or concern that put limitations on their services for a variety of reasons. In addition to restrictive district policies, some O\&M specialist employed as dual TVI and O\&M specialists reported their district or cooperative's administration choose to utilize them in split duties (i.e. 60\% TVI caseload to a $40 \%$ O\&M caseload). Of the dually certified participants ( $N=37)$, three participants (8\%)noted that preference was given to their TVI caseload and $28(76 \%)$ provided O\&M services for less than $50 \%$ of their contracted hours. With a shortage faced by both the O\&M field and the TVI field (Ferrell, 2007), a preference imposed by administration could negatively impact O\&M service delivery for students with vision loss. Recruitment efforts for the field of O\&M may be better served by recruiting as singly prepared O\&M specialists rather than dual O\&M with other vision specialties. This could serve to ensure that as we build the number of practitioners entering the workforce and a singly certified O\&M specialist could provide more service minutes than two or more dually certified with preference given to vision services.

Over a third of participants noted that they have worked as an O\&M specialist for over 16 years. This group of participants should be regarded as the veteran O\&M specialist, with a wealth of knowledge and experiences to benefit the field. However, this group is also likely approaching retirement age. As such, the concerted recruitment efforts mentioned above should remain a priority of the field.

Caseloads. When asked about their caseload, $47 \%$ of the participants indicated that their caseload impacted their ability to qualify a student for services. Sixty-two percent indicated that their caseload impacted the amount of service minutes that they were able to recommend. On average participants noted their caseload included approximately 12 students for direct services 
and 8 students for indirect services. A work week of 37.5 hours minus planning time and meals equals about 35 hours or 2,100 minutes. Participants reported a range of total service minutes from 60 minutes to well in excess of the 2,100 minutes at (3600 minutes or 60 hours). However, most participants reported that they provide direct services for less than 600 minutes per week. If each of the providers are using about 600 minutes a week for the 12 students receiving direct service, this comes to about 48 minutes per week for each student. These numbers are subject to dramatic changes if an O\&M specialist provides services to multiple students at the same time. This occurs infrequently outside of residential schools due to the geographic dispersion of students. Bryan (1989) expressed young students receive optimal benefit from O\&M instruction with students in preschool through the third grade by receiving about 30 to 50 minutes daily. However for adolescents (4th-6th grade) Bryan indicated that for the optimal benefit they need 4080 minutes per week and young adults ( $7_{\text {th }}-12_{\text {th }}$ grade and transition) need 120-180 or more minutes per week. Based on these recommendations the average response of 600 minutes per week would not be sufficient instruction for optimal benefit for young students (Pk-3rd grade) or young adults ( 7 th-12th grade and transition). Furthermore, this scenario would not leave time in the O\&M specialists' professional schedule to provide indirect services to the average 8 students also on their caseload. Since the publishing of the Bryan article service delivery decision tools were created to assist O\&M specialists in selecting the amount of instructional time needed.

\section{Limitations}

As discussed in chapter two and throughout the study, O\&M is an emerging field both in practice and research. Consequently, the field grew quickly to meet the need of children and adults with vision loss, in developing techniques for service providers, and a current research 
base. However, this has left field with an incomplete research base, with gaps of much needed information. In addition to major shortages of personnel.

There is a limited understanding of the actual number O\&M specialist working in the US. Each professional organization has a vastly different calculation, or no calculation at all regarding the number of $\mathrm{O} \& \mathrm{M}$ professionals employed. These numbers often are based on their own membership lists with no mechanism to track the movement of an O\&M specialist. Because of this, there is no way to calculate the number of individuals eligible to complete the survey. In comparison to other electronic surveys, this survey captured a small sample size limiting the ability to generalize the findings of the study. However, due to the extreme shortage of O\&M specialist the sample size was larger than initially anticipated. This may be due to the dissemination of the survey by AERBVI and ACVREP during the timeframe where summer webinars and conferences are advertised, increasing the website foot traffic.

Another possible limiting factor of the participant pool was due to another concurrent survey of O\&M professionals completed by Dr. Penrod and his research team. This survey came with the added incentive of offering continuing education units (CEU) that are needed for recertifying of our credentials. I was unaware of the other survey or it's incentive until after the survey for this study was published and disseminated. The other survey may have caused confusion from potential participants of the study, as they may have not realized there were multiple surveys or which surveys they had already completed. Also, while each of the Midwest states had representation in the participant pool, there were no guide dog mobility instructors (GDMI) or national orientation and mobility certificates (NOMC) represented.

In the design of the study, ideally there would be a series of discussion groups for O\&M specialist from across the Midwest that would have provided another robust layer to this study. 
Though focus groups could have provided a greater depth of understanding, the logistics of time, cost, and geographic dispersion would have limited the study’s feasibility. O\&M specialist are spread throughout each state at varying distances, only gathering annually or biannually. In order to conduct focus groups including participants from each state, I would need to attend 11 state level vision conferences throughout the calendar year or one international vision conference in the summer of 2020. Furthermore, attending these conferences is a privilege for the O\&M specialist that are costly and require time away from work. As a result, not every O\&M specialist can attend these conferences so focus groups would not have a representative sampling. In light of these factors, either option for inclusion of focus groups would have been time and cost prohibitive to both the participant and myself.

The use of electronic survey and removal of potential focus groups was also to provide each participant with anonymity as a means of professional protection. Some of the questions asked included a risk to the participants by asking them to recount times they have made recommendations against policy, best practice, or their professional ethical code. For this reason, participants may not have been entirely forthcoming in their responses. Some participants chose to provide identifying information or were potentially identifiable due to some of their responses. As a means of protecting their confidentiality, some participant's language was changed and some variables were not analyzed in conjunction.

The survey used for this study is based on the participant's perception of events they can recollect for the last five years. Their individual recollection of factors and events may be impacted by their experiences, both professionally and personally. In addition, as a perceptionbased survey participants may tailor their responses toward what they feel I was looking for. It should also be noted that I created the survey tool alone for a pilot study of my state. After it was 
created three faculty members, two of whom have extensive knowledge of sensory disabilities and itinerant teaching, were consulted to strengthen the tool. However, the tool was not officially validated before use.

\section{Future Implications}

While this study was able to answer some questions following reviews of articles like Wall Emerson and Anderson (2014), a series of replication studies are needed. The series should include a similar method to explore the responses of O\&M specialists by region of the U.S. to provide a more representative sample that could offer generalizability of the data obtained. Furthermore, a secondary analysis of the collective data could be used to explore if there are relationships between themes and variables like states with university preparation programs, by population density, and by region. An additional line of research could examine the assessment process through service qualification and service delivery decisions from the practitioner's point of view. It is the hopes that this research could capture the factors impacting their decisions, like the ones found through this dissertation, in real time through the O\&M specialist's in the moment narrative.

Also, it became apparent through this study and the foundational research discussed throughout chapters one and two that the organizations overseeing the O\&M field do not currently know the number of O\&M specialists nationally. Of the 19 university preparation programs nationally, many depend on 'soft' or grant funds to recruit new students and to remain open. Currently, the field is dependent on a "guestimation" provided by Mason (2000) and Ferrell (2007) rather than accurate data. Having access to an accurate count could lend credence to university program's requests for funding from governmental organizations like Office of Special Education Programs (OSEP) and Institute of Educational Sciences (IES). The 
Orientation and Mobility Specialist Association, a new organization formed in early 2019, has charged its strategic planning committee with compiling the national numbers available from individual organizations, as well as state by state. It is the hope of that committee to complete this task in 2020, providing the field with desperately need information as simple as basic demographics of practicing and retiring O\&M specialists.

\section{Conclusion}

Still in its infancy, the field of O\&M still has many core questions yet to answer. Since its inception in the 1940 we have established a strong foundation and framework for the development of the field. Now with the newest generation of researchers in the area of O\&M we must continue this momentum forward, and work to fill the gaps left behind in the swift development of the founding members. This study is offered to fill one of these gaps; establishing what O\&M specialists consider when deciding the instructional needs of a student outside of an assessment. While each O\&M specialist is guided by their own individual experiences, they report looking for things not subject to change or control, like a student's life goals and their geographic area. Then they look at items that may be remediable, like scheduling possibilities/ issues and the support of the district administrators and IEP team. By focusing our attention on the things we can changes we may be able to mitigate the impact the shortage of O\&M specialist has on the next generation of individuals with vision loss while we strive to reduce the shortage. 


\section{REFERENCES}

Academy for Certification of Vision Rehabilitation \& Education Professionals (2018) Certified Orientation and Mobility Specialist handbook. Retrieved from https://www.acvrep.org/certifications/coms

Association for the Education and Rehabilitation of the Blind and Visually Impaired (2017). O\&M division. Retrieved from https://aerbvi.org/about/divisions/orientation-mobilitydivision/

Batshaw. (2002) Children with Disabilities. Baltimore, MD: Paul H. Brookes Publishing Company.

Barrella, K., Besden, C., Crow, N., Delgado Greenberg, M., Shrieves G., Smith, K., \& Vickroy, M. (2011). Striving to provide innovative orientation and mobility services in times of diminishing resources. Journal of Visual Impairments and Blindness, 105, 587-590. doi: https://doi.org/10.1177/0145482X1110501005

Blasch, B., \& Wiener, W. (2010). Foundations of orientation and mobility (3rd ed.). New York, NY: American Foundation for the Blind Press.

Blasch, B., Wiener, W., \& Welsh, R. (2006). Foundations of orientation and mobility (2nd ed.). New York, NY: American Foundation for the Blind Press.

Bourquin, E., Mascia, J., \& Rusenski, S. (2002). Community-based services for deaf-blind consumers: A successful rehabilitation and vocational model. Journal of Visual Impairment \& Blindness, 96, 668-71. doi: https://doi.org/10.1177/0145482X0209600909

Brown, J., Hallak, T., Garrett, M., Nelson, G., Sewell, D., ...Reeves, G. (2019). Texas 2 STEPS curriculum and evaluation. [Set]. Austin, TX: Texas School for the Blind and Visually Impaired. 
Bryan, W. H. (1989). Itinerant orientation and mobility in public schools. Journal of Visual Impairment and Blindness, 83, 473-75.

Cameto, R., \& Nagle, K., (2008). Orientation and mobility skills of secondary school students with visual impairments. Menlo Park, CA: SRI International.

Centers for Disease Control (2017). Blindness and vision impairment. Retrieved from https://www.cdc.gov/healthcommunication/toolstemplates/entertainmented/tips/Blindness .$h t m l$

Cmar, J., McDonnall, M., \& Crudden, A. (2018). Transporting self-efficacy and employment among individuals with a visual impairment. Journal of Vocational Rehabilitation, 48, 257-268. doi: 10.3233/JVR-180925

Corn, A. (1989). Instruction in the use of vision for children and adults with low vision. ReView, 21(1), 26-38.

Couper, M. (2000). Web-based surveys: A review of issues and approaches. Public Opinion Quarterly, 64, 464-494. doi: https://doi.org/10.1086/318641

Cutter, J. (2007). Independent movement and travel in blind children: A promotion model. Information Age Publishing Inc. Charlotte: NC.

Daugherty, W. (2014). A brief history of how and why the Texas School for the Blind and Visually Impaired developed its diversified model of service delivery. Journal of Visual Impairments and Blindness, 108, 487-491. doi:

https://doi.org/10.1177/0145482X1410800606 
Dewald, H., Faris, C., Borg, K., Maner, J., Martinez-Cargo, L., \& Carter, M. (2015). Expanding the frontiers of orientation and mobility for infants and toddlers in New Mexico and Utah. Journal of Visual Impairments and Blindness, 109, 502-507. doi: https://doi.org/10.1177/0145482X1510900608

Dignan, K. (Eds.). (n.d.). Benefits of orientation and mobility. Austin, TX. Texas School for the Blind and Visually Impaired.

Dodson-Burk, B. \& Roman, C. (2012). Preschool orientation and mobility screening. Alexandria, VA: Association for Education and Rehabilitation of the Blind and Visually Impaired.

Duncan, J. (2019). Why become a vision professional?. Retrieved from whyeyeteach.com Elementary Teachers' Federation of Ontario (2016). Understanding your professional judgement. Retrieved from http://www.etfo.ca/SupportingMembers/Professionals/ PJdocs/PJflyer.pdf

Ferrell, K. (2007, May 14). Issues in the field of blindness and low-vision. Retrieved from http://www.unco.edu/ncssd/resources/issues_bvi.pdf

Fraenkel, J., Wallen, N., \& Hyun H. (2015). Sampling. In How to design and evaluate research in education (9th ed., pp. 91-110). New York, NY: McGraw-Hill Education

Fraenkel, J., Wallen, N., \& Hyun, H. (2015). Survey Research. In How to design and evaluate research in education (9th ed.; pp 390-420). McGraw Hill Education Publishing.

Fry, R. (2018, April 11). Millennials are the largest generation in the U.S. labor force. Retrieved from https://www.pewresearch.org/fact-tank/2018/04/11/millennials-largest-generationus-labor-force/ 
Geruschat, D. R. (1980). Orientation and mobility for the low functioning deaf-blind child. Journal of Visual Impairment and Blindness, 74, 29-31. doi: https://doi.org/10.1177/0145482X8007400107

Geruschat, D. R., \& De l'Aune, W. (1989). Reliability and validity of O and M instructor observations. Journal of Visual Impairment and Blindness, 83, 457-60.

Harley, R. K., \& Merbler, J. B. (1980). Development of an orientation and mobility program for multiply impaired low vision children. Journal of Visual Impairment and Blindness, 74, 9-14. doi: https://doi.org/10.1177/0145482X8007400103

Hayes, A. (2018). Economics basics: Supply and demand. Retrieved from https://www.investopedia.com/university/economics/economics3.asp

Hill, E. W., Dodson-Burk, B., \& Talor, C. (1992). The development and evaluation of an orientation and mobility screening for preschool children. Re:View, 23(4), 165.

Hill, M., \& Hill, E. W. (1990). Model programmes and practice issues in orientation and mobility. Peabody Journal of Education, 67(2), 121-34. doi:

https://doi.org/10.1080/01619569009538685

Hill, M., \& Hill, E. W. (1991). Provision of high-quality orientation and mobility services to older persons with visual impairments. Journal of Visual Impairment \& Blindness, 85, 402-408. doi: https://doi.org/10.1177/0145482X9108501004

Hill, E., \& Ponder, P. (1976). Orientation and mobility techniques: A guide for the practitioner. New York: American Foundation for the Blind.

Illinois State Board of Education (2016). Illinois best practices guide for the education of students with visual impairment. Retrieved from https://www.isbe.net/Documents/compbest-practices.pdf\#search $=0 \% 26 \mathrm{M}$ 
Individuals with Disabilities Education Act Amendments of 1997, H.R.5 (105th)

Individuals with Disabilities Education Act, 20 U.S.C. § 1400 (2004)

Institute of Education Sciences (2018). Find what works based on the evidence. Retrieved from https://ies.ed.gov/ncee/wwc/FWW/Results?filters=,Children-Youth-with-Disabilities

Lord, F. E. (1969). Development of scales for the measurement of orientation and mobility of young blind children. Exceptional Children, 36(2), 77-81.

doi:10.1177/001440296903600202

Lydon, W., \& McGraw, M. (1973). Concept development for visually handicapped children. New York, NY.: American Foundation for the Blind.

Mason, C. (2000). Shortages of personnel in the low incidence area of blindness: Working and planning together. Teaching Exceptional Children, 32, 91-92. doi: https://doi.org/10.1177/004005990003200414

Michigan Department of Education-Low Incidence Outreach (2017). The Michigan orientation \& mobility severity rating scale (revised). Retrieved from https://mdelio.org/sites/default/files/documents/BVI/SRS/OMSRS\%20Revised\%208.15.2 017.pdf

Mills, R. (1980). Visually handicapped children. In R. Welsh \& B. Blasch (Eds.), Foundations of orientation and mobility (1st Ed.) New York, NY.: American Foundation for the Blind.

Misra, T., (2016). A complex portrait of rural America. City Lab. Retrieved from https://www.citylab.com/equity/2016/12/a-complex-portrait-of-rural-america/509828/

Mullins, W. (2012). How to manipulate the law of supply and demand. Retrieved from https://www.quicksprout.com/2012/08/16/how-to-manipulate-the-law-of-supply-anddemandand-make-a-lot-more-money/ 
Munro, H., Darst, S., \& Pogrund, R. (2018). Development and initial validation of the O\&M VISSIT for orientation and mobility specialists to determine service intensity. International Journal of Orientation and Mobility, 9. doi: 10.21307/ijom-2018-003.

National Blindness Professional Certification Board. (2008). NOMC certification overview. Retrieved from http://www.nbpcb.org/pages/NOMCcertificationoverview.php

National Center for Health Statistics (2014). National health statistics report. Retrieved from http://www.cdc.gov/nchs/products/nhsr.htm.

National Federation of the Blind (2018). Statistical facts about blindness in the United States. Retrieved from https://nfb.org/blindness-statistics

New Mexico School for the Blind and Visually Impaired (2016). Orientation and mobility inventory (version 4.0). Retrieved from http://www.nmsbvi.k12.nm.us/ominventory.html

Norris, M., Spaulding, P., \& Brodie, F. (1957). Blindness in children. Chicago, IL. University of Chicago Press

O'Mea, M. L. (2013). Implementing applied behavior analysis for effective orientation and mobility instruction of students with multiple disabilities. Journal of Visual Impairment \& Blindness, 107, 65-70. doi:10.1177/0145482X1310700107

Pierangelo, R., \& Guiliani, G. (2017). Assessment in special education: A practical approach (5th ed.) Boston, MA: Pearson Education, Inc.

Pogrund, R., Cowan, C., Darst, S., Gray, K., Hallak, T., ... Tabb, C. (2017). O\&M VISSIT: Orientation and mobility visual impairment scale of service intensity of Texas. Austin, TX: TSBVI. 
Pogrund, R., Darst, S., Munro, H. (2019). Beyond the O\&M VISSIT: Advocating for appropriate service intensity. Presented at South Western Orientation and Mobility Association in Nacogdoches, TX.

Pogrund, R., Sewell, D., Anderson, H., Calaci, L., Cowart, M. F., ... Robertson-Smith, B. (2012). Teaching age-appropriate purposeful skills: An orientation and mobility curriculum for students with a visual impairment (3rd Ed.). Austin, TX: TSBVI.

Randles, L. (2018). How is the shortage of O\&Ms in Illinois impacting our students?. Unpublished manuscript, Illinois State University, Bloomington, IL.

Sewell, D., Hallak-Burleson, T., Walker, S., Wood, M., Brown, J., ... Nelson, G. (2016). Texas 2 STEPS: Successfully teaching early purposeful skills. White Settlement, TX: SLSBVI.

Smith, K., \& Herlich, S. (2014). Separated by a driveway: Collaboration between two state specialized schools to assess students with deafblindness. Journal of Visual Impairments and Blindness, 108, 501-505. doi: https://doi.org/10.1177/0145482X1410800609

United States Census Bureau. (2017). 2011-2015 American community survey 5-year estimates. Retrieved from https://www.census.gov/acs/www/data/data-tables-and-tools/dataprofiles/2015/

United States Census Bureau (2018). U.S. and World population clock. Retrieved from https://www.census.gov/popclock/

University of Missouri. (n.d.). Research vs practitioner articles module. In Library Resources for Special Education Students. Retrieved from https://libraryguides.missouri.edu/c.php?g=338566\&p=3235586 
Wall Emerson, R., \& Anderson, D. (2014). Michigan Severity Rating Scales: Usage and validity. Journal of Visual Impairments and Blindness, 108, 151-156. doi: https://doi.org/10.1177/0145482X1410800208

Wall Emerson, R., \& Corn, A. (2006). Orientation and mobility content for children and youths: A delphi approach pilot study. Journal of Visual Impairments and Blindness, 100, 331342. doi: https://doi.org/10.1177/0145482X0610000604

Zimmerman G. \& Roman C. (2006). In B. Blasch, W. Wiener, \& R. Welsh Foundations of Orientation and Mobility (2nd ed). New York: NY.: American Foundation for the Blind Press. 


\section{APPENDIX A: SURVEY TOOL}

1. Informed consent

a. Yes, I am over 18 years old and I consent to participate in this study.

b. No, I do not consent to participate in this study.

If $B$ push to Thank you message

\section{Demographic Responses}

2. Which title best describes your current or most recent position?
a. $\mathrm{O} \& \mathrm{M}$
b. Dual O\&M/TVI
c. Dual O\&M/ other vision specialty
d. TVI
e. Other

If $\mathrm{D}$ or $\mathrm{E}$ push to Thank you message

3. Which of the following currently describes your employment status in terms of O\&M?
a. Currently employed.
b. Retired or left the position within the last five years.
c. Retired or left the position more than five years ago.

If $\mathrm{C}$ push to thank you message

4. For your entire job, how many hours a week are you employed? (ie 37.5 hours). If retired, approximately how many hours a week were you employed?

5. How many hours of your contract are devoted to O\&M services? If you are retired, approximately how many hours of your last contract were devoted to O\&M services?

6. Which of the following states are you employed in?
a. Illinois
b. Indiana
c. Iowa
d. Michigan
e. Minnesota
f. Missouri
g. Nebraska
h. North Dakota 
i. Ohio

j. South Dakota

k. Wisconsin

1. Other

If $\mathrm{L}$ push to thank you message

7. As of June 2019, how many years have you been (if retired, were you) employed as an O\&M specialist?
a. 1-2 years
b. 3-5 years
c. 6-10 years
d. 11-15 years
e. 16-20 years
f. 20+ years

8. Do you provide O\&M services to travelers who are ages 3-21, school age students?
a. Yes
b. No

If $B$ push to thank you message

9. Which title best describes your certification?
a. A university earned orientation and mobility license
b. Certified Orientation and Mobility Specialist (COMS)
c. National Orientation and Mobility Certificate (NOMC)
d. Other (push to text field)

10. Which is your closest O\&M university preparation program to your employment, geographically?
a. California State University
b. Florida State University
c. Hunter College (New York)
d. New Mexico State University
e. North Carolina State University
f. Northern Illinois University
g. Ohio State University 
h. Salus University (Pennsylvania)

i. San Francisco State University

j. South Carolina State University

k. Stephen F. Austin State University (Texas)

1. Texas Tech University

m. University of Arkansas at Little Rock

n. University of Massachusetts at Boston

o. University of Northern Colorado

p. University of Pittsburgh

q. Western Michigan University

r. Portland State University

11. Approximately how far (in miles) is your employment from the university program you selected?
a. Less than 50 miles
b. $51-100$
c. $101-200$
d. 201-300
e. $300-400$
f. $400+$

12. Approximately how many travelers are on your caseload? (If retired, in your last position) *Direct-instruction provided to the student by the O\&M specialist in a one to one or group session. **Consult-instructional or functional supports provided to the staff, family, and student.
a. Text field for Direct
b. Text field for Consult

13. Using the toggle below, please indicate the amount of your professional time serving students in urban suburban, or rural. Your total should be $100 \%$.

14. Which statement best describes your current (most recent) assigned direct minutes per week for O\&M? *Instruction provided to the student by the O\&M specialist in a one to one or group setting.

a. Less than 300 minutes per week/ 5 hours 
b. 300-600 minutes per week/ 5-10 hours

c. 600-1000 minutes per week/ 10-16 hours

d. 1000-1200 minutes per week/ 16-20 hours

e. 1200-1400 minutes per week/ 20-23 hours

f. 1400-1600 minutes per week/ 23-26 hours

g. 1600-1800 minutes per week/ 26-30 hours

h. 1800-2000 minutes per week/ 30-33 hours

i. Over 2000 minutes per week/ Over 33 hours

15. Which statement best describes your current assigned (most recent) consult minutes per week for O\&M? *Instruction and functional supports provided to the staff, family, and student to ensure academic and functional success in school.
a. Less than 300 minutes per week/ 5 hours
b. 300-600 minutes per week/ 5-10 hours
c. 600-1000 minutes per week/ 10-16 hours
d. 1000-1200 minutes per week/ 16-20 hours
e. 1200-1400 minutes per week/ 20-23 hours
f. 1400-1600 minutes per week/ 23-26 hours
g. 1600-1800 minutes per week/ 26-30 hours
h. 1800-2000 minutes per week/ 30-33 hours
i. Over 2000 minutes per week/ Over 33 hours

16. What tools do you use to complete O\&M assessments (please select all that apply)?
a. TAPS (Teaching Age Appropriate Skills)
b. Oregon Project
c. NSMBVI Inventory (New Mexico School for the Blind and Visually Impaired O\&M Inventory)
d. Preschool O\&M screening
e. Texas 2 Step
f. Teacher Created
g. Other

Other link to text box 
17. How do you justify your decision to recommend or deny orientation and mobility services?

18. Check all of the tools below that utilize to justify or confirm service needs.
a. The Michigan Severity Scale
b. The O\&M VISSIT
c. My professional judgement
d. Other

Other to text field.

\section{Open Ended}

19. Please explain what factors, outside of the orientation and mobility assessment, impact your recommendation for service qualification?

20. Please explain what factors, outside of the orientation and mobility assessment, impact your recommendation for the amount of service minutes?

\section{Likert Matrix}

21. Please answer each of the statements based on your experiences in the past five years. Likert-(Most of the time, sometimes, rarely, never)

a. Have you felt that your caseload has impacted your recommendation to qualify a student for O\&M services?

b. Have you felt that your caseload has impacted your recommendation for O\&M service minutes?

c. Have you qualified a student for services or identified needed service minutes that may not be able to be fulfilled without additional personnel?

\section{Ending Question}

22. Briefly describe any factors outside the students need for services that you feel has impacted your recommendation for minutes not covered above? 


\section{APPENDIX B: SOLICITATION OF SURVEY DISSEMINATION}

\section{(Head of AERBVI O\&M Division/ACVREP President)}

My name is Lauralyn Randles. I am a doctoral candidate at Illinois State University, as well as a licensed teacher of the visually impaired and certified orientation and mobility specialist. As part of my dissertation, I hope to complete a survey of orientation and mobility (O\&M) specialists practicing in the Midwest. I am asking that you assist me in this process by disseminating the link to the survey via your listserv and/or social media presence. As part of my institution's review board process, I will need a confirmation from your organization that you will agree to this dissemination.

In short, I will ask O\&M specialist information about the tools they using to guide assessment results and service delivery recommendation. I will also ask them information regarding other decisions specialist makes when qualifying students for services and delivery of service.

The survey has been designed to aid in the confidentiality of participants through the provided survey link. The survey will take approximately 20 minutes to complete and the survey window will be four weeks long. After two weeks I will send a second email, in the hopes that you can resend the survey invitation to you listserv and/or social media presence. Your members may choose to participate in the survey, however their participation is completely voluntary.

In addition to myself, this study is facilitated by Dr. Olaya Landa-Vialard of the Illinois Deafblind Project, Dr. Carrie Anna Courtad, Dr. Stephanie Gardiner-Walsh, and Dr. Mark Zablocki of the Illinois State University in the Department of Special Education. If you have any questions, please do not hesitate to contact myself at lkbogar@ilstu.edu or my dissertation chair, Dr. Carrie Anna Courtad, at cacourt@ilstu.edu.

Please contact Lauralyn Randles if your organization is interested in participating in this important research venture.

Sincerely,

Lauralyn Randles 


\title{
APPENDIX C: AERBVI APPROVAL LETTER
}

\section{Re: Research Participation}

Randles, Lauralyn

Thu 4/18/2019 4:47 PM

To: Chris Tabb $<$ tabbc@tsbvi.edu $>$

Chris

Thank you so much for your quick response and support. I love how supportive our field is of one another. I hope to make it through IRB in the coming weeks and share the survey then.

I also saw your other email for SWOMA. Molly and I look forward to meeting you in Texas this fall. It will be so nice to make the connection.

Thank you again for your support.

Lauralyn

Sent from my iPhone

On Apr 16, 2019, at 4:19 PM, Chris Tabb <tabbc@tsbvi.edu> wrote:

\begin{abstract}
[This message came from an external source. If suspicious, report to abuse@ilstu.edu]
Hi Lauralyn,

I am happy to help you in any way I can. I am able to share your link on a variety of social media pages, specifically, TSBVI Outreach Programs Orientation and Mobility, Southwest Orientation and Mobility Association (SWOMA), AER Orientation and Mobility Division, and Orientation and Mobility Specialists; most of these have Twitter accounts that I can include as well. If you like, I can also share the link and a description on the two Orientation and Mobility listserv (i.e. AER OM Division and the open listserv at http://lists.blindcanadians.ca/mailman/listinfo/orientationandmobility lists.blindcanadians.ca)
\end{abstract}

Will be on the lookout for the link and survey description you would like shared. You can reach me at this email or if you need to reach me via cell, the number is 512.660 .2750

Chris Tabb : )

$--$

Christopher J. Tabb, M.A., COMS

Statewide Orientation and Mobility Consultant

Outreach Programs

Texas School for the Blind and Visually Impaired

1100 West 45th Street

Austin, TX 78756

Direct: 512.206 .9226

Fax: 512.206.9320

E-mail: tabbc@tsbvi.edu

Twitter: @TSBVI_Outreach, https://twitter.com/tsbvi outreach

Facebook: www.facebook.com/omoutreach

Web page: http://www.tsbvi.edu/o-m-page

[http:///] 


\section{APPENDIX D: ACVREP APPROVAL LETTER}

\section{Re: Research participation}

Randles, Lauralyn

Tue 4/16/2019 4:05 PM

To: Kathleen Zeider <kzeider@acvrep.org>

Kathie

Thank you so much for getting back to me so quickly! I will be targeting Illinois, Indiana, Iowa, Michigan, Minnesota, Missouri, Nebraska, North Dakota, Ohio, South Dakota, and Wisconsin. I am hoping to make it through IRB in the next week or two so that I can get the survey started soon. When I pass through IRB I will touch bases with you again.

You are amazing! Thank you for all of your support.

Lauralyn

Lauralyn Randles COMS

Doctoral Candidate in Special Education Department

NLCSD Scholar

From: Kathleen Zeider <kzeider@acvrep.org>

Sent: Tuesday, April 16, 2019 3:46 PM

To: Randles, Lauralyn

Subject: RE: Research participation

[This message came from an external source. If suspicious, report to abuse@ilstu.edu]

We will be happy to send the survey out for you. Please just define the states from which you would like the information because I am able to target COMS in specific states as group.

Congratulations on your hard work this far and what a wonderful team you have to work with. Will look forward to calling you Dr. Randles !!

Best,

Kathie

Kathleen Zeider

President/CEO

ACVREP

4380 N. Campbell Ave., Suite 200

Tucson Arizona, 85718

5208876816 Ext.106

www.acvrep.org

Advancing professional competency so all people with visual impairment

receive services from highly qualified professionals

From: Randles, Lauralyn <lkbogar@ilstu.edu>

Sent: Tuesday, April 16, 2019 1:23 PM

To: Kathleen Zeider <kzeider@acvrep.org>

Subject: Research participation

\section{Mrs. Zeider}

My name is Lauralyn Randles. I am a doctoral candidate at Illinois State University, as well as a licensed teacher of the visually impaired and certified orientation and mobility specialist. As part of my 


\section{APPENDIX E: EMAIL AND SOCIAL MEDIA RECRUITMENT LETTER}

Dear Midwest Vision Team

I am Lauralyn Randles, a doctoral student in the Department of Special Education at Illinois State University. With my committee, I am working to conduct a survey of orientation and mobility specialists in the Midwest (IL, IN, IA, MI, MN, MO, NE, ND, OH, SD, WI). Through the survey we want to explore your experiences with qualifications for service and service delivery models. We are inviting your participation in the survey, found through the link below. The survey will take approximately 20 minutes of your time and your responses will remain anonymous. Survey participants must be 18 years or older and licensed orientation and mobility specialists.

For questions about this research study please contact Lauralyn Randles at lkbogar@ilstu.edu. Your participation in the survey is voluntary and you can withdraw from the survey at any time and without penalty. If you are interested in participating in this survey, please follow the link provided below.

\section{https://illinoisstate.az1.qualtrics.com/jfe/form/SV_3I9go4nqsWQ93sV}

Thank you for your time and consideration,

Lauralyn Randles, COMS 